\title{
A!
}

This is an electronic reprint of the original article.

This reprint may differ from the original in pagination and typographic detail.

Ceschin, Fabrizio; Gaziulusoy, Idil

Design for Sustainability: A Multi-level Framework from Products to Socio-technical Systems

DOI:

$10.4324 / 9780429456510$

Published: 01/01/2020

Document Version

Publisher's PDF, also known as Version of record

Published under the following license:

CC BY-NC-ND

Please cite the original version:

Ceschin, F., \& Gaziulusoy, I. (2020). Design for Sustainability: A Multi-level Framework from Products to Sociotechnical Systems. (1 ed.) (Routledge focus on environment and sustainability). Routledge.

https://doi.org/10.4324/9780429456510

This material is protected by copyright and other intellectual property rights, and duplication or sale of all or part of any of the repository collections is not permitted, except that material may be duplicated by you for your research use or educational purposes in electronic or print form. You must obtain permission for any other use. Electronic or print copies may not be offered, whether for sale or otherwise to anyone who is not an authorised user. 
ROUTLEDGE FOCUS

\section{DESIGN FOR SUSTAINABILITY}

A Multi-level Framework from Products to Socio-technical Systems

Fabrizio Ceschin and İdil Gaziulusoy

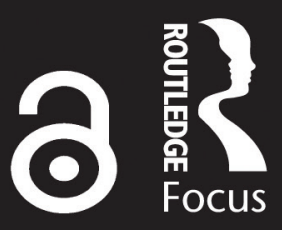




\section{Design for Sustainability}

This book discusses the most significant ways in which design has been applied to sustainability challenges using an evolutionary perspective. It puts forward an innovation framework that is capable of coherently integrating multiple design for sustainability (DfS) approaches developed so far.

It is now widely understood that design can and must play a crucial role in the societal transformations towards sustainability. Design can in fact act as a catalyst to trigger and support innovation, and can help to shape the world at different levels: from materials to products, productservice systems, social organisations and socio-technical systems. This book offers a unique perspective on how DfS has evolved in the past decades across these innovation levels, and provides insights on its promising and necessary future development directions.

For design scholars, this book will trigger and feed the academic debate on the evolution of DfS and its next research frontiers. For design educators, the book can be used as a supporting tool to design courses and programmes on DfS. For bachelor's and master's level design, engineering and management students, the book can be a general resource to provide an understanding of the historical evolution of DfS. For design practitioners and businesses, the book offers a rich set of practical examples, design methods and tools to apply the various DfS approaches in practice, and an innovation framework which can be used as a tool to support change in organisations that aim to integrate DfS in their strategy and processes.

Fabrizio Ceschin is Senior Lecturer in Design for Sustainability at Brunel University London, UK.

İdil Gaziulusoy is Assistant Professor of Sustainable Design at Aalto University, Finland. 


\section{Routledge Focus on Environment and Sustainability}

\section{Productivity and Innovation in SMEs}

Creating Competitive Advantage in Singapore and Southeast Asia Azad Bali, Peter McKiernan, Christopher Vas and Peter Waring

Climate Adaptation Finance and Investment in California Jesse M. Keenan

Negotiating the Environment: Civil Society, Globalisation and the UN Lauren E. Eastwood

\section{Carbon Inequality}

The Role of the Richest in Climate Change

Dario Kenner

The UNESCO Manual for Developing Intercultural Competencies

Story Circles

Darla K. Deardorff

\section{Design for Sustainability}

A Multi-level Framework from Products to Socio-technical Systems Fabrizio Ceschin and İdil Gaziulusoy

For more information about this series, please visit:

www.routledge.com/Routledge-Focus-on-Environment-andSustainability/book-series/RFES 


\section{Design for Sustainability}

A Multi-level Framework from Products to Socio-technical Systems

\section{Fabrizio Ceschin and İdil Gaziulusoy}


First published 2020

by Routledge

2 Park Square, Milton Park, Abingdon, Oxon OX14 4RN

and by Routledge

52 Vanderbilt Avenue, New York, NY 10017

Routledge is an imprint of the Taylor \& Francis Group, an informa business

(C) 2020 Fabrizio Ceschin and İdil Gaziulusoy

The right of Fabrizio Ceschin and İdil Gaziulusoy to be identified as authors of this work has been asserted by them in accordance with sections 77 and 78 of the Copyright, Designs and Patents Act 1988.

The Open Access version of this book, available at www.taylorfrancis.com, has been made available under a Creative Commons Attribution-Non Commercial-No Derivatives 4.0 license.

Trademark notice: Product or corporate names may be trademarks or registered trademarks, and are used only for identification and explanation without intent to infringe.

British Library Cataloguing-in-Publication Data

A catalogue record for this book is available from the British Library

Library of Congress Cataloging-in-Publication Data

A catalog record has been requested for this book

ISBN: 978-1-138-31516-7 (hbk)

ISBN: 978-0-429-45651-0 (ebk)

Typeset in Times New Roman

by Newgen Publishing UK 
We dedicate this book to those researchers, designers, practitioners, activists and others who, through their ideas and actions, strive to make this world a better and kinder place to live in, and to our students who give us hope for the future. 


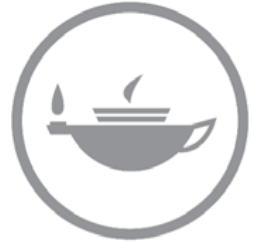

Taylor \& Francis Taylor \& Francis Group

http://taylorandfrancis.com 


\section{Contents}

List of illustrations $\quad$ ix

List of boxes $\quad$ xi

Acknowledgements xii

List of abbreviations xiii

Introduction 1

1 Addressing sustainability by design 5

2 Green design and product ecodesign 12

3 Emotionally durable design 26

4 Design for sustainable behaviour 39

5 Cradle-to-cradle design 53

6 Biomimicry design 63

7 Product-service system design for sustainability 73

8 Design for the base of the pyramid 87

9 Design for social innovation 102

10 Systemic design 113 
viii Contents

11 Design for sustainability transitions

124

12 Reflections on the past, present and future of design for sustainability

Index 


\section{Illustrations}

\section{Figures}

2.1 Berol Karisma coloured pencils 13

2.2 Tetra Pak street furniture 14

2.3 The FRIA refrigerator designed by Ursula Tischner 15

2.4 The Sayl office chair with its suspension back 16

3.1 The Do Scratch lamp: example of personalisation 29

3.2 The Do Scratch lamp: brand new and examples of personalisation $\quad 29$

3.3 The Stain teacup before use 30

3.4 The Stain teacup after a number of uses 30

3.5 Save/Space/Vase: the process to make vases unique 31

3.6 A set of different Save/Space/Vase vases 31

4.1 The comprehensive action determination model (CADM) 41

4.2 The Power-Aware Cord 42

4.3 A screenshot from the Super Amma animated film 43

4.4 The decision support framework for promoting sustainable behaviour, combining a set of existing DfSB approaches

5.1 Nike Considered boots 55

6.1 The Shinkansen bullet train, Japan 65

6.2 The Supertree Grove, Singapore 65

6.3 Diagram showing Supertrees' design and operation 66

7.1 The Riversimple car 77

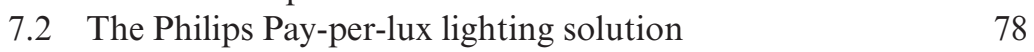

8.1 The SafariSeat all-terrain wheelchair 91

8.2 The SafariSeat all-terrain wheelchair: one of the codesign sessions held to test and improve the product 92

8.3 The Sun Shines for All solar energy package 92

8.4 The Mitti Cool refrigerator 93 
8.5 Mansukhbhai Prajapati, the inventor of the Mitti Cool refrigerator

8.6 The design methodological framework proposed by Gomez Castillo et al.

10.1 Visual representation of the current productive and value chain for coffee waste

10.2 Visual representation of the new productive and value chain for coffee waste

10.3 Visual representation of the designed household water purification system

11.1 The MLP of system innovations model

11.2 Visualisations of the four scenarios produced in the Visions and Pathways 2040 project

11.3 A pathway development workshop for mid-range

12.1 The DfS innovation framework

12.2 The process of positioning design approaches in the framework (with the green design approach used as an example)

12.3 The DfS innovation framework with the DfS approaches mapped onto it

12.4 The evolution of the DfS field

12.5 The DfS innovation framework with the additional socio-technical-ecological system level

\section{Table}

12.1 An overview of the DfS approaches in chronological order of their development 


\section{Boxes}

2.1 Green design examples 13

$\begin{array}{lll}2.2 & \text { Ecodesign examples } & 15\end{array}$

2.3 Ecodesign principles, strategies and guidelines 18

3.1 EDD examples 29

4.1 DfSB examples 42

4.2 DfSB methods and tools 46

5.1 CTC design examples 55

5.2 CTC design tools and methods $\quad 57$

6.1 BM design examples 64

6.2 BM design methods and tools 68

7.1 PSS design for sustainability examples 77

7.2 PSS design for sustainability methods and tools $\quad 79$

8.1 DfBoP examples 91

8.2 DfBoP methods and tools 96

9.1 DfSI examples 104

9.2 DfSI tools and methods 106

10.1 SD examples 116

$\begin{array}{ll}10.2 \text { SD methods and tools } & 120\end{array}$

11.1 The MLP of system innovations 126

$\begin{array}{ll}11.2 & \text { DfST examples } \\ 11.3 & 128\end{array}$

11.3 DfST methods and tools 133 


\section{Acknowledgements}

We would like to thank Silvia Barbero, Richard Bonser, Han Brezet, Jonathan Chapman, Chiara Del Gaudio, Sampsa Hyysalo, Dan Lockton, Ravi Mokashi, Chris Ryan and Dario Toso for reviewing chapters of the book and providing us with useful comments and insights.

Fabrizio: I would like to thank my colleagues and the researchers and academics that are part of the Learning Network on Sustainability, in particular Carlo Vezzoli, for the continuous and fruitful exchange of ideas, which helped to enrich the book. I am also grateful to my family and friends for their constant encouragement throughout the whole writing journey.

İdil: I would like to thank my colleagues at Aalto University and in my wider academic network for inspiring and useful conversations. I am grateful to my family and friends for their ongoing support and encouragement and to my two cats for valuable play time during intense times of writing.

Finally, a big 'thank you!' to our editor, Leila Walker, for her patience, help and attention to detail. 


\section{Abbreviations}

$\begin{array}{ll}\text { BM } & \text { Biomimicry } \\ \text { CTC } & \text { Cradle-to-cradle } \\ \text { DfBoP } & \text { Design for the base of the pyramid } \\ \text { DfS } & \text { Design for sustainability } \\ \text { DfSB } & \text { Design for sustainable behaviour } \\ \text { DfSI } & \text { Design for social innovation } \\ \text { DfST } & \text { Design for sustainability transitions } \\ \text { EDD } & \text { Emotionally durable design } \\ \text { MLP } & \text { Multi-level perspective } \\ \text { PSS } & \text { Product-service system } \\ \text { SD } & \text { Systemic design } \\ \text { TM } & \text { Transition management }\end{array}$




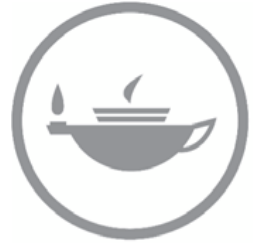

Taylor \& Francis Taylor \& Francis Group

http://taylorandfrancis.com 


\section{Introduction}

\section{How did this book come about?}

The idea of writing about the evolution of the design for sustainability (DfS) field had been cooking up in our minds for a while; we had both studied and researched the field for a long time and completed our $\mathrm{PhDs}$ in the early 2010s. We have both had the chance to work with some of the pioneers in the field (including Carlo Vezzoli, Han Brezet, Chris Ryan and Ezio Manzini). This exposure has given us the opportunity to learn about the historical development of the field, not only through our own studies but also through listening to first-hand stories from these early thinkers over the years we worked with them. Finally, we realised our idea through a collaboratively authored article (Ceschin \& Gaziulusoy, 2016), in which we provided an overview of the DfS field and proposed an evolutionary framework. The article achieved such high popularity - based on both citation and download counts - in a short period of time that it became clear to us that the topic was a timely one for the broader design research community. In the meantime, we were approached by Routledge who asked if we would consider turning the article into a short-form book. For us this presented itself as an unmissable opportunity to expand on and update the content of the article and our thinking on the evolutionary framework.

\section{The themes of the book}

This book traces the history of DfS and presents the evolution and current status of the broader field of DfS. When we use the term design approach we refer to the overall mindset or philosophy with which the design is to be conducted (Sanders, Brandt, \& Binder, 2010), which is usually associated with a coherent set of design principles, methods and/ or tools. The book shows how DfS approaches have broadened in scope 


\section{Introduction}

over the years, from having a focus on environmental impact improvement to the current cutting edge that deals with long-term and largescale transformations. It covers green design and product ecodesign, emotionally durable design, design for sustainable behaviour, cradle-tocradle design, biomimicry design, sustainable product-service systems, design for the base of the pyramid, design for social innovation, systemic design and design for sustainability transitions. We present the updated version of the evolutionary framework in Chapter 12. This framework synthesises DfS as a broad field that is still in development, consisting of a range of approaches with distinct and complementary attributes.

\section{Who is this book for?}

Although this book is an academic book written with attention to the currency, accuracy and comprehensiveness of information, we have aimed to make it relevant for a wide-ranging readership. We hope that the book will engage those who are curious about DfS, are studying DfS, those who teach or would like to teach DfS, those who have been researching DfS or would like to research DfS and practitioners who would like to understand the different approaches of DfS. Specifically, the different ways in which the book might be useful include the following:

- The book can be a general resource for bachelor's and master's level design, engineering and management students. The book provides an understanding of the historical evolution of DfS and information on the different approaches that emerged over time. Therefore students can develop an overview and understanding of the field.

- The book can be an all-in-one resource for teachers. The book presents DfS approaches as separate chapters, following an identical structure in a comparable manner giving examples for each approach. The teachers can either use the book to teach a general overview of the field, with equal depth allocated to each approach, or choose to focus on a selection of fields and find further resources on these from the textboxes and by consulting the reference lists provided at the end of each chapter.

- The book can be a starting point for researchers new to DfS. Experienced or novice researchers who would like to start a research journey related to DfS can gain an overview and understanding of the field though reading the book and use the future research directions identified for each approach as tools with which to make decisions about their research framing. 
- The book can be a point of departure for dedicated DfS researchers. Those who have been researching one or more of the approaches of the DfS field can gain an understanding of the wide spectrum of approaches that are presented through an evolutionary and relational lens. This may assist them to reflect on their specific research focus in relation to the broader field and develop new research directions by exploring synergies between approaches.

- The book can be an exploration, learning and decision-making tool for practitioners. Practitioners - including designers, design and innovation managers, and strategic managers - can use the book to explore the array of design approaches that aim to address environmental and social issues; they can choose and learn about those approaches that are particularly relevant for a project in detail (using the examples and by exploring the further references provided) or they can make strategic decisions regarding which DfS competencies to develop.

\section{The structure of the book}

The book consists of 12 chapters in total, including an introductory chapter (Chapter 1) that discusses the sustainability challenge and its relevance to design and a concluding chapter (Chapter 12) that presents the evolutionary framework we developed and our overall reflections on the further development of the DfS field. Ten chapters (Chapters 2-11) are each dedicated to a key approach of DfS.

Each chapter (except for Chapters 1 and 12) provides a concise description of a DfS approach and presents key theoretical contributions, as well as the main design methods and tools associated with the approach. These chapters are all similar in structure:

- There is a section explaining the main characteristics/features of the DfS approach addressed in the chapter and its innovative aspects. This section also includes representative examples.

- There is a section on the existing design methods and tools that can be used to apply the DfS approach in practice. This section is also complemented with a textbox listing the most important methods and tools.

- There is a section discussing the main sustainability benefits derived from adopting this approach, as well as its limitations and unresolved issues.

- There is a section discussing the current and future research directions for the approach covered in the chapter. 


\section{Introduction}

One final note before the reader dives deeper into DfS. As the discourse of sustainability has matured over the years, society's understanding of the concept has evolved from being an idealised, generalised and static property of individual (system) elements to being the contextual and dynamic properties of systems themselves (Faber, Jorna, \& van Engelen, 2005). In this book, we also understand sustainability as a dynamic and systemic property, one that relates to the interactions between the environment, society, technology, culture and economy. Despite the systemic understanding, sustainability is still often understood by many as an environmental property. Also, the term social sustainability prevails in order to differentiate a focus on social issues from the focus of environmental sustainability. Therefore, although we understand sustainability as a property of interrelated systems, we also use the terms environmental sustainability and social sustainability when it is necessary to clarify the specific focus of the theory and practice covered in this book.

\section{References}

Ceschin, F., \& Gaziulusoy, İ. (2016). Evolution of design for sustainability: From product design to design for system innovations and transitions. Design Studies, 47, 118-163. doi:10.1016/j.destud.2016.09.002

Faber, N., Jorna, R., \& van Engelen, J. (2005). The sustainability of "sustainability" - a study into the conceptual foundations of the notion of "sustainability". Journal of Environmental Assessment Policy and Management, 7(1), 1-33.

Sanders, E. B. N., Brandt, E., \& Binder, T. (2010). A framework for organizing the tools and techniques of participatory design. In Proceedings of the 11th Biennial Participatory Design Conference, Sydney, Australia, 29 November-3 December (pp. 95-198). 


\section{Addressing sustainability by design}

\subsection{The sustainability challenge}

We are going through very challenging times as a human society. The emission reduction targets that must be met in order to reduce the risk of severe climate change are still not being met and the window for limiting the average global temperature rise to between $1.5^{\circ} \mathrm{C}$ and $2{ }^{\circ} \mathrm{C}$ above pre-industrial levels is closing (Raftery, Zimmer, Frierson, Startz, \& Liu, 2017, UNEP, 2017). In a recent special report, the Intergovernmental Panel on Climate Change (IPCC) discussed the impacts of a global average temperature rise of $1.5^{\circ} \mathrm{C}$ above pre-industrial levels on natural and human systems (IPCC, 2018). According to the report, human activities have already caused a temperature rise approximately $1{ }^{\circ} \mathrm{C}$ above pre-industrial levels and the increase is likely to reach $1.5^{\circ} \mathrm{C}$ between 2030 and 2052 if the trend continues at the current rate. The report also compared a rise of $1.5^{\circ} \mathrm{C}$ with a rise of $2^{\circ} \mathrm{C}$. Although the risks are projected to increase with a rise of $1.5^{\circ} \mathrm{C}$, they will increase even more if warming is not limited further; a $2^{\circ} \mathrm{C}$ temperature rise implies a very substantial increase in risk for some impact areas. One to three decades from today are left for significant climate action to limit the temperature rise to $1.5^{\circ} \mathrm{C}$; this is considered urgent. Although addressing climate change is quite often considered a technical and behavioural challenge (i.e. it is considered to fall into the 'practical' sphere of transformation), there is a need for the transformation of the systems and structures that facilitate or constrain the practical responses to climate change (i.e. the 'political' sphere of transformation) (O'Brien, 2018). There is also a need for the transformation of the beliefs, values, worldviews and paradigms that influence how people perceive, define or constitute systems and structures, and a need for the transformation of their behaviours and practices (i.e. the 'personal' sphere of transformation) (O'Brien, 2018). 


\section{Addressing sustainability by design}

Although arguably the most urgent sustainability challenge, climate change is only one of the several sustainability challenges we are facing. The 'Planetary Boundaries' framework (Steffen et al., 2015) sets out precautionary boundaries - a safe operating space - for nine critical processes of human-driven environmental change. According to this framework, two boundaries have currently been severely breached (biosphere integrity and biochemical flows), posing a high risk; two have been breached (climate change and land-system change), posing an increasing risk; and two are yet to be quantified (novel entities and atmospheric aerosol loading). Only three of the nine boundaries have currently not been breached (freshwater use, ocean acidification and stratospheric ozone depletion). Beyond these nine boundaries, we all face the possibility of abrupt, large-scale changes in Earth system functioning and significant risks to societies and economies worldwide. Raworth (2012) developed the concept of social foundations to complement the Planetary Boundaries framework and argued for a 'safe and just operating space' which lies between the environmental ceiling and social foundations. The social foundations include food security, water and sanitation, health care, education, energy, gender equality, social equity, voice, jobs and resilience. She demonstrated through illustrative indicators that humanity is currently failing to provide these social foundations.

If we look at the sustainability challenge from a material point of view, we might be able to understand the above-listed overarching challenges from the perspective of production-consumption systems. According to the estimates of the World Wide Fund for Nature (WWF, 2010), in 2007 the size of the global ecological footprint was double what it had been in 1966, and if the trend continues, this means that in 2030 humanity will need the capacity of two Earths to absorb the waste generated and keep up with natural resource consumption. According to the United Nations (UN, 2016), by 2050 we would need three Earths to sustain our current lifestyles. Based on the Factor 10 benchmark of Schmidt-Bleek (1993), who argued for the need to reduce material consumption by a factor of ten to achieve sustainability, Lettenmeier (2018) developed the lifestyle material approach. Using this approach, he calculated that in Finland, for example, households would need to reduce their lifestyle footprint to eight tonnes (an $80 \%$ reduction) by 2050. Although reducing resource use is a key requirement in order to achieve sustainability, there is another dimension that needs to be considered and which adds to the complexity of the sustainability challenge. This dimension is resource distribution; $20 \%$ of the world's richest countries consume $80 \%$ of the resources, with similar distribution inequality also within 
these rich countries. The inequality of resource distribution and significant discrepancies of resource-use levels between the rich and the poor across and within countries relate to the ethics of responsibility, sustainability politics and environmental justice.

In order to address the sustainability challenge and associated complexities, a profound, radical transformation of our development model is necessary. As underlined by Manzini (1999), there are not only production processes and artefacts (products and services, infrastructure and all the various forms of anthropological settlements) under discussion but also patterns of consumption and access to goods and services. In fact, over the next few decades we must enable ourselves to move from a society wherein well-being and economic health are measured in terms of growth to a society where we are able to live better, consuming far less (Manzini \& Vezzoli, 1998). In other words, it is required that we change the way in which needs are fulfilled and develop consumption patterns and lifestyles based on the consumption of far fewer resources. It is increasingly acknowledged that we have to urgently move towards socio-technical systems that are capable of operating within the planet's limits while ensuring that this move follows pathways that are ethical and just.

\subsection{Responses from design}

\subsubsection{The beginnings}

The earliest concerns about resource limits and the impact of our material production on the environment are often traced back to Buckminster Fuller's teachings and work (Fuller, 1969). Fuller coined the concept of 'Spaceship Earth', drawing attention to the physically bounded limits of our planet. A few years before this, Meadows, Meadows, Randers, $\&$ Behrens (1972) published the results of their mathematical systems model for those limits. Fuller also argued that unless humans take responsibility to care for and maintain the Earth, the Earth's functions will be compromised or even collapse. While Fuller is not the first to be concerned about the pressures put on the environment by human society (scholarly concern can be traced back as far as Alexander von Humboldt's writings from the late eighteenth/early nineteenth century; Wulf, 2015), he was the first to frame these concerns in an engineering and design context. Madge (1993) traced the connections between design and ecology back to the 1960s and 1970s, to the first great wave of the environmental movement. She remarked that terminological changes, which reflect changes in values and priorities, can disguise continuities. 
Along with this remark, she identified catchphrases of the 1970s, such as 'design for need' and 'alternative design', as precursors of the green design and ecodesign of the 1980s.

Madge (1993) also referred to several resources from the era of this first wave of environmentalism as related to design; however, the seminal work introducing environmental considerations into the world of designers is considered to be Victor Papanek's book Design for the Real World: Human Ecology and Social Change (Papanek, 1985). The first edition of this book was published in Sweden in 1970 and in the USA in 1971, after being rejected by 12 publishers (Madge, 1993). In this book, Papanek provided an in-depth critique of the design profession, pointing out its role in encouraging consumption and therefore contributing to ecological and social degradation. His work reflected a sophisticated response, focusing not only on improving the outputs of design activity but also on promoting the transformation of the design profession.

The 1980s saw a series of interventions in the form of books, conferences, exhibitions and lobbying that aimed to bring the environmental agenda to the attention of designers, industrialists and the general public (Madge, 1993). The publication of the book Green Design by the Design Council in the UK (Burall, 1991) could perhaps be seen as the beginning of a wider and more systematic interest in design with regard to sustainability. Nevertheless, the 'pickup' has been slow; sustainability has only become a central topic in design very recently.

\subsubsection{From green design to design for sustainability transitions}

The initial responses in design in the early 1990s focused on a redesign approach, adopted to reduce environmental impacts and increase the efficiency of individual products (green design). This was accompanied in the second half of the 1990s by a focus on the entire life cycle of a product (ecodesign). Although considered as significant initial steps, green design and ecodesign had a sole focus on environmental impacts, and the early implementations failed to replace high-impact products and instead created a new market for more environmentally friendly products. While ecodesign offered a range of design strategies with which to extend product lifespans, psychological obsolescence (which is linked to the disposal of products that are still functioning) was identified as a challenge in reducing consumption. In order to address this, emotionally durable design strategies were developed, starting from the second half of the 2000s. Emotionally durable design aims to enhance the emotional tie between the user and the product in order to delay or 
avoid product replacement. Around the same time, another approach that diverged from the technical focus of reducing impact stemmed from the realisation that human behaviour also had a role in the environmental impacts of products, particularly of those products that consume materials or energy during their use. Design for sustainable behaviour aims to address use-related impacts by implementing strategies that target influencing user behaviour so that it tends towards pro-environmental modes. While some designers focused on addressing the shortcomings of product-focused technical interventions with the aim of reducing environmental impacts through positioning the user in the picture as an important element in these endeavours, interest has also risen in adopting nature as a model for achieving sustainability through design. The two prominent approaches promoting the latter are biomimicry and cradle-to-cradle, developed respectively from around the late 1990s and the early 2000s. Although similar in their approach of seeing waste as a nutrient, the former puts emphasis on closing the loops in production while the latter studies the materials and processes of nature as an inspiration for design. On the other hand, around the same time, sustainable product-service systems targeted functional innovation in order to address the limitations and rebound effects associated with product-centred approaches, along with recognising that there is a need for radical changes in the production-consumption system. The focus on sustainable product-service systems represents a shift from product design thinking to system design thinking, as products, services and networks of actors need to be designed simultaneously, giving way to new organisational models through which needs are met. All of these approaches are predominantly focused on addressing sustainability issues in the Global North. However, while one end of sustainability requires addressing the overconsumption of resources in the Global North, the other end requires the reduction of poverty in the Global South. Design for the base of the pyramid initially focused on the Global South as a new market for selling products and services developed by companies of the Global North. This gained criticism as such a strategy did not place poverty reduction at its centre and had an exploitative attitude. The second generation of the base-of-the-pyramid interventions, on the other hand, focused on the base of the pyramid as a business partner to be empowered, enabled and involved in the process of business co-creation. Design for the base of the pyramid gradually expanded the scope of intervention range from products to business models and complex socio-ethical aspects. While business interest has been the main driver in all of these approaches, the recognition that some social needs are not met by established practices gave rise to design 
for social innovation around the second half of the 2000s. In design for social innovation, the main role of design shifted from designing for a target group to designing with communities to assist them in meeting their own needs. In design for social innovation, design becomes an activity situated in the systemic context of communities. On the other hand, systemic design put emphasis on systems thinking in the creation of complex industrial systems. It combines elements of cradle-to-cradle design and biomimicry with industrial ecology in order to understand and improve industrial systems by focusing on material and energy flows and their impacts on the environment. Currently, the cutting edge of the DfS field is marked by an emerging research and practice area, namely DfS transitions or, in short, transition design. DfS transitions focuses on the transformation of socio-technical systems through technological, social, organisational and institutional innovations. In this regard, it can be understood as an overarching approach which embodies the other approaches discussed in this book, including design for product-service systems and design for social innovation. Aligned with the increasing emphasis on cities as being among the key intervention contexts for sustainability transformations, DfS transitions expanded its focus from businesses and production-consumption systems to cities, which are essentially systems of socio-technical systems.

\section{References}

Burall, P. (1991). Green Design. London, UK: Design Council.

Fuller, R. B. (1969). Operating manual for Spaceship Earth. Carbondale, IL: Southern Illinois University Press.

IPCC. (2018). Summary for Policymakers. In V. Masson-Delmotte et al. (Eds.), Global warming of $1.5^{\circ} \mathrm{C}$ : An IPCC Special Report on the impacts of global warming of $1.5^{\circ} \mathrm{C}$ above pre-industrial levels and related global greenhouse gas emission pathways, in the context of strengthening the global response to the threat of climate change, sustainable development, and efforts to eradicate poverty. Geneva, Switzerland: World Meteorological Organization.

Lettenmeier, M. (2018). A sustainable level of material footprint - benchmark for designing one-planet lifestyles. Aalto, Finland: Aalto University.

Madge, P. (1993). Design, ecology, technology: A historiographical review. Journal of Design History, 6(3), 149-166.

Manzini, E. (1999). Sustainable solutions 2020 - systems. In Proceedings of the 4th International Conference Towards Sustainable Product Design, Brussels, Belgium, 12-13 July.

Manzini, E., and Vezzoli, C. (1998) Lo sviluppo di prodotti sostenibili. I requisiti ambientali dei prodotti industriali. Rimini, Italy: Maggioli Editore. 
Meadows, D. H., Meadows, D. L., Randers, J., \& Behrens, W. W. (1972). The Limits to growth: A report for the Club of Rome's project on the predicament of mankind. New York: Universe Books.

O'Brien, K. (2018). Is the $1.5^{\circ} \mathrm{C}$ target possible? Exploring the three spheres of transformation. Current Opinion in Environmental Sustainability, 31, 153160. doi:10.1016/j.cosust.2018.04.010

Papanek, V. (1985). Design for the real world: Human ecology and social change. New York: Van Nostrand Reinhold.

Raftery, A. E., Zimmer, A., Frierson, D. M. W., Startz, R., \& Liu, P. (2017). Less than $2^{\circ} \mathrm{C}$ warming by 2100 unlikely. Nature Climate Change, 7(9), 637-641. doi:10.1038/nclimate 3352

Raworth, K. (2012). A safe and just space for humanity: Can we live within the doughnut? Oxfam Discussion Paper.

Schmidt-Bleek, F. (1993). Revolution in resource productivity for a sustainable economy - a new research agenda. Fresenius Environmental Bulletin, 2(8), 485-490.

Steffen, W., Richardson, K., Rockström, J., Cornell, S. E., Fetzer, I., Bennett, E. M., ... Sörlin, S. (2015). Planetary boundaries: Guiding human development on a changing planet. Science, 347(6223), 1259855.

UN. (2016). Sustainable development goal 12: Ensure sustainable consumption and production patterns. United Nations. Retrieved from www.un.org/ sustainabledevelopment/sustainable-consumption-production/.

UNEP. (2017). Emissions gap report 2017: A UN environment synthesis report. United Nations Environment Programme.

Wulf, A. (2015). The invention of nature: The adventures of Alexander von Humboldt, the lost hero of science. London, UK: John Murray.

WWF. (2010). Living planet report 2010: Biodiversity, biocapacity and development. Gland, Switzerland: World Wide Fund for Nature. 


\section{Green design and product ecodesign}

\subsection{From addressing the individual qualities of products to adopting a life cycle perspective}

Although Papanek (1985) exemplified sophisticated design responses to environmental and social issues quite early on, the subsequent early adoption of 'green' attitudes in the design profession did not demonstrate a similarly high desire for transformational change. The early applications of green design practice (Burall, 1991; Mackenzie, 1997; see examples in Box 2.1) primarily focused on lowering environmental impact through redesigning the individual qualities of individual products. Typical examples include optimising the amount of material used in a product, using recyclable materials, replacing virgin materials with recycled materials and replacing hazardous/toxic materials with non-hazardous ones. This period also saw early designs focusing on the use of renewable energy, such as designs for solar street lamps (FuadLuke, 2002). For some, considering the environment in design meant efficiency improvements in product and process engineering (e.g. Fiksel, 1996). Guidelines and toolkits advocating Design for X (X standing for any of the 'more preferable' attitudes in design: recycling and recyclability, the ease of dismantling, repairability etc.) were developed (for an overview, see Chiu \& Kremer, 2011).

The late 1980s saw the emergence of the concept of a 'green consumer' and the realisation of the significant environmental pollution being caused by products; this resulted in regulatory developments and industry-led voluntary initiatives, referred to as the 'greening of the market' (Ryan, Hosken, \& Greene, 1992). During 1989 and 1990, two very large government-funded projects (one in the Netherlands EcoDesign - and one in Australia - EcoReDesign) were created to design a range of exemplar products from EU and Australian manufacturers (C. Ryan, personal communication, 20 February 2019). Ecodesign (see examples in Box 2.2) has one main significant difference from 


\section{Box 2.1 Green design examples}

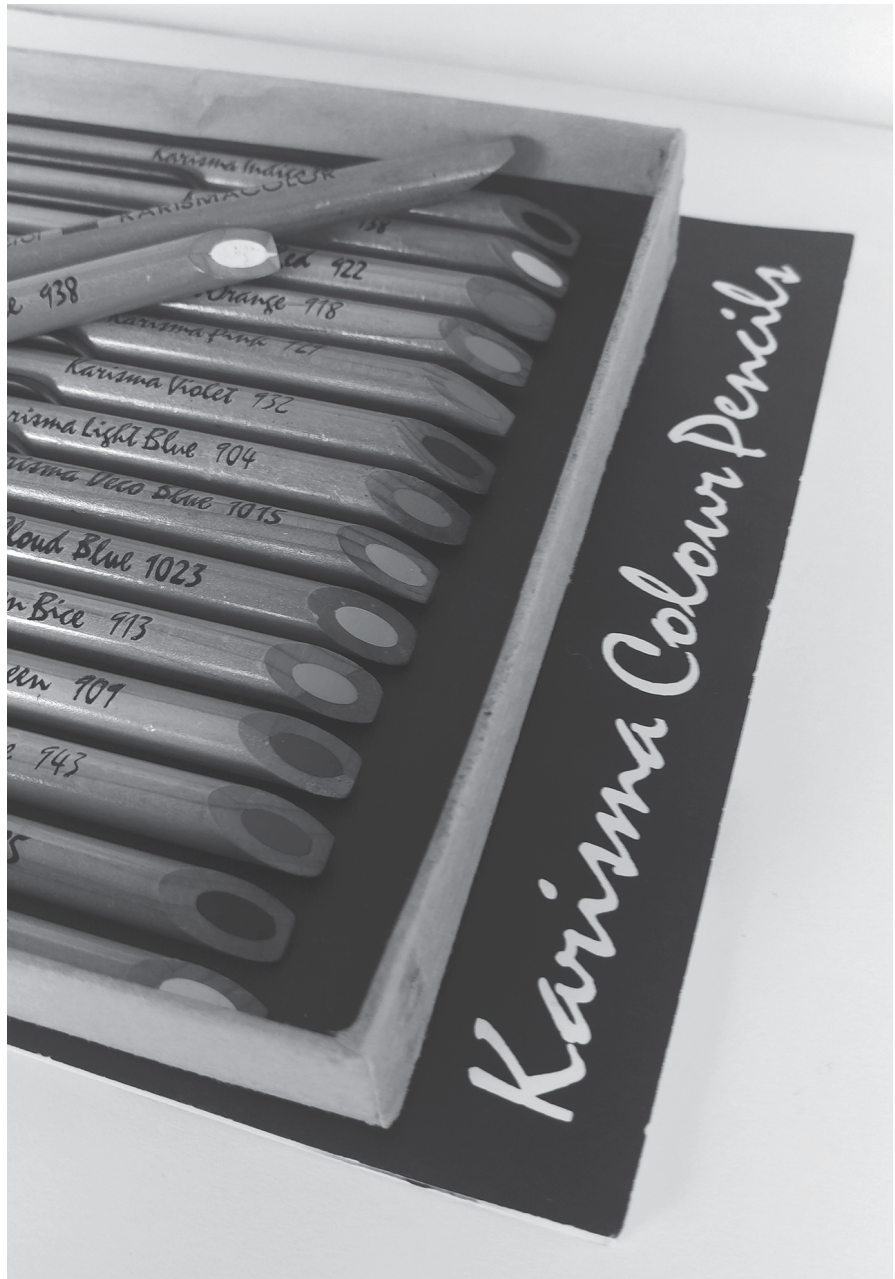

Figure 2.1 Berol Karisma coloured pencils Source: Photo (C) Gülsüm Baran.

Berol's Karisma coloured pencil series replaced the toxic paint used to indicate the colour of the pencil with non-toxic transparent resin. The colour of each pencil was instead indicated by cutting the end of the pencil diagonally to make it easy to see the coloured core. 


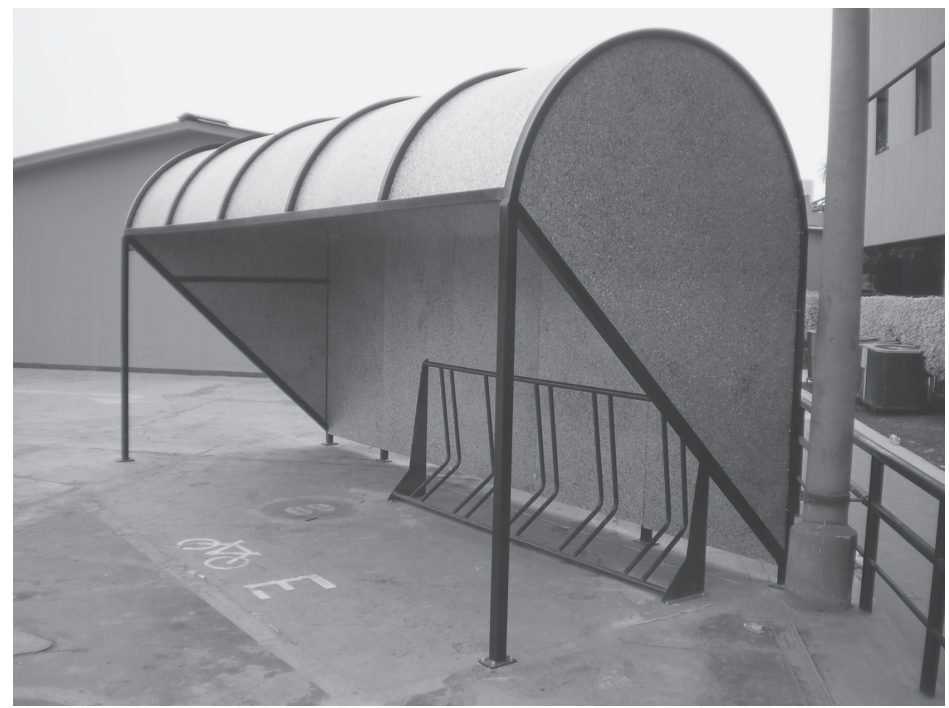

Figure 2.2 Tetra Pak street furniture

Source: Image courtesy of Tetra Pak.

Having been subjected to criticism for producing non-recyclable packaging, Tetra Pak began to repurpose this composite material to produce a variety of products including office and street furniture in the late 1990s. This practice is still ongoing. The image shows a bicycle parking shelter produced from recycled Tetra Pak packaging.

and strength over green design. Rather than improving an individual aspect of a product, ecodesign puts emphasis on the whole life cycle of the product, ranging from the extraction of raw materials, through manufacturing, distribution and use, and on to final disposal (Vezzoli \& Manzini, 2008; Boks \& McAloone, 2009; Pigosso, McAloone, \& Rozenfeld, 2015; Tischner \& Charter, 2001). This enabled the profiling of the environmental impact of products across all life-cycle phases, identifying those phases with the highest environmental impact and therefore providing a strategic direction for design interventions. The experimentation that was initiated through the ecodesign movement yielded significant ecoefficiency improvements through, for example, remanufacturing trials (see, for example, the Xerox case study in the 


\section{Box 2.2 Ecodesign examples}

FRIA (designed by Ursula Tischner) is a multi-chamber refrigerator meant to be installed near the (northern) exterior wall of the house. It is designed to use cold outside air to cool the compartments in winter, thus reducing energy consumption by around $50 \%$ compared to conventional refrigerators. The refrigerator is designed with a modular architecture: the cooling system is independent from the chambers, which can be repaired or replaced separately, leading to a longer lifespan.

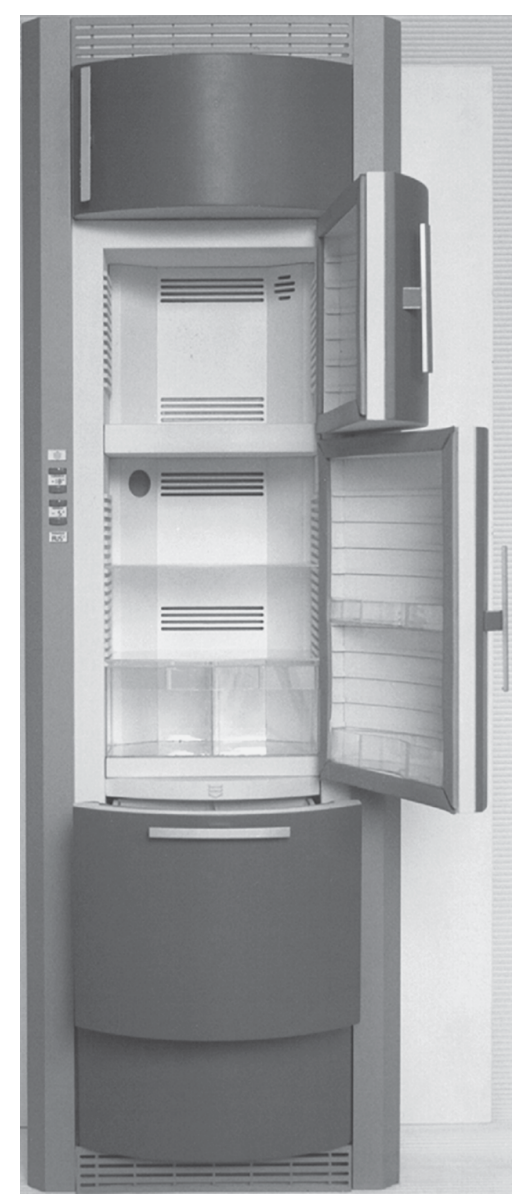

Figure 2.3 The FRIA refrigerator designed by Ursula Tischner Source: Image (C) Ursula Tischner. 
The Sayl office chair adopts a set of design solutions to reduce the environmental impact of different life-cycle phases. It minimises the material content of the chair, as exemplified by the Y-shaped back support, designed to maximise mechanical performance with the least amount of material. It reduces the number of parts and types of materials (for example, the frameless back is made with only a single piece of elastomeric material), thus reducing maintenance/repair activities and potentially extending longevity. Packaging materials are part of a closed-loop recycling scheme. At its end of life, the product is designed to be disassembled and $86 \%$ of the material content is recyclable.
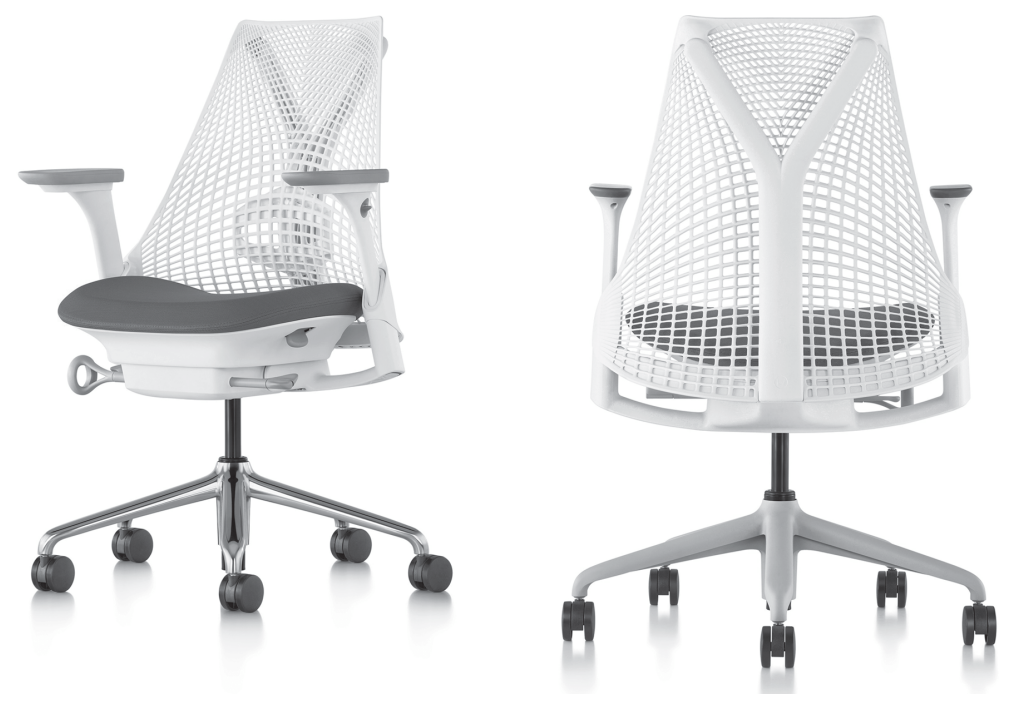

Figure 2.4 The Sayl office chair with its suspension back Source: Images C Herman Miller.

study by Kerr \& Ryan, 2001), which became the precursors of sustainable product-service systems (see Chapter 7).

The life-cycle approach of ecodesign has been supported by lifecycle assessment (LCA) methods. LCA enables the quantification of environmental impacts; therefore, meaningful comparisons between different product concepts that deliver the same functional unit become possible. Once such comparisons are available, design decisions can be geared towards managing, minimising or eliminating negative impacts 
(Andersson, Eide, Lundqvist, \& Mattsson, 1998; Bhander, Hauschild, \& McAloone, 2003; Millet, Bistagnino, Lanzavecchia, Camous, \& Poldma, 2006). The overall goal of ecodesign is to minimise the environmental impact of the different product life-cycle stages while maximising the benefits for the product's users. In ecodesign, the environment is given the same status as more traditional industrial values such as profit, functionality, aesthetics, ergonomics, image and overall quality (Brezet \& van Hemel, 1997).

With the adoption and further development of the Ecodesign Framework Directive by the European Commission (EC, 2005, 2009), which mandates that LCAs are undertaken in association with environmental management systems, ecodesign has become an important consideration for companies. Although the directive initially targeted primarily energy-using products, its scope was later expanded to include resource efficiency measures (Bundgaard, Mosgaard, \& Remmen, 2017). The development of implementation measures for the directive has been slow and is still in progress. Nevertheless, the directive is also a very important legislative piece for the implementation of the European Union Circular Economy Action Plan (EC, 2015), and it is also relevant for products manufactured outside of the European Union, as compliance requires the measurement and reporting of life-cycle impacts. Therefore, it is safe to assume that ecodesign will remain on the agenda of designers in the foreseeable future.

\subsection{Design practice}

One of the main strategies of green design is to follow the 'waste hierarchy'. The concept of the waste hierarchy was first introduced by the European Economic Community's Waste Framework Directive (EEC, 1975). This directive proposed a hierarchy of reduce-reuse-recycle in the management of waste. Later the scope of this hierarchy was expanded to include the prevention of waste as being of higher priority than reducing and recovering energy and materials before final disposal (EC, 2008). The waste hierarchy immediately translates into several design strategies. These strategies include reducing the amount of materials used in a product, reusing parts or whole products in the design of new products, repurposing parts or whole products at the end of their functional life, designing for ease of disassembly and dismantling (e.g. by avoiding non-recyclable composite materials, using mechanical rather than chemical ways of binding product parts and reducing the number of product parts) and using recyclable materials. Other green design strategies relate to resource and energy efficiency, pollution 


\section{Box 2.3 Ecodesign principles, strategies and guidelines}

A fairly complete set of ecodesign principles and guidelines has been developed by several authors (see, e.g., Bhamra \& Lofthouse, 2007; Brezet \& van Hemel, 1997; Luttropp \& Lagerstedt, 2006; Tischner, 2001; Vezzoli \& Manzini, 2008). Some authors (e.g. Brezet \& van Hemel, 1997; Tischner, 2001) have clustered guidelines around the different life-cycle phases. Vezzoli and Manzini (2008) proposed grouping guidelines into five main strategies: material minimisation, the selection of low environmental impact materials, lifespan optimisation, material life extension and design for disassembly.

\section{Ecodesign processes}

Examples of systematic ecodesign processes can be found in the work of Brezet and van Hemel (1997) and Tischer (2001).

\section{Ecodesign tools}

Tools for analysing the environmental strengths and weaknesses of a product or concept

These can be used to assess a reference product or problem, to compare concept alternatives or to compare the final design against the reference product.

Quantitative tools include:

- LCA

- cumulative energy demand (CED)

- material input per service (MIPS)

- the ecological footprint.

Qualitative tools include:

- ecodesign checklists

- the material energy and toxicity (MET) matrix (Brezet \& van Hemel, 1997)

- $\quad$ Philips' Fast Five (Meinders, 1997).

Tools for setting design priorities

These are used to orient the design process by defining which aspects (e.g. energy consumption, product longevity) have a 
greater importance in relation to environmental impact and thus should be dealt with first. These tools include:

- $\quad$ ecodesign priority matrix (see Crul, Diehl, \& Ryan, 2009, p. 52)

- $\mathrm{ABC}$ analysis

- $\quad$ ecodesign spider diagrams (see, e.g., the LiDS wheel; Brezet \& van Hemel, 1997).

\section{Tools to support idea generation}

These can be used to trigger and facilitate the generation of ideas for low environmental impact products. These include:

- $\quad$ ecodesign guidelines (see, e.g., Vezzoli \& Manzini, 2008)

- $\quad$ the ecodesign strategy wheel (Brezet \& van Hemel, 1997).

Tools to visualise environmental improvements of concepts and final designs

These include ecodesign spider diagrams.

For a comprehensive overview of ecodesign tools, see Tischner (2001).

prevention or reduction, and the prevention of environmental impact. Specific design actions taken to address these include replacing virgin materials with recycled materials in products, replacing hazardous/ toxic materials with non-hazardous alternatives, improving the energy efficiency of energy-using products and adding end-of-pipe pollutionreducing components, such as filters, to product outlets.

Green design strategies are also fundamental for and have been integrated into ecodesign (see Box 2.3 for an overview of ecodesign principles, strategies and guidelines). Nevertheless, the life-cycle approach in ecodesign plays a significant role in the optimisation of strategy selection and implementation by enabling the identification of the main life-cycle phases, and product components that are of concern from an environmental impact point of view. In addition, the life-cycle focus of ecodesign brings into consideration aspects that are related to manufacturing but not controlled solely by the decisions of designers, such as the geographical sourcing of materials, which influences transport and componentproduction related impacts. Therefore the practice of ecodesign requires thinking of design decisions strategically at the company level and a more systemic understanding of the impact of design decisions. 
The ecodesign process is not essentially different from the traditional product design process. It simply integrates environmental aspects into the different stages of the process. In this respect, typical ecodesign activities included in the process are (Tischner, 2001; Vezzoli, Ceschin, \& Cortesi, 2009) LCA and/or qualitative environmental analysis of the reference product or problem under consideration, setting environmental design priorities, ecodesign-focused idea generation, analysis of the environmental strengths and weaknesses of concept alternatives, and comparative LCA (the final design vs. the reference product).

\subsection{Benefits and limitations}

Although introducing the green prefix to the lexicon of the design profession and developing and improving the still-valid rules of thumb for improving the environmental performance of products, green design and ecodesign fall short on intellectual and political depth (Madge, 1997). In particular, early implementations of green design, rather than replacing high-impact products, created a new market segment for socalled green products and thus promoted green consumerism.

Although the life-cycle focus of ecodesign provides significant strengths over the early practice of green design, it also has significant shortcomings. Lacking complexity like green design, ecodesign focuses solely on environmental performance (Gaziulusoy, 2015) and therefore disregards the social dimensions of sustainability, which cover issues that relate to the distribution of resources and the products' social impacts.

Although early implementations of ecodesign resulted in huge environmental gains, once the inefficiencies and 'bad design' were removed from products, the gains started to become marginal and increasingly costly, resulting in ecodesign becoming problematised (Ryan, 2013). Moreover, the efficiency gains on a single product basis did not resolve the impacts associated with the ever-increasing consumption of products, which outpaced unit efficiency improvements (Brookes, 2000; Ryan, 2002; 2003).

In addition, although ecodesign is supposed to focus on the whole life cycle, this is mainly done from a technical perspective, paying limited attention to the human-related aspects, in particular to the influence that users' behaviour can have on the overall impact of a product (Bhamra, Lilley, \& Tang, 2011) or to the role that the emotional bond between the user and the product can play in reducing the service life a product (FuadLuke, 2010). More generally, ecodesign shows a narrow understanding of design problems in the sense that (similarly to LCA) it basically deals with the utilitarian function of a product. All other types of product functions (e.g. aesthetic, symbolic and spiritual) are barely addressed by ecodesign, 
despite playing a fundamental role in orienting customer choices and behaviours. Finally, it can be argued that although ecodesign can be used to effectively support incremental innovation, it does not offer appropriate guidance on how to develop radically new product concepts. In other words, it is excellent for optimising/improving existing products, but it is less effective for generating radically alternative ideas.

Despite these shortcomings, green design and ecodesign have introduced and developed fundamental rules of thumb for reducing the environmental impacts of products. These rules of thumb are still valuable and valid. Nevertheless, rather than being taken as sufficient strategies for sustainable design, they need to be seen as useful components of long-term and systemic innovation strategies at company, regional, national and supranational levels.

\subsection{Future research directions}

In the last decade, ecodesign went through a process of consolidation of knowledge and tools, and current research is focused on expanding the traditional ecodesign scope towards the more managerial and strategic issues linked to ecodesign implementation (Pigosso et al., 2015). For example, Fargnoli, De Minicis and Tronci (2014) developed a general design management framework that provides support for both managers and designers in meeting customer satisfaction requirements and economic constraints while assisting in translating all stakeholders' requirements into design decisions for the development of more sustainable products. Similarly, aiming to support companies' ecodesign practices strategically, Pigosso, Rozenfeld and McAloone (2013) developed a management framework that is used for the diagnosis of the current maturity profile of a company's ecodesign implementation and enables the development of strategic road maps so that the most suitable ecodesign practices and improvement projects can be applied.

In addition to strategic tools targeting the management of ecodesign processes, researchers are also developing decision support systems for the practice of ecodesign (e.g. Romli, Prickett, Setchi, \& Soe, 2015). To support the integration of ecodesign practices, methods and tools during product planning, Pinheiro, Jugend, Demattê Filho, \& Armellini (2018) developed a theoretical framework which can be used to guide further consolidation in the field and support the development of managerial and strategic ecodesign tools.

An important future research direction relates to the inclusion of other dimensions of sustainability in addition to the environmental dimension in ecodesign approaches and tools. Ahmad, Wong, Tseng, \& Wong (2018) 
undertook a systematic review to look at the inclusion of economic and social dimensions in ecodesign tools. Their findings indicated that there are more tools that include only one of these aspects than both, and those which included only one aspect mostly included the economic dimension. They also stated that the tools which included both dimensions were not mature and had limited applicability in industry. This may be interpreted as the product level not being appropriate for trying to address the more complex and social dimensions of sustainability, at least not on its own. Therefore, another future research direction relates to opening up ecodesign research and practice to other ongoing, systems-related sustainable design research. One interesting and emerging idea is to seamlessly integrate the design of future products and their associated production systems (Lumsakul, Sheldrick, \& Rahimifard, 2018).

Finally, in relation to considering ecodesign in the context of larger systemic transformations, it is important to conduct research on how ecodesign strategies can be combined with other sustainable design approaches. An example of this is how a hypothetical mobile phone product-service system design (see Chapter 7) synergistically used ecodesign strategies with emotionally durable design strategies (see Chapter 3) in the wider context of circular economy transformations (Hobson, Lynch, Lilley, \& Smalley, 2018).

\section{References}

Ahmad, S., Wong, K. Y., Tseng, M. L., \& Wong, W. P. (2018). Sustainable product design and development: A review of tools, applications and research prospects. Resources, Conservation and Recycling, 132, 49-61. doi:10.1016/ j.resconrec.2018.01.020

Andersson, K., Eide, M. H., Lundqvist, U., \& Mattsson, B. (1998). The feasibility of including sustainability in LCA for product development. Journal of Cleaner Production, 6(3-4), 289-298.

Bhamra, T., Lilley, D., \& Tang, T. (2011). Design for sustainable behaviour: Using products to change consumer behaviour. The Design Journal, 14(4), 427-445.

Bhamra, T., \& Lofthouse, T. (2007). Design or sustainability. A practical approach. Aldershot, UK: Gower Publishing, Ltd.

Bhander, G.S., Hauschild, M., \& McAloone, T. (2003) Implementing life cycle assessment in product development. Environmental Progress \& Sustainable Energy, 22(4), 255-267.

Boks, C., \& McAloone, T. C. (2009). Transitions in sustainable product design research. International Journal of Product Development, 9(4), 429-449.

Brezet, H., \& van Hemel, C. (1997). ECODESIGN: A promising approach to sustainable production and consumption. Paris, France: UNEP. 
Brookes, L. (2000) Energy efficiency fallacies revisited. Energy Policy, 28(6/7): 355-366.

Bundgaard, A. M., Mosgaard, M. A., \& Remmen, A. (2017). From energy efficiency towards resource efficiency within the Ecodesign Directive. Journal of Cleaner Production, 144, 358-374. Doi:10.1016/j.jclepro.2016.12.144

Burall, P. (1991). Green design. London, UK: Design Council.

Chiu, M. C., \& Okudan Kremer, G. E. (2011). Investigation of the applicability of Design for $\mathrm{X}$ tools during design concept evolution: A literature review. International Journal of Product Development, 13(2), 132-167. Doi:10.1504/ IJPD.2011.038869

Crul, M. R. M., Diehl, J. C. \& Ryan, C. (2009) Design for sustainability: A stepby-step approach. Paris, France: UNEP.

EC. (2005). Directive 2005/32/EC of the European Parliament and of the Council of 6 July 2005 establishing a framework for the setting of ecodesign requirements of energy-using products and amending Council Directive 92/42/ EEC and Directives 96/57/EC and 2000/55/EC of the European Parliament and of the Council.

EC. (2008). Directive 2008/98/EC of the European Parliament and of the Council of 19 November 2008 on waste and repealing certain Directives.

EC. (2009). Directive 2009/125/EC of the European Parliament and of the Council of 21 October 2009 establishing a framework for the setting of ecodesign requirements for energy-related products (recast).

EC. (2015). Communication from the Commission to the European Parliament, the Council, the European Economic and Social Committee and the Committee of the Regions: Closing the loop - An EU action plan for the Circular Economy; COM/2015/0614 final.

EEC. (1975). Directive 1975/442/EEC of the Council of the European Communities on waste.

Fargnoli, M., De Minicis, M., \& Tronci, M. (2014). Design management for sustainability: An integrated approach for the development of sustainable products. Journal of Engineering and Technology Management, 34, 29-45.

Fiksel, J. R. (Ed.). (1996). Design for environment: Creating eco-efficient products and processes. New York: McGraw-Hill.

Fuad-Luke, A. (2002). Ecodesign: The sourcebook. London, UK: Thames \& Hudson.

Fuad-Luke, A. (2010). Adjusting our metabolism: Slowness and nourishing rituals of delay in anticipation of a post-consumer age. In T. Cooper (Ed.), Longer lasting products: Alternatives to the throwaway society (pp. 133-155). Farnham, UK: Gower.

Gaziulusoy, A. İ. (2015). A critical review of approaches available for design and innovation teams through the perspective of sustainability science and system innovation theories. Journal of Cleaner Production, 107, 366-377. doi:10.1016/j.jclepro.2015.01.012

Hobson, K., Lynch, N., Lilley, D., \& Smalley, G. (2018). Systems of practice and the Circular Economy: Transforming mobile phone product service 
systems. Environmental Innovation and Societal Transitions, 26, 147-157. doi:10.1016/j.eist.2017.04.002

Kerr, W., \& Ryan, C. (2001). Eco-efficiency gains from remanufacturing: A case study of photocopier remanufacturing at Fuji Xerox Australia. Journal of Cleaner Production, 9(1), 75-81. doi:10.1016/S0959-6526(00)00032-9

Lumsakul, P., Sheldrick, L., \& Rahimifard, S. (2018). The sustainable co-design of products and production systems. Procedia Manufacturing, 21, 854-861. doi:10.1016/j.promfg.2018.02.193

Luttropp, C., \& Lagerstedt, J. (2006). EcoDesign and The Ten Golden Rules: generic advice for merging environmental aspects into product development. Journal of Cleaner Production, 14(15), 1396-1408. doi:10.1016/ j.jclepro.2005.11.022

Mackenzie, D. (1997). Green design: Design for environment (2nd ed.). Hong Kong: Laurence King.

Madge, P. (1997). Ecological design: A new critique. Design Issues, 13(2), 44-54.

Meinders, H. (1997). Point of no return - Philips EcoDesign guidelines. Eindhoven, the Netherlands: Philips Electronics.

Millet, D., Bistagnino, L., Lanzavecchia, C., Camous, R., \& Poldma, T. (2006). Does the potential of the use of LCA match the design team needs? Journal of Cleaner Production, 15(4), 335-346.

Papanek, V. (1985). Design for the real world: Human ecology and social change. New York: Van Nostrand Reinhold.

Pigosso, D. C. A., McAloone, T. C., \& Rozenfeld, H. (2015). Characterization of the state-of-the-art and identification of main trends for ecodesign tools and methods: Classifying three decades of research and implementation. Journal of the Indian Institute of Science, 95(4), 405-427.

Pigosso, D .C. A., Rozenfeld, H., \& McAloone, T. C. (2013). Ecodesign maturity model: A management framework to support ecodesign implementation into manufacturing companies. Journal of Cleaner Production, 59, 160-173.

Pinheiro, M. A. P., Jugend, D., Demattê Filho, L. C., \& Armellini, F. (2018). Framework proposal for ecodesign integration on product portfolio management. Journal of Cleaner Production, 185, 176-186. doi:https://doi.org/ 10.1016/j.jclepro.2018.03.005

Romli, A., Prickett, P., Setchi, R., \& Soe, S. (2015). Integrated eco-design decision-making for sustainable product development. International Journal of Production Research, 53, 549-571.

Ryan, C. (2002). Global status report: Sustainable consumption. Paris, France: UNEP

Ryan, C. (2003). Learning from a decade (or so) of eco-design experience, Part I. Journal of Industrial Ecology, 7(2), 10-12.

Ryan, C. (2013). Critical agendas: Designing for sustainability from products and systems. In S. Walker \& J. Giard (Eds.), The Handbook of design for sustainability. London, UK: Bloomsbury.

Ryan, C. J., Hosken, M., \& Greene, D. (1992). EcoDesign: Design and the response to the greening of the international market. Design Studies, 13(1), 3-22. doi:10.1016/0142-694X(92)80002-G 
Tischner, U. (2001). Tools for ecodesign and sustainable product design. In M. Charter \& U. Tischner (Eds.), Sustainable solutions: Developing products and services for the future (pp. 118-138). Sheffield, UK: Greenleaf Publishing.

Tischner, U., \& Charter, M. (2001). Sustainable product design. In M. Charter \& U. Tischner (Eds.), Sustainable solutions: Developing products and services for the future (pp. 118-138). Sheffield, UK: Greenleaf Publishing.

Vezzoli, C., Ceschin, F. \& Cortesi, S. (2009). Metodi e strumenti per il Life Cycle Design: Come progettare prodotti a basso impatto ambientale. Rimini, Italy: Maggioli Editore.

Vezzoli, C., \& Manzini, E. (2008). Design for environmental sustainability. London, UK: Springer. 


\section{Emotionally durable design}

\subsection{Designing the emotional bond between the product and the user}

As we saw in Chapter 2, ecodesign offers a range of design strategies to extend product lifespan. These include aspects such as enhancing reliability, facilitating maintenance and repairs, and facilitating upgradeability. This combination of strategies allows designers to properly address the technical and functional aspects related to the extension of the product lifespan. However, the problem is that, for some product categories, the end of the product lifespan is not caused by the end of its technical life. Some products are in fact discarded even though they still function properly. Estimates show that this is the case for a high percentage of products: in the UK, for example, $33 \%$ of appliances were discarded while still functional (Cooper, 2004), while in Brazil the percentage rises to $47 \%$ (Echegaray, 2016). In these cases we can talk about relative obsolesce, as opposed to absolute obsolesce (when a product reaches the end of its technical life) (Cooper, 2010).

The so-called psychological obsolescence (Cooper, 2004) plays an important role in affecting relative obsolescence. The main influencing factors of psychological obsolescence include changes in users' perceived needs, the desire for social status emulation and new trends in fashion and style (Cooper, 2004). Typical examples of products which are subject to this type of obsolescence include clothing and furniture products. Consumption is of course motivated by a complex set of factors, but we can agree that, in these cases, the problem lies mainly in the relationship between the user and the product and not in the technical, functional or economic aspects of the product. In these cases, we face a failed subject-object relationship (Chapman, 2010).

Ecodesign cannot provide an answer to this problem because of its lack of attention to the human-related aspects (Fuad-Luke, 2010). In 
fact, ecodesign principles and strategies cannot fully support designers in developing products capable of influencing the consumption behaviour of users. In some cases, applying product lifespan extension strategies may even be counterproductive; for example, improving the technical reliability of a product might require additional resources, but these are not justified if the reasons for replacing the product are related to psychological obsolescence.

In order to fill this gap, design researchers have begun to explore the user-product relationship and the role of design in strengthening that relationship in order to lengthen the product lifespan (see, e.g., Brezet \& Van Hemel, 1997; Van Hinte, 1997; Chapman, 2005; Mugge, 2007; Chapman, 2009). Common labels used to define this field of research are emotionally durable design (EDD), coined by Chapman (2005), and design for product attachment (see examples in Box 3.1). The focus of these approaches is on enhancing the emotional tie between the user and the product so that the user-product relationship remains satisfactory over time and product replacement can be delayed or avoided. It is about designing products that can continuously provide meaning and value to the user over time.

A complex range of factors affects both consumption behaviour and the choice to replace a product. These can be categorised (van Nes, 2010) as product characteristics (e.g. technical conditions, comfort of use), situational influences (e.g. peer influence, media influence, market developments) and consumer characteristics (e.g. replacement morality). An important aspect is the fact that products are also used as a 'symbol of what we are, what we have been, and what we are attempting to become' (Schultz, Kleine, \& Kernan, 1989, p. 361). Within the complexity of consumption behaviour, (design) researchers have investigated the factors which can foster user-product attachment, defined as 'the strength of the emotional bond a consumer experiences with a product' (Schifferstein \& Zwartkruis-Pelgrim, 2008).

From a broader perspective, Norman (2004) explains the userproduct connection, identifying three emotional levels: the visceral level, which is based on the appearance, aesthetic pleasure and immediate emotional impact of the product on the user; the behavioural level, which is based on the use of the product and includes aspects such as function, usability and performance; and the reflective level, which is based on the meaning, message and cultural component associated with a product or its use and concerns aspects such as self-image, personal satisfaction and remembrance.

Products can elicit human emotions in various ways (Desmet, 2012): by the product itself, its meaning, and by interaction with it and the 
activity facilitated by this interaction. Desmet (2012) proposed a basic set of 25 positive human emotion types that can be experienced in human-product interaction. These represent opportunities for designers to enhance product attachment. It is also interesting to note that even negative emotions can contribute to rich and meaningful experiences and thus can potentially deepen the connection between users and objects (Fokkinga \& Desmet, 2012).

Going into the details of the product meanings that can enhance product attachment, four main determinants can be identified (Mugge, 2007):

- Self-expression: the ability of the product to express one's unique identity. It is human nature to differentiate oneself from others and express one's identity. Products can be used for this purpose. In fact, the ways in which products are displayed and used can symbolically represent and communicate personal identity (Solomon, 1983; Tian, Bearden, \& Hunter, 2001). Research shows that people tend to develop a stronger attachment to products that are used to characterise and express their personal identity (see, e.g., Schultz et al., 1989; Mugge, 2007). Product personalisation and customisation, and the involvement of users in designing, finishing or making (part of) the product are also linked to self-expression and help to establish and maintain a stronger bond with the product (Mugge, 2007; Grant, Straker, Muller, \& Wrigley, 2013; Diefenbach, Jung, Diller, Franze, \& Maciejczyk, 2018).

- Group affiliation: the ability of a product to express one's belonging to a group. In addition to the need to express an identity that is different from that of others, human beings also need to belong and feel part of social groups. They are motivated to be connected and to interact with other people. Some products can be used as a vehicle to symbolise a connection with a particular social group, and it has been found that people become more attached to these products (see, e.g., Schultz et al., 1989; Kleine, Kleine, \& Allen, 1995; Schifferstein \& Zwartkruis-Pelgrim, 2008; Ahde-Deal, Paavilainen, \& Koskinen, 2016).

- Memories: the ability of a product to remind one of the past. Products can act as reminders of an event, a place or a person. They can represent a link to something important that took place in the past, and in this way they can help to define and maintain one's identity (Mugge, 2007). It has been shown that people become more attached to products that are capable of reminding the user of people, places or events that are particularly meaningful and important to them 


\section{Box 3.1 EDD examples}

Do Scratch (Droog Design) is a lamp painted black. Users can scratch the surface to liberate areas which the light can then pass through. This allows users to personalise their lamp and create a unique product. Self-expression and product uniqueness are two factors that can potentially extend the emotional bond between the user and the lamp.

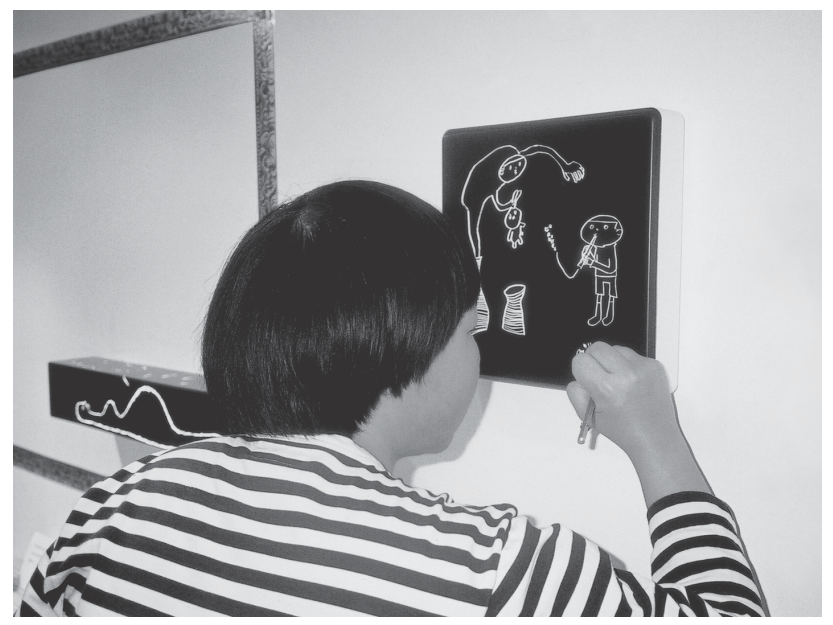

Figure 3.1 The Do Scratch lamp: example of personalisation Source: (C) Droog Design.

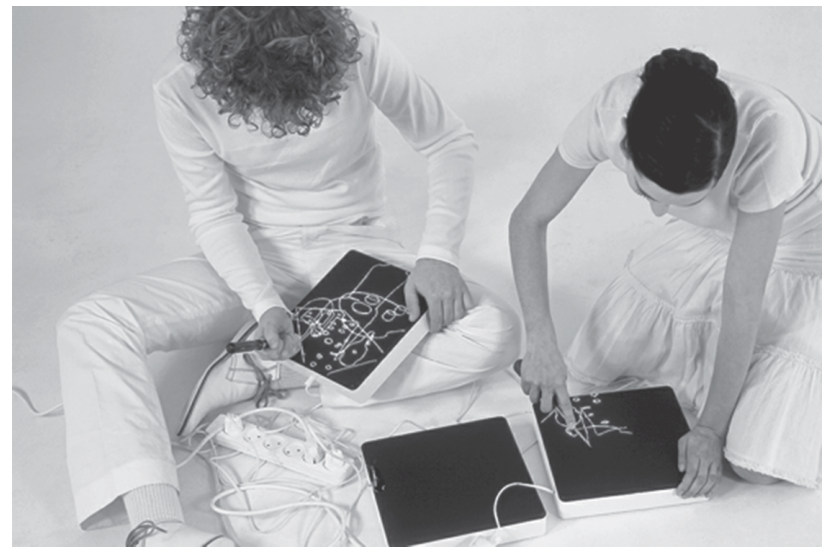

Figure 3.2 The Do Scratch lamp: brand new and examples of personalisation Source: (C) Droog Design. 
Stain (designed by Bethan Laura Wood) is a set of a teacups designed to aesthetically improve through use. This is achieved by treating the interior surface of the cup so that it stains more in specific areas. The design pattern is gradually and slowly revealed, use after use. This results in a dynamic product that changes over time by showing signs of use. Potentially, this could help in renewing the interest of the user in the product.

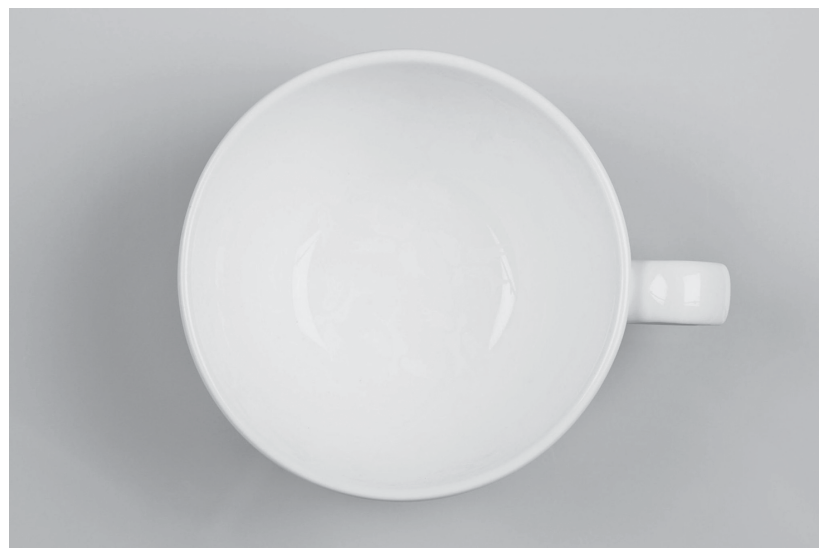

Figure 3.3 The Stain teacup before use Source: (C) Bethan Laura Wood.

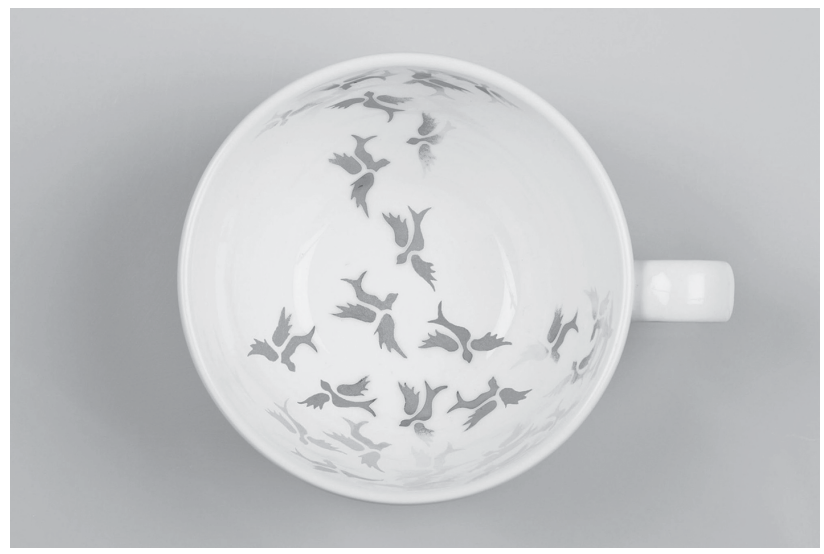

Figure 3.4 The Stain teacup after a number of uses Source: (C) Bethan Laura Wood. 
Save/Space/Vase (by Plust, Joe Velluto design) is a set of plastic vases manufactured through a rotational moulding process. In the last step of the manufacturing process, each vase is compressed under a load, giving it a unique shape. Unique products may be valued more by users, potentially leading to a stronger product attachment.

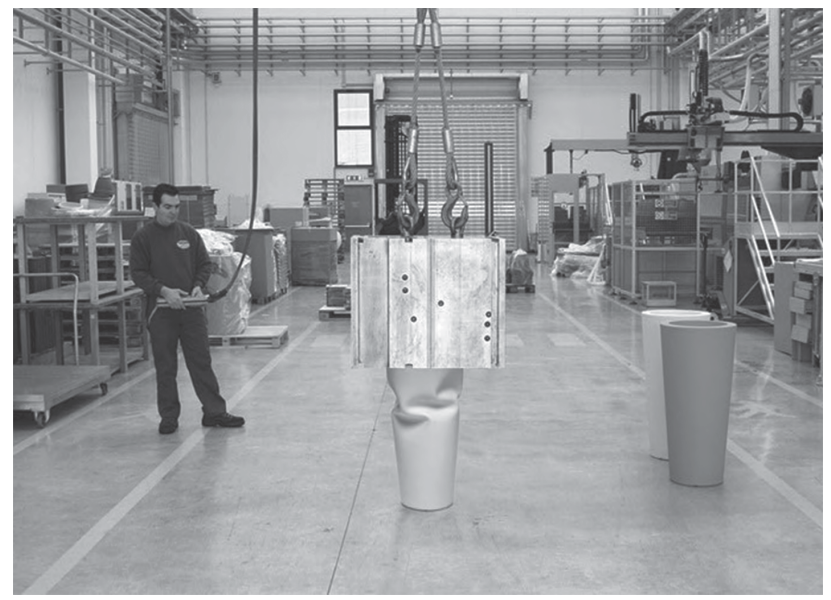

Figure 3.5 Save/Space/Vase: the process to make vases unique Source: (C) Euro3plast Spa.

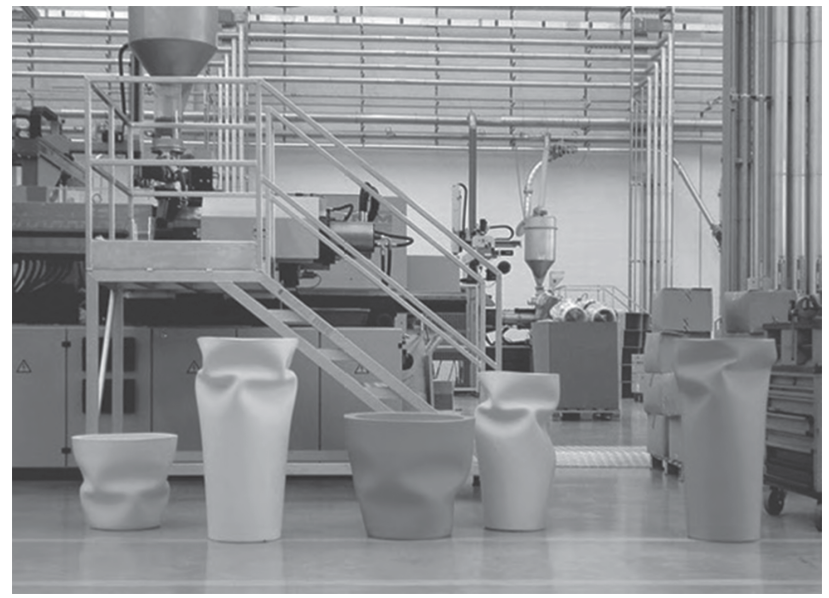

Figure 3.6 A set of different Save/Space/Vase vases Source: (C) Euro3plast Spa. 


\section{Emotionally durable design}

(see, e.g., Schultz et al., 1989; Kleine et al., 1995; Mugge, 2007; Schifferstein \& Zwartkruis-Pelgrim, 2008; Mugge, Schifferstein, \& Schoormans, 2010; Deal, Paavilainen, \& Koskinen, 2016).

- Pleasure: the ability of a product to provide pleasure. This product meaning relates to the experience derived from owing, displaying and/or using a product. This might be linked to a product's superior utility (e.g. greater usability or higher quality; Jordan, 1998) or to the appearance and aesthetic qualities of a product, without consideration for its utility (e.g. the manufacturing and material quality; Jordan, 1998). Research shows that the experience of pleasure can be associated with product attachment (see, e.g., Norman 2004; Mugge, 2007; Schifferstein \& Zwartkruis-Pelgrim, 2008; Mugge, Schifferstein, \& Schoormans, 2010).

Building upon consumption behaviour theories and findings from product attachment studies, researchers on EDD have then investigated how to use these insights to support design practitioners, leading to a rich set of design strategies (see Section 3.2).

\subsection{Design practice}

Over recent years design researchers have proposed a set of EDD strategies, seeking to stimulate product attachment through the previously mentioned determinants. The main design strategies can be summarised as follows:

- Developing highly unique products, which by definition are scarce and not easily replaceable. A unique product may be valued more by the user compared to a standardised product, and thus enhance attachment. This can be achieved by producing limited edition series (Mugge, Schoormans, \& Schifferstein, 2005; Mugge, 2007; Grant et al., 2013). Production anomalies, flaws and defects can also be exploited to create products with unique features (Ostuzzi, Salvia, Rognoli, \& Levi, 2011), as in the Save/Space/Vase example (see Box 3.1). Similarly, digital manufacturing technologies can also provide opportunities for fostering the creation of unique products (Campbell \& Bernabei, 2017). Personalisation and co-creation (as detailed below) can also play a role.

- Involving the user in personalisation, customisation and co-design activities, to stimulate product attachment and irreplaceability by encouraging user self-expression (Mugge et al., 2005; Mugge, 2007). Depending on the degree of personalisation/customisation, this 
can also lead to the creation of unique products. The value of this strategy also lies in the satisfaction and personal accomplishment experienced by the user (Salvia, 2016; Diefenbach et al., 2018).

- Involving the user in finishing or making (parts of) the product, enabling the development of unique products and expressing aspects of the 'self' by adding personal elements to the product (Mugge et al., 2005; Mugge, 2007), as in the Do Scratch example (see Box 3.1). Again, product attachment can also be fostered by the personal accomplishment derived from the making experience (Salvia, 2016; Diefenbach et al., 2018).

- Designing products that 'age with dignity', using materials and finishing that will show signs of age and use (Van Hinte, 1997; Chapman, 2005), as in the Stain example (see Box 3.1). This can result in products that aesthetically change over time and continuously stimulate and intrigue the user. The work done by Lilley, Smalley, Bridgens, Wilson, \& Balasundaram (2016) and Bridgens et al. (2019) on exploring user perceptions of aged materials applied to a smartphone case is also interesting in this respect.

- Designing products that allow users to capture memories and in this way to incorporate layers of narratives (Chapman, 2005). This can enable the user to gradually add elements to a product, embodying experiences and memories into it. Personalisation, co-design and making activities (see previous strategies) might also lead to the association of memories with a product.

- Designing adaptable products and encouraging the user to adapt/ interact with the products over time in relation to changes in his or her needs. In this way the user can become the co-producer of the experience rather than a passive and inert observer of the product (Chapman, 2005). Modular and reconfigurable furniture represents a typical exemplification of this strategy.

- Involving the user in do-it-yourself repair activities, which can extend the functional life of a product as well as foster product attachment by creating a unique/personalised product.

Although co-design and design for customisation methods and tools have been developed in the past, a comprehensive EDD method or tool has never been created.

\subsection{Benefits and limitations}

The EDD approach can support designers in developing products that can establish and maintain an emotional bond with the user over time. 
This can potentially provide a positive effect on the environment by postponing or avoiding product disposal/replacement. It is important to highlight that EDD addresses an aspect of product design that is overlooked by other product-related DfS approaches, and thus it can provide a complementary design perspective.

On the other hand, there are a number of limitations that must be taken into account. First of all, it must be said that it is particularly challenging for designers to effectively stimulate product attachment because emotional attachment is subjective. Designers can embed appropriate EDD strategies in a product, but in the end it is the user who gives a particular meaning to a product (Mugge, 2007). This means that it is problematic to foresee the extent to which a particular strategy will result in an improved emotional attachment. The same product features that enhance product attachment in a particular user might not work for another user.

In addition to being subjective, emotional attachment is also dependent on cultural and social factors. The result is that the same product can generate different meanings and different degrees of attachment in individuals with different social and cultural characteristics (Chapman, 2005; Kazmierczak, 2003).

Another weakness relates to the limited range of product categories where EDD can be applied. In fact, product attachment determinants are much less relevant for those products which are mainly purchased for utilitarian reasons (e.g. a washing machine; Mugge et al., 2005). In these cases, this approach cannot play a particularly significant role in extending product lifespan.

More generally, we need to question the relevance of EDD in the light of the recent large-scale diffusion of social media. Digital platforms are in fact increasingly used for self-expression, online identity formation and creating a sense of belonging (Seidman, 2013). As a consequence, social media is partly taking over the role that physical products used to play in relation to these aspects.

From a sustainability point of view, there are some potential rebound effects that must be underlined. Firstly, extending longevity beyond a certain point might not be environmentally beneficial for some product categories. This is in particular related to those products whose main impact is in the use phase (i.e. those products that consume resources in use). In fact, in these cases it might be environmentally beneficial, after a certain amount of time, to replace the product with a new and more efficient one, leading to a reduction in resource consumption in use.

In addition, developing products that express a person's identity might result in early product disposal. In fact, we need to consider that 
a person's identity might change over time, and these changes might weaken product attachment and lead people to dispose of products that are no longer aligned with their self-image (McAlexander, 1991).

From an economic perspective, it is worth noting that manufacturers might be averse to implementing product attachment strategies because this might slow down the product replacement rate, with a consequent reduction in sales (Mugge et al., 2005). A potential way to address this issue is to integrate EDD strategies with product-service system innovations (see Chapter 7).

\subsection{Future research directions}

There is an inherent difficulty in conducting research on EDD. Studying product attachment means that relatively long periods of time must be taken into consideration. Decades might pass between the purchase, use and disposal of a product. Thus, in this context, the challenge is to understand how to effectively measure and verify product attachment. Past research has mainly focused on investigating product attachment through questionnaires, interviews or limited timespan longitudinal studies. There are some limitations connected to the use of these research methods, especially in relation to questionnaires and interviews. Research participants might not entirely recollect the reasons for purchasing, valuing, keeping and/or discarding a product. Thus, the first important research direction relates to the methodological aspect: in order to gather more solid and robust research results, studies exploring product attachment during the whole lifespan of a product should be conducted (Mugge, 2007). This might lead to a better and deeper understanding of the set of factors triggering product attachment and detachment.

As noted in the previous sections, product attachment is subjective and linked to socio-cultural factors. Thus, another area that requires additional research is the understanding of the role that culture and user values play in creating, enhancing, maintaining and decreasing product attachment (Mugge, 2007). This would potentially lead to the development of more tailored EDD strategies.

As shown in Section 3.2, a rich set of product attachment design strategies has been developed over recent years. However, as pointed out by Mugge (2007), even if product attachment design strategies can be justified theoretically, further research is required to test the effectiveness of implementing these strategies in products. In fact, so far design strategies have been generated as a result of understanding product attachment determinants (see, for example, the approach conducted 
by Schifferstein and Zwartkruis-Pelgrim, 2008) and there is a lack of empirical validation. However, it is clear that testing these strategies poses challenges in terms of the length of the studies because, as pointed out before, product attachment can only be truly measured over a long period of time.

Another aspect that requires further investigation is the identification of the effectiveness of different design strategies on different product categories. At the moment, EDD strategies are generic (they do not refer to specific product categories), and for designers it is problematic to understand which of them works best in relation to specific types of products. A more in-depth understanding of this aspect would better inform designers in applying appropriate strategies.

It is also interesting to look at emerging digital manufacturing technologies (e.g. additive manufacturing) and the opportunities that these can provide in terms of product personalisation, as well as involving users in co-design and co-creation processes (see, for example, the work of Campbell and Bernabei, 2017).

Finally, it is worth considering that EDD only focuses on the product level. This might limit the potential of design interventions (e.g. as discussed previously, manufacturers might not be economically incentivised to apply this approach). For this reason, it is important to start exploring how this approach can be integrated and applied in synergy with other DfS approaches. An interesting example moving in this direction comes from the work of Hobson, Lynch, Lilley, \& Smalley (2018), who have applied EDD in conjunction with product-service system design (see Chapter 7) and ecodesign (see Chapter 2) in order to address the environmental problems of mobile phones. In addition, considering the role that social media plays in relation to self-expression and affiliation, it seems promising to look at how digital platforms might be used to strengthen and extend the emotional bond with physical artefacts.

\section{References}

Ahde-Deal, P., Paavilainen, H., \& Koskinen, I. (2016). 'It's from my Grandma.' How jewellery becomes singular. The Design Journal, 20(1), 29-43.

Brezet, J. C., \& Van Hemel, C. G. (1997). Ecodesign: A promising approach to sustainable production and consumption. Paris, France: United Nations Environmental Programme.

Bridgens, B., Hobson, K., Lilley, D., Lee, J., Scott, J. L., \& Wilson, G. T. (2019). Closing the loop on e-waste: A multidisciplinary perspective. Journal of Industrial Ecology, 23(1), 169-181.

Campbell, R. I., \& Bernabei, R. (2017). Increasing product attachment through personalised design of additively manufactured products. In A. Maier et al. 
(Eds.), Proceedings of the 21st International Conference on Engineering Design (ICED17), Vancouver, Canada, 21-25 August, Vol. 5: Design for X, Design to $X$ (pp. 71-79).

Chapman, J. (2005). Emotionally Durable Design: Objects, experiences, and empathy. London, UK: Earthscan.

Chapman, J. (2009). Design for (emotional) durability. Design Issues, 25(4), $29-35$.

Chapman, J. (2010). Subject/object relationships and emotionally durable design. In T. Cooper (Ed.), Longer lasting products: Alternatives to the throwaway society. Farnham, UK: Gower.

Cooper, T. (2004). Inadequate life? Evidence of consumer attitudes to product obsolescence. Journal of Consumer Policy, 27(4), 421-449.

Cooper, T. (Ed.). (2010). Longer lasting products: Alternatives to the throwaway society. Farnham, UK: Gower.

Desmet, P. M. A. (2012). Faces of product pleasure: 25 positive emotions in human-product interactions. International Journal of Design, 6(2), 1-29.

Diefenbach, S., Jung, S., Diller, T., Franze, C., \& Maciejczyk, S. (2018). The secret of self-made: The potential of different types of consumer participation for product attachment and commercial value. Social Sciences, 7(4), 52.

Echegaray, F. (2016). Consumers' reactions to product obsolescence in emerging markets: The case of Brazil. Journal of Cleaner Production, 134(Part A), 191-203.

Fokkinga, S. F., \& Desmet, P. M. A. (2012). Darker shades of joy: The role of negative emotion in rich product experiences. Design Issues, 28(4), 42-56.

Fuad-Luke, A. (2010). Adjusting our metabolism: Slowness and nourishing rituals of delay in anticipation of a post-consumer age. In T. Cooper (Ed.), Longer lasting products: Alternatives to the throwaway society. Farnham, UK: Gower.

Grant, K. E., Straker, K., Muller, C., \& Wrigley, C. (2013). The search for individualism: Self-expression through product personalisation. The International Journal of Designed Objects, 6(1), 17-29.

Hobson, K., Lynch, N., Lilley, D., \& Smalley, G. (2018). Systems of practice and the Circular Economy: Transforming mobile phone product service systems. Environmental Innovation and Societal Transitions, 26, 147-157.

Jordan, P. (1998). Human factors for pleasure in product use. Applied Ergonomics, 29(1), 25-33.

Lilley, D., Smalley, D., Bridgens, B., Wilson, G. T., \& Balasundaram, K. (2016). Cosmetic obsolescence? User perceptions of new and artificially aged materials. Materials and Design, 101(5), 355-365.

Kazmierczak, E. T. (2003). Design as meaning making: From making things to the design on thinking. Design Issues, 19(2), 45-59.

Kleine, S. S., Kleine, R. E., \& Allen, C. T. (1995). How is a possession "me" or "not me"? Characterizing types and an antecedent of material possession attachment. Journal of Consumer Research, 22(3), 327-343.

McAlexander, J. H. (1991). Divorce, the disposition of the relationship, and everything. In R. Holman \& M. R. Solomon (Eds.), Advances in Consumer 
Research, Vol. 18 (pp. 43-48). Provo, UT: Association for Consumer Research.

Mugge, R. (2007). Product attachment. Doctoral dissertation. Delft University of Technology, Delft, the Netherlands.

Mugge, R., Schifferstein, H. N. J., \& Schoormans, J. P. L. (2010). Product attachment and satisfaction. Journal of Consumer Marketing, 27(3), 271-282.

Mugge, R., Schoormans, J. P. L., \& Schifferstein, H. N. J. (2005). Design strategies to postpone consumers' product replacement: The value of a strong person-product relationship. The Design Journal, 8(2), 38-48.

Norman, D. A. (2004). Emotional design. New York: Basic Books.

Ostuzzi, F., Salvia, G., Rognoli, V., \& Levi, M. (2011). The value of imperfection in industrial product. In Proceedings of the 2011 Conference on Designing Pleasurable Products and Interfaces (DPPI'11), Milan, Italy, 22-25 June.

Salvia, G. (2016). The satisfactory and (possibly) sustainable practice of do-ityourself: The catalyst role of design. Journal of Design Research, 14(1), 22-41.

Seidman, G. (2013). Self-presentation and belonging on Facebook: How personality influences social media use and motivations. Personality and Individual Differences, 54(3), 402-407.

Schifferstein, H. N. J., \& Zwartkruis-Pelgrim, E. P. H. (2008). Consumerproduct attachment: Measurement and design implications. International Journal of Design, 2(3), 1-13.

Schultz, S. E., Kleine R. E., \& Kernan J. B. (1989). 'These are a few of my favorite things': Toward an explication of attachment as a consumer behavior construct. In T. Scrull (Ed.), Advances in Consumer Research, Vol. 16 (pp. 359-366). Provo, UT: Association for Consumer Research.

Solomon, M. R. (1983). The role of products as social stimuli: A symbolic interactionism perspective. Journal of Consumer Research, 10, 319-329.

Tian, K. T., Bearden, W. O., \& Hunter G. L. (2001). Consumers' need for uniqueness: Scale development and validation. Journal of Consumer Research, 28, 50-66.

Van Hinte, E. (1997). Eternally yours: Visions on product endurance. Rotterdam, the Netherlands: 010 Publishers.

Van Nes, C. G. (2010). Understanding replacement behaviour and exploring design solutions. In T. Cooper (Ed.), Longer lasting products: Alternatives to the throwaway society. Farnham, UK: Gower. 


\section{Design for sustainable behaviour}

\subsection{Triggering and supporting changes in human behaviour}

As discussed in Chapter 2, ecodesign can provide designers with a set of design strategies to reduce the environmental impact of a product life cycle. This approach deals with the technical aspects of a product life cycle but unfortunately does not devote much attention to the influence that the user's behaviour can have on the overall impact of a product. The problem is that the way in which users interact with products can determine substantial environmental impacts (Environmental Change Unit, 1997; Lilley, 2009). For example, for many products that consume energy through their use, energy consumption is mainly determined by users' behaviour (Tang \& Bhamra, 2009). The understanding of this critical weakness of ecodesign has prompted design researchers to explore ways in which to positively influence human behaviour.

However, the interest of design researchers in shaping human behaviour did not only spring from the need to mitigate ecodesign's shortcomings. More broadly, it was about understanding how to facilitate shifts in the everyday behaviour of people in order to support the adoption of sustainable innovations (Crocker \& Lehman, 2013). Thus, the scope of intervention does not necessarily cover only products, but more broadly it can span over systems of products and services, digital artefacts, the built environment and even policies. More generally, this area of study sparks from the acknowledgement that, as suggested by Jelsma (2006), designers need to take moral responsibility for the actions of people as a result of interactions with designed artefacts. 
It must be said that design for behavioural change is not necessarily concerned with sustainability aspects and implications. Thus, we can define design for behavioural change as the area of study focused on how design can shape or influence human behaviour for health, safety and social benefit reasons, as well as for commercial benefit (Lockton, Harrison, \& Stanton, 2010). When design for behavioural change is applied to support the adoption of sustainable innovations and behaviours, we can speak of design for sustainable behaviour (DfSB).

Starting from the second half of the 2000s, design researchers began exploring the role of design in influencing user behaviour for sustainability (e.g. Rodriguez \& Boks, 2005; Lilley, 2007, 2009; Wever, van Kuijk, \& Boks, 2008) and subsequently developing approaches, articulated sets of guidelines and tools (e.g. Bhamra, Lilley, \& Tang, 2011; Lockton et al., 2010; Zachrisson \& Boks, 2012) and applying these in a number of studies (e.g. Daae \& Boks, 2016; Tang \& Bhamra, 2012).

The DfSB approaches and tools developed so far have been built upon various behavioural change theories. As noted by Niedderer et al. (2014), there are many different DfSB approaches because there are many different models of behavioural change in the social sciences. These models can be divided into three main groups:

- individualistic rational choice models, where the focus is on the agency of individuals to make choices and act independently;

- context-driven models, which see behaviour as a consequence of the contextual elements of the social structure in which individuals live;

- middle-ground models, which combine the individual agency and the contextual approaches.

(Niedderer et al., 2014)

There have been attempts to unify behavioural change models. In this respect, the comprehensive action determination model (CADM) (Klöckner \& Blöbaum, 2010) is a model that integrates previous behavioural change theories and aims to encompass the internal and external factors affecting behaviour, as well as to explain their key causal influences. The CADM (see Figure 4.1) explains that individual behaviour is directly determined by influences from three possible sources (habitual, intentional and situational processes) and indirectly determined by influences from a fourth one (normative processes). 


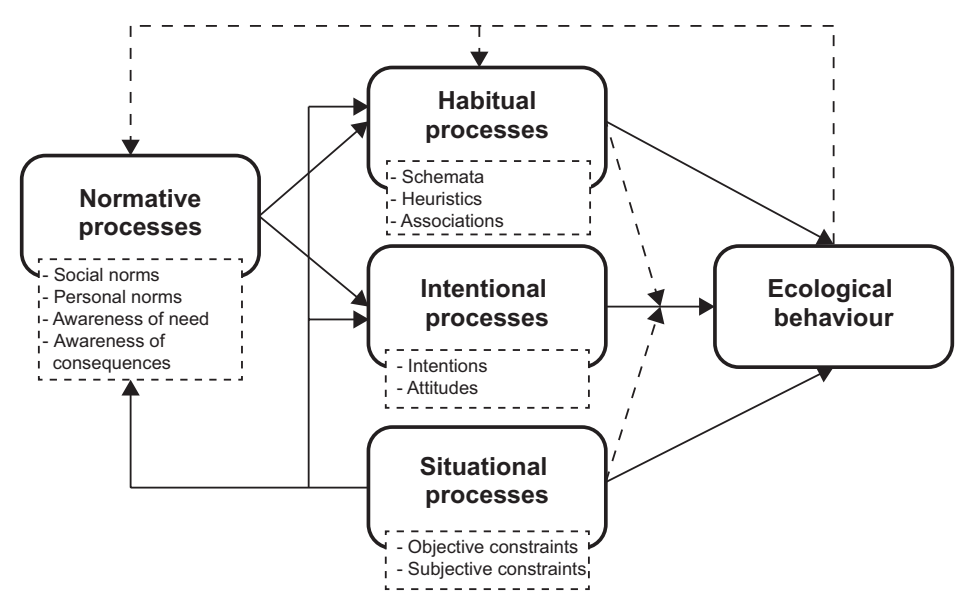

Figure 4.1 The comprehensive action determination model (CADM) Source: Klöckner \& Blöbaum (2010).

If attempts have been made to develop a unified model of behavioural change, the same cannot be said for DfSB. Some of the existing DfSB approaches/tools focus more on internal factors while others are more concerned with external factors (see Section 4.2). Thus, at the moment a unified model of DfSB - or, more generally, design for behavioural change - is missing. This is probably due to the fact that DfSB is a relatively young area of study. Nevertheless, most approaches and tools developed are centred around one or more of the four basic principles (Niedderer et al., 2014):

- making it easier for people to adopt the desired behaviour;

- making it harder for people to perform the undesired behaviour;

- making people want to perform the desired behaviour;

- making people not want to perform the undesired behaviour.

Currently, examples of applications of DfSB that can be found in the literature address the environmental dimension of sustainability (i.e. stimulating users to adopt more environmentally sustainable patterns of use - [see, e.g., the work of Tang and Bhamra, 2012]) and/or the social dimension (e.g. enabling users to adopt a healthier behaviour or improve safety in built environments). Applications include products (see the 


\section{Box 4.1 DfSB examples}

The Power-Aware Cord (by the Swedish Interactive Institute) is a power cord that visualises energy consumption through patterns of glowing and pulsating light: the higher the energy usage, the faster the flow of light. This allows users to be aware of and reflect on the energy consumption of electrical devices. As a result, this can potentially lead the user to adopt more sustainable behaviours (additional details and images are available at www.poweraware.com).

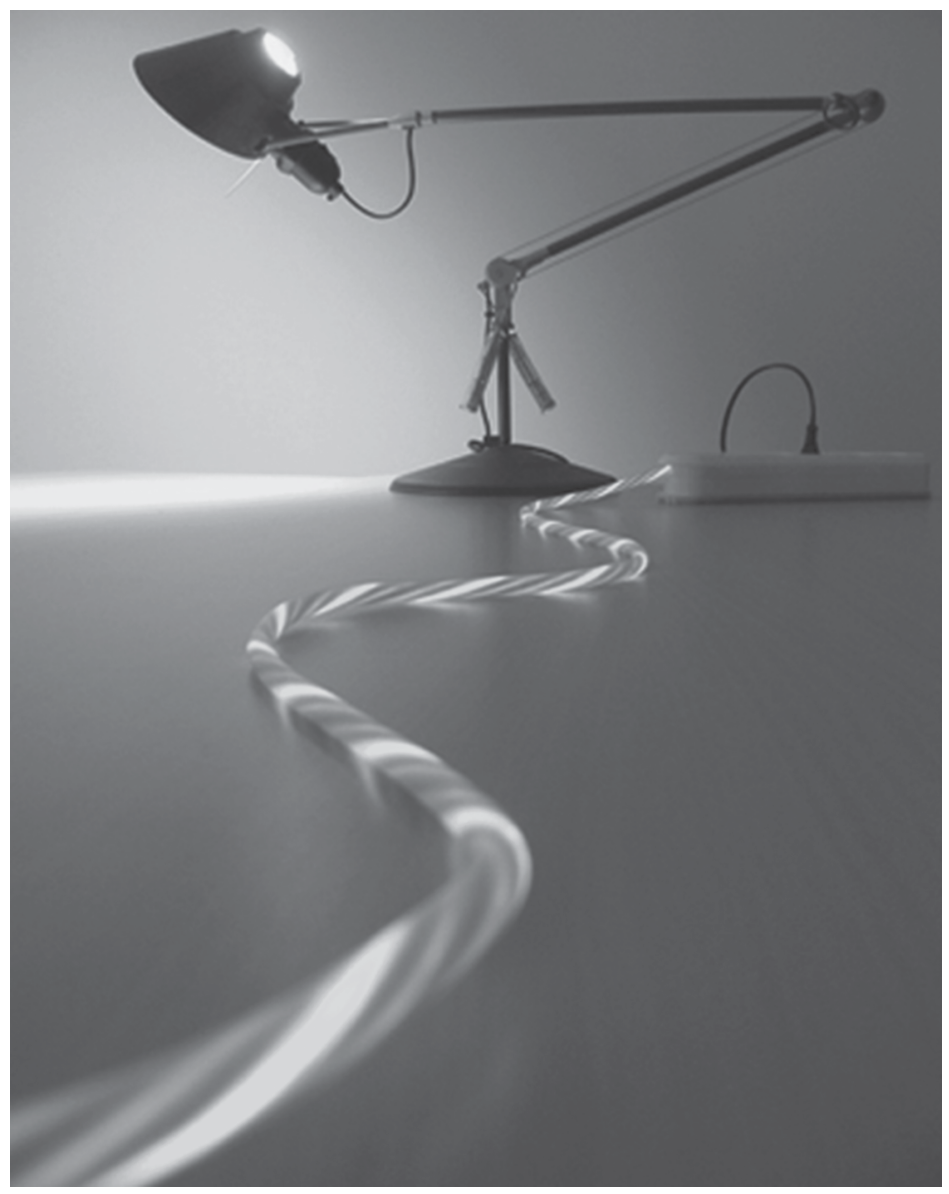

Figure 4.2 The Power-Aware Cord

Source: (C) Poweraware AB. 
The Museum of Modern Art (MOMA) in New York has been designed with wide staircases. These are also more easily accessible than elevators. The end goal is to encourage people to use the stairs rather than the lifts. This is an example of how design for behavioural change can be applied at a contextual level in order to favour and/or limit behaviour.

SuperAmma (or SuperMum) (by the London School of Hygiene \& Tropical Medicine) is a behavioural change intervention aimed at increasing the rates of women and children in rural India washing their hands with soap. The campaign includes several elements, including an animated film that embodies the central insights, a jingle with campaign messages embedded in it, a skit for schools and a pledge for willing participants. The campaign and the animated film are centred around the SuperAmma character who is the best possible role model for mothers in the target audience. (The campaign is available at www.superamma.org; additional details on the campaign and its results can be found in the work of Biran et al. [2014].)

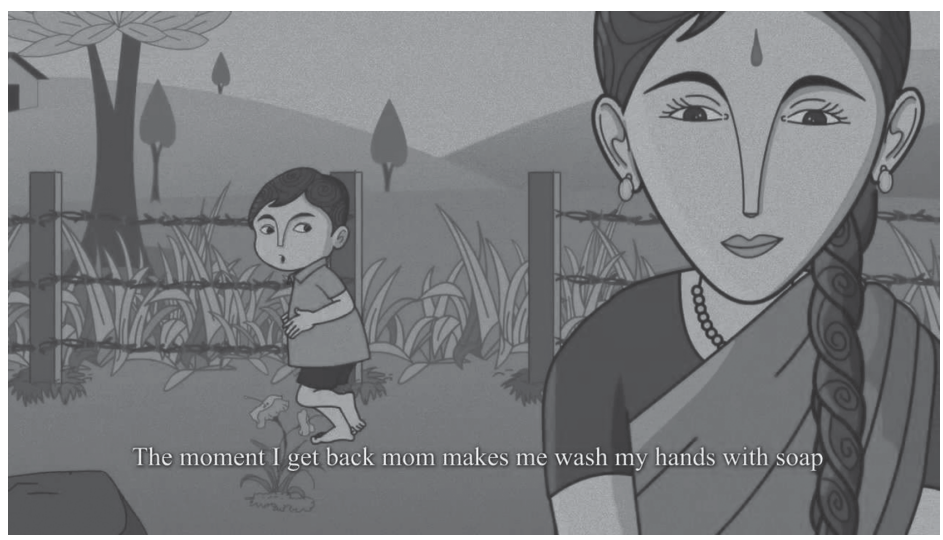

Figure 4.3 A screenshot from the SuperAmma animated film Source: www.superamma.org/download-English.html. 
Power-Aware Cord example in Box 4.1), product-service systems, mobile interactions, awareness campaigns (see the SuperAmma example in Box 4.1), the built environment (see the MOMA example in Box 4.1) and policy.

\subsection{Design practice}

Several DfSB approaches, methods and tools have been developed in recent years, particularly within the last ten years (see Box 4.2). We can classify these tools into three broad groups (Niedderer et al., 2016): (1) those which primarily focus on the cognition of individuals and aim to change individuals' behaviour (see, e.g., the Power-Aware Cord example, (2) those which primarily focus on the context and aim to shape behaviour through changing the environment where individuals operate, for example, by acting on the built environment or at a policy level (see, e.g., the MOMA example) and (3) middle-ground approaches which aspire to combine both cognition and context.

Attempts have been made to combine some of these approaches into a unified framework. In this respect, De Medeiros, Da Rocha, \& Ribeiro (2018) have identified similarities and complementarities in six existing approaches and proposed a decision support system that combines these approaches into a single framework (see Figure 4.4). This involves four phases:

- $\quad$ Phase 1 - User analysis, in which designers focus on evaluating the cultural context in which the solution will be adopted.

- Phase 2 - The level of user or product control, in which designers decide if the control will be with the user, with the product or a mixture of both. This is based on the continuum proposed by Lilley (2009), Bhamra et al. (2011) and Tang and Bhamra (2012).

- Phase 3 - Strategy definition, in which designers decide whether it is necessary to inform, maintain or ensure the change in behaviour. This part essentially comes from the models developed by Bhamra et al. (2011) and Tang and Bhamra (2012).

- $\quad$ Phase 4 - The means to incorporate strategies into the product, in which designers can adopt a set of detailed strategies. These combine design with intent strategies (Lockton et al., 2010) with the 11 strategies presented by Tromp, Hekkert, \& Verbeek (2011).

(De Medeiros et al., 2018) 


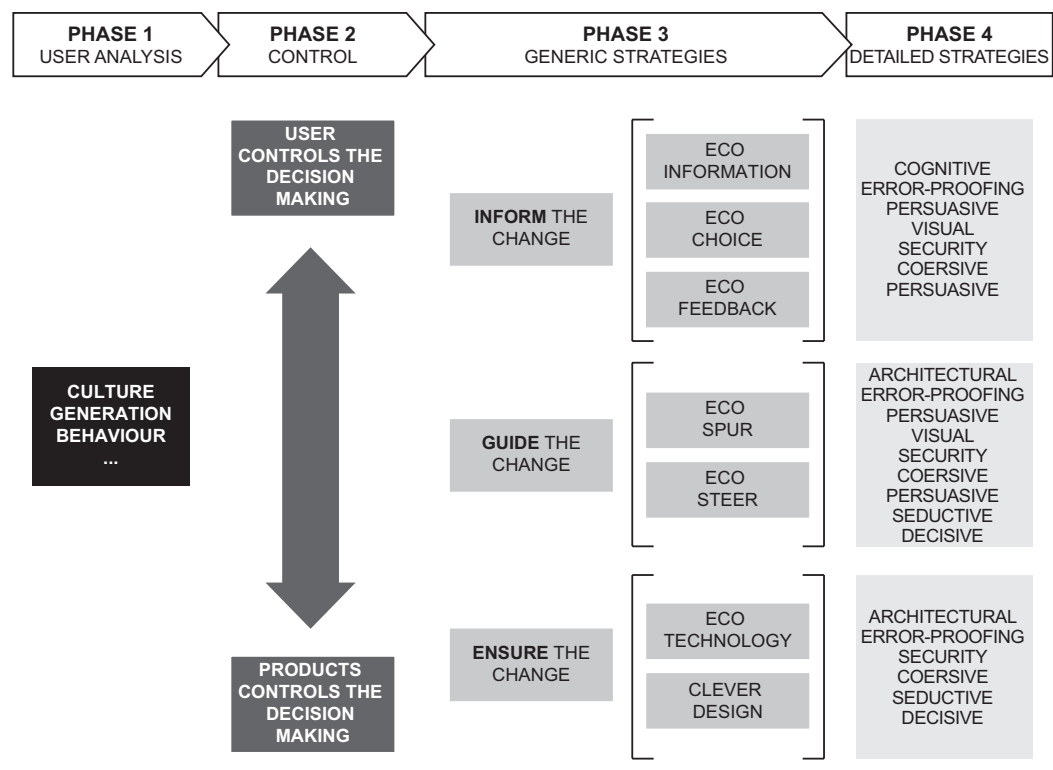

Figure 4.4 The decision support framework for promoting sustainable behaviour, combining a set of existing DfSB approaches

Source: Adapted from De Medeiros et al. (2018).

Recently, attention has also moved to exploring the process of designing, implementing and testing behavioural change interventions. In this respect, an important contribution came from Aunger and Curtis (2016), who developed the behaviour-centred design (BCD) framework that provides both a theory of change for behaviour and a practical process for designing and evaluating interventions. $\mathrm{BCD}$ has been successfully applied to a range of behavioural change interventions, for example, interventions related to handwashing, oral rehydration, food hygiene, and child and maternal nutrition (see, e.g., Biran et al., 2014). In addition, and in contrast toother approaches, it does not narrow its application to product design alone. Rather, it has the advantage of being applicable to different design innovation categories, including products, services, communication artefacts and policies. 


\section{Box 4.2 DfSB methods and tools}

Following the classifications of Niedderer et al. (2016), the most common DfSB methods and tools can be clustered into three categories (the below descriptions are adapted from Niedderer et al. [2016]):

\section{Individual-cognitive methods and tools}

- The designing moralised products model integrates user logic (cognitive models) and responding 'scripts' into the design process in order to encourage the sought-after user-product interaction (Jelsma, 2006).

- User-centred DfSB aims to support industry in designing products to stimulate environmentally friendly user behaviour (Wever et al., 2008).

- The Loughborough model proposes a set of design intervention strategies based on informing, empowering, providing feedback, rewarding and using affordances to promote an individual's sustainable behaviour (Bhamra et al., 2011; Lilley, 2009).

- Design for sustainable consumption behaviour focuses on behavioural solutions to reduce resource consumption in an industrial context (Selvefors, Pedersen, \& Rahe, 2011).

- The design for healthy behaviour framework focuses on the different stages of decision-making that are necessary in order to change people's health behaviour through design interventions (Ludden \& Hekkert, 2014).

\section{Middle-ground methods and tools}

- The MINDSPACE model aims to inform policymakers by providing them with guidance and a set of checklists for effective behavioural change (Dolan et al., 2009).

- The design with intent toolkit draws from a variety of fields and proposes eight lenses (architectural, error-proofing, interaction, perceptual, cognitive, security, ludic and Machiavellian lenses) for enabling, motivating, constraining or encouraging behaviour (Lockton, 2013; Lockton et al., 2010; Lockton, Harrison, \& Stanton, 2013). See http://designwithintent.co.uk/ for further details. 
- The community-based social marketing with design model uses prompts, norms, incentives and the removal of barriers to facilitate behavioural change (Clune, 2010).

- Socially responsible design focuses on the user experience to stimulate desirable behaviour and stifle undesirable behaviour (Tromp et al., 2011).

- Practice-orientated product design applies social practice theory in order to influence the trajectory of everyday practices (Kuijer, 2014).

- The dimensions of behavioural change tool comprises a set of cards designed to support designers by specifying techniques for influencing environmental behaviour (Daae \& Boks, 2014).

- The categorisation of different artefactrelated aspects that affect people's preconditions for sustainable behaviour (from the overarching layer of enabled activity, through artefact type[s], operative functions, interactive functions and, finally, communicative functions) (Selvefors, Strömberg, \& Renström, 2016).

- The behaviour-centred design approach can be used to plan the process of designing, implementing and testing a behavioural change intervention (Aunger \& Curtis, 2016). Guidance and examples can be found at www.lshtm.ac.uk/research/centresprojects-groups/bcd.

\section{Context-driven methods and tools}

- Architectural design against crime addresses the problem of crime prevention by intervening in the environment where human behaviour occurs (Crowe, 2000).

\subsection{Benefits and limitations}

A key benefit of DfSB is that it complements other product-related approaches (see Chapters 2, 3, 5, 6 and 8). It represents an effective tool with which to address a key limitation of these approaches, that is (as discussed before), the lack of attention paid to the impacts determined by how a product is used. More widely, it is an approach that can effectively enable societal change by shaping or instilling new behaviours and habits. It is a shared understanding that the transition towards sustainability will also require cultural changes and a reduction of 
consumption, and DfSB is an approach that can facilitate and support these changes.

However, despite its potential, DfSB presents some important challenges and limitations. First of all, there are some ethical implications. There are in fact concerns about the extent to which designers and companies are entitled to drive user behaviour (Pettersen \& Boks, 2008; Bhamra et al., 2011). Are designers allowed (or able) to define what constitutes and what does not constitute sustainable behaviour? Is there a limit to the influence they can apply to individuals' behaviour and habits? What happens if a well-intentioned behavioural change intervention leads to unwanted behaviour? To what extent are designers responsible for such unwanted consequences? Attempts have been made to address some of these ethical questions (see, e.g., Brey, 2006; Lilley \& Lofthouse, 2010), but the ethical dimension still remains to be further explored and discussed.

Looking more at the operational aspects, the key problem is that there is currently a lack of metrics with which to measure the effect of DfSB strategies and a lack of evidence-based examples (Niedderer et al., 2014). At the moment, the extent to which individual DfSB strategies are effective in achieving a certain behavioural change is not fully clear. There are very few studies that quantify the effects of a DfSB intervention (see, e.g., Biran et al., 2014). The difficulty of this task lies also in the fact that the effectiveness might change depending on the type of artefact the strategy is applied to, as well the socio-cultural context in which the solution is intended to be used. In addition, and in a similar way to emotionally durable design, the same strategy might have different effects on different individuals.

In connection with the previous aspect, we also need to consider the uncertainties related to environmental trade-offs. Implementing DfSB strategies might require the use of additional materials and resources (e.g. the eco-feedback strategy adopted in the Power-Aware Cord example that requires additional energy consumption) and the related environmental impact might be higher than the supposed environmental gain (see, e.g., Wever, Van Onselen, Silvester, \& Boks, 2010).

Finally, from a financial perspective, business stakeholders might not be incentivised to implement DfSB strategies because the investment required might not be counterbalanced by immediate financial gains (Lilley, 2009). As discussed in relation to emotionally durable design, a potential way to tackle this problem would be to integrate DfSB with innovation at a business model level (see Chapter 7) in order to create economic incentives for manufacturers to implement certain sustainability-driven solutions. 


\subsection{Future research directions}

As previously discussed, several DfSB frameworks, models and tools have been developed in recent years. In some cases these approaches share common aspects, such as a similar clustering of design strategies. In other cases, approaches complement one another; for example, some might focus on shaping individual behaviour while others might address the context in which individuals act. In any case, there is uncertainty and confusion, especially from design practitioners, about which approach/ tool should be adopted in order to address a certain design challenge. This is aggravated by the lack of common terminology used across different approaches. Thus, an important research direction is to investigate how to combine existing approaches into a unified model/framework (as recently attempted by De Medeiros et al. [2018]) or to develop a framework for the selection of the most appropriate approach(es) to be used. This would be beneficial in terms of improving and facilitating the practical implementation of DfSB.

Complementary to what has been said above, there is also the need to better understand how to select those DfSB strategies that are most likely to be effective depending on the particular situation. In fact, as pointed out by Coskun, Zimmerman and Erbug (2015) and Wever (2012), it is important to identify which strategies are working and which are not in the specific contexts of application. In this area, the initial work has been done by Zachrisson and Boks (2012), who used behavioral psychology to understand when different behavioural change strategies are likely to be effective and thus guide their appropriate selection.

Understanding the effectiveness of DfSB strategies requires the adoption of consistent evaluation protocols. As highlighted by Niedderer et al. (2014), the development of assessment metrics and techniques for a systematic analysis and evaluation of strategies represents another important direction for future research. This could be used to develop a database of practical DfSB examples that provides empirical evidence about the effectiveness of design strategies. To this end, it is crucial to carry out longitudinal studies to test DfSB strategies and their ability to support the adoption and retention of new behaviour (as done by, e.g., Zachrisson Goile, Seljeskog and Boks [2016] in relation to woodburning stoves).

Linked to the aforementioned research direction, Coskun, Zimmerman and Erbug (2015) pointed out that there is also a need to broaden the scope of intervention of DfSB. Previous studies have mainly focused on energy consumption in domestic contexts, and future 
research should investigate other types of consumption, other contexts and diverse user groups (ibid.).

From a more operational and organisational perspective, Weaver (2012) also identified a future research direction in the need to understand how DfSB frameworks, approaches and tools can be easily integrated into existing innovation processes within different organisational environments. Finally, the adoption and integration of DfSB by companies and design consultancies is also linked to the need to develop a consistent vocabulary that is more accessible for professionals (Daae \& Boks, 2014; Niedderer et al., 2016).

\section{References}

Aunger, R., \& Curtis, V. (2016). Behaviour centred design: Towards an applied science of behaviour change. Health Psychology Review, 10(4), 425-446.

Bhamra, T., Lilley, D., \& Tang, T. (2011). Design for sustainable behaviour: Using products to change consumer behaviour. The Design Journal, 14(4), 427-445.

Biran, A., Schmidt, W. P., Varadharajan, K. S., Rajaraman, D., Kumar, R., Greenland, K., ... Curtis, V. (2014). Effect of a behaviour-change intervention on handwashing with soap in India (SuperAmma): A clusterrandomised trial. Lancet Global Health, 2(3), 145-154.

Brey, P. (2006). Ethical aspects of behavior-steering technology. In P. P. Verbeek \& A. Slob (Eds.), User behavior and technology development: Shaping sustainable relations between consumers and technologies (pp. 357-364). Dordrecht, the Netherlands: Springer.

Clune, S. (2010). Design for behavioural change. Journal of Design Strategies, $4(1), 68-75$.

Coskun, A., Zimmerman, J., \& Erbug, C. (2015). Promoting sustainability through behavior change: A review. Design Studies, 41(Part B), 183-204.

Crocker, R., \& Lehman, S. (2013). Motivating change: Sustainable design and behaviour in the built environment. Oxford, UK: Routledge.

Crowe, T. D. (2000). Crime prevention through environmental design: Woburn, MA: Butterworth-Heinemann.

Daae, J., \& Boks, C. (2014). Dimensions of behaviour change. Journal of Design Research, 12(3), 145-172.

Daae, J., \& Boks, C. (2016). A classification of user research methods for design for sustainable behaviour. Journal of Cleaner Production, 106, 680-689.

De Medeiros, J. F., Da Rocha, C. G., \& Ribeiro, J. L. D. (2018). Design for sustainable behavior (DfSB): Analysis of existing frameworks of behavior change strategies, experts' assessment and proposal for a decision support diagram. Journal of Cleaner Production, 188, 402-415.

Dolan, P., Hallsworth, M., Halpern, D., King, D., Metcalfe, R., \& Vlaev, I. (2009). Mindspace: Influencing behaviour through public policy. London, UK: Cabinet Office \& Institute for Government. 
Environmental Change Unit (1997). 2MtC-DECADE: Domestic equipment and carbon dioxide emissions. Oxford, UK: Oxford University.

Jelsma, J. (2006), Designing 'moralized' products. In P.P. Verbeek \& A. Slob (Eds.), User behavior and technology development: Shaping sustainable relations between consumers and technologies. Berlin, Germany: Springer.

Klöckner, C. A., \& Blöbaum, A. (2010). A comprehensive action determination model: Toward a broader understanding of ecological behaviour using the example of travel mode choice. Journal of Environmental Psychology, 30(4), 574-586.

Kuijer, L. (2014). Implications of social practice theory for sustainable design. Doctoral dissertation. Delft University of Technology, Delft, UK.

Lilley, D. (2007). Designing for behavioural change: reducing the social impacts of product use through design. Doctoral dissertation. Loughborough University, Loughborough, UK.

Lilley, D. (2009). Design for sustainable behaviour: Strategies and perceptions. Design Studies, 30(6), 704-720.

Lilley, D., \& Lofthouse, V. A. (2010). Teaching ethics for design for sustainable behaviour: A pilot study. Design and Technology Education: An International Journal, 15(2), 55-68.

Lockton, D. (2013). Design with intent: A design pattern toolkit for environmental \& social behaviour change. Doctoral dissertation. Brunel University London, London, UK.

Lockton, D., Harrison, D., \& Stanton, N. A. (2010). The Design with Intent method: A design tool for influencing user behaviour. Applied Ergonomics, 41(3), 382-392.

Lockton, D., Harrison, D., \& Stanton, N. A. (2013). Exploring design patterns for sustainable behaviour. The Design Journal, 16(4), 431-459.

Ludden, G. D. S., \& Hekkert, P. (2014). Design for healthy behavior: Design interventions and stages of change. In Proceedings of the 9th International Conference on Design and Emotion, Bogota, Colombia, 6-10 October.

Niedderer, K., Ludden, G., Clune, S. J., Lockton, D., Mackrill, J., Morris, ... Hekkert, P. P. (2016). Design for behaviour change as a driver for sustainable innovation: Challenges and opportunities for implementation in the private and public sectors. International Journal of Design, 10(2), 67-85.

Niedderer, K., Mackrill, J., Clune, S., Lockton, D., Ludden, G., Morris, A., ... Hekkert, P. (2014). Creating sustainable innovation through design for behaviour change: Full project report. University of Wolverhampton, Project Partners \& AHRC.

Pettersen, I. N., \& Boks, C. (2008). The ethics in balancing control and freedom when engineering solutions for sustainable behaviour. International Journal of Sustainable Engineering, 1(4), 287-297.

Rodriguez, E., \& Boks, C. (2005). How design of products affects user behaviour and vice versa: The environmental implications. In Proceedings of the 4th International Symposium on Environmentally Conscious Design and Inverse Manufacturing (Eco Design 2005), Tokyo, Japan, 12-14 December (pp. 54-61). 
Selvefors, A., Pedersen, K., \& Rahe, U. (2011). Design for sustainable consumption behaviour: Systematising the use of behavioural intervention strategies. In Proceedings of the 5th Conference on Designing Pleasurable Products and Interfaces (DPPI'11), Milan, Italy, 22-25 June.

Selveforsa, A., Strömberg, H., \& Renström, S. (2016). What a designer can change: A proposal for a categorisation of artefact-related aspects. In Proceedings of the Design Research Society Conference 2016, Brighton, UK, 27-30 June.

Tang, T., \& Bhamra, T. A. (2009). Improving energy efficiency of product use: An exploration of environmental impacts of household cold appliance usage patterns. In Proceedings of the 5th International Conference on Energy Efficiency in Domestic Appliances and Lighting (EEDAL'09), Berlin, Germany, 16-18 June.

Tang, T., \& Bhamra, T. A. (2012) Putting consumers first in design for sustainable behaviour: A case study of reducing environmental impacts of cold appliance use. International Journal of Sustainable Engineering, 5(4), 288-303.

Tromp, N., Hekkert, P., \& Verbeek, P. (2011). Design for socially responsible behaviour: A classification of influence based on intended user experience. Design Issues, 27(3), 3-19.

Wever, R. (2012). Editorial: Design research for sustainable behaviour. Journal of Design Research, 10(1/2), 1-6.

Wever, R., van Kuijk, J., \& Boks, C. (2008). User-centred design for sustainable behaviour. International Journal of Sustainable Engineering, 1(1), 9-20.

Wever, R., Van Onselen, L., Silvester, S., \& Boks, C. (2010). Influence of packaging design on littering and waste behavior. Packaging Technology and Science, 23(5), 239-252.

Zachrisson, J., \& Boks, C. (2012). Exploring behavioural psychology to support design for sustainable behaviour research. Journal of Design Research, 10(1/ 2), 50-66.

Zachrisson, J., Goile, F., Seljeskog, M., \& Boks, C. (2016). Burning for sustainable behaviour. Journal of Design Research, 14(1), 42-65. 


\section{Cradle-to-cradle design}

\subsection{Closing the loops}

Among some thinkers in the DfS field, there is the belief that imitating nature's materials and processes is the only way to achieve sustainability. This is broadly referred to as nature-inspired design. Cradle-to-cradle (CTC) design (see examples in Box 5.1) is one of two prominent and currently popular frameworks representing this belief. The other framework, biomimicry, is covered in Chapter 6 .

CTC was pioneered and advocated by the architect William McDonough and the chemist Michael Braungart (Braungart, McDonough, \& Bollinger, 2007; McDonough \& Braungart, 2002). The approach is based on three interrelated design principles: waste equals food, eco-effectiveness and respect diversity. Eco-effectiveness is a fundamentally different concept from eco-efficiency; while eco-efficiency aims to minimise negative environmental impacts, eco-effectiveness focuses on increasing the positive impacts of materials and products. In other words, eco-effectiveness advocates industry to adopt a regenerative (rather than depletive) approach. The 'waste equals food' principle implies imitating nature's nutrient cycles in human productionconsumption systems. In nature, one organism's waste becomes another organism's food or resource. Based on this formulation, a regenerative (i.e. eco-effective) approach is operationalised in CTC by defining two types of nutrients: biological and technical.

Biological nutrients, as defined by Braungart et al. (2007), are 'biodegradable materials (or the result of biodegradation processes) posing no immediate or eventual hazard to living systems that can be used for human purposes and be safely returned to the environment to feed biological processes' (p. 1343). Biological nutrients flow optimally through the biological metabolism, which includes the processes of resource extraction, manufacturing, use and eventual return to natural systems. Such nutrients cover not only natural materials but also biopolymers 
and other synthetic materials that are safe for humans and ecosystems. Technical nutrients, on the other hand, are synthetic or mineral and have the potential to be circulated within production systems, through recovery and reuse, without losing their quality and function. Biological nutrients are used in 'products of consumption'; they are products that are gradually consumed during their lifespan, such as shoe soles and brake pads. As the product degrades, the nutrients go back into the natural environment and become nutrients for living systems. Technical nutrients are used in 'products of service'; they are durable goods that provide a particular service to the customer while the ownership remains with the manufacturer (who then, at the end of the life of the product, handles the reuse of the materials and parts). This proposed model resembles a use-oriented product-service system (see Chapter 7). The assumption underlying CTC is that if these nutrients are circulated in open loops (for biological nutrients) or closed loops (for technical nutrients), human society can continue production, consumption and economic growth indefinitely. Complementary to the 'waste equals food' and eco-effectiveness principles, CTC argues that human productionconsumption systems should only use renewable energy (i.e. photovoltaic, geothermal, wind, hydroelectric and biomass). According to McDonough and Braungart (2002), if this condition is met the amount of energy used throughout the life cycle of a CTC product is irrelevant.

The 'respect diversity' principle refers to what McDonough and Braungart (2002) call 'nature's design framework' (p. 118). They point out that the current human design response is a counter-attack on diversity, manifesting itself in the obliteration of ecosystems, the blandness and uniformity of buildings that lack beauty and cultural distinctiveness, the favouring of monoculture in agricultural production and a general monotony of the built environment. CTC therefore advocates for designs that mimic healthy and complex natural ecosystems and which support not only biodiversity but also socio-cultural and conceptual diversity (Ankrah et al., 2018).

\subsection{Design practice}

It is important to understand CTC from two angles. The first is as a vision and design philosophy for creating seamlessly interconnected production-consumption systems. To comply with the foundational principles of CTC (i.e. waste equals food, eco-effectiveness and respect diversity) requires considering the design of artefacts at all scales of the built environment - or the techno-, socio- and ecospheres - covering compounds, materials, parts, products, industrial sites and even cities 


\section{Box 5.1 CTC design examples}

Nike Considered is a line of shoes that predominantly integrates the 'waste equals food' principle of CTC. For example, they are designed to be more easily recycled by using mechanical rather than adhesive interlocking systems (in particular for the outsole), they are made from locally sourced materials close to the factory and they are made from a relatively high percentage of renewable materials, such as hemp and cotton fabrics.

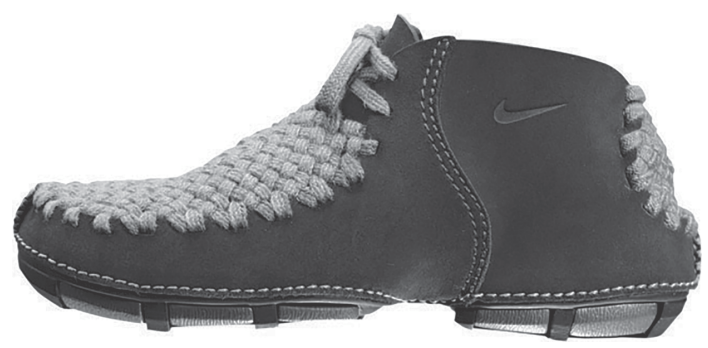

Figure 5.1 Nike Considered boots

Source: (c) Nike Inc.

Biobased Xorel by Carnegie Fabrics Inc. is an interior textile collection made of polyethylene yarn, $60-85 \%$ of which is derived from plant-based (sugarcane-based) materials. The product is Gold certified by the Cradle to Cradle Products Innovation Institute. For every ton of raw material produced for use in the manufacturing of this product, 2.5 tons of carbon is captured. (For more information see https://carnegiefabrics.com/xorel/ biobased-xorel.)

in relation to one another. Putting into practice such a comprehensive vision in full is not possible in our current industrial systems which operate within the logic of a linear economy. Nonetheless, this vision has inspired several projects, some of which have partially implemented the foundational principles, while others have proposed strategies for the implementation of the vision in particular systems. For example, Chong, Chiu, Liao, Hung, \& Pan (2015) proposed a framework interconnecting plastic recycling, pre-treatment, extrusion to filaments, $3 \mathrm{D}$ printing and users in order to minimise or eliminate the waste associated with 3D printing practices. Similarly, Contreras-Lisperguer, 
Muñoz-Cerón, Aguilera, \& Casa (2017), pointing to the expected increase in the volume of decommissioned photovoltaic panels in the medium term, developed a conceptual model and a suitable time-space scale for a closed-loop material cycle for industrial flow. These and several other projects which have adopted CTC are predominantly focused on products and product components (see, e.g., Rossi, Charon, Wing, \& Ewell, 2008; Steidal, 2017). Ankrah et al. (2018), on the other hand, investigated the development and integration of CTC into the design of two pilot business sites.

The second perspective is a not-for-profit (yet proprietary) certification programme known as the Cradle-to-Cradle Certified Product Standard, which enables companies to monitor and market their progress in CTC compliance (MBDC, 2016). The certification programme applies to materials, sub-assemblies and finished products. The categories covered in the standard are material health, material reutilisation, renewable energy and carbon management, water stewardship and social fairness, and each of the categories is scored on a five-grade system with increasing stringency of requirements. The five steps for putting eco-effectiveness into practice are as follows (McDonough \& Braungart, 2002; Braungart, McDonough, \& Bollinger, 2007).

Step 1. Get 'free of' known culprits. Create products that are free of obviously harmful substances.

Step 2. Follow informed personal preferences. Make educated decisions about replacing harmful substances with more preferable ones.

Step 3. Create a 'passive positive' list. Systematically assess all the ingredients used in a product in order to classify their toxicological and eco-toxicological characteristics and determine their capacity to flow within biological and technical metabolisms. Prepare a list of substances that are actively defined as healthy and safe.

Step 4. Activate the positive list. Optimise the passive positive list developed in Step 3 to the point at which each ingredient in a product becomes a biological or technical nutrient.

Step 5. Reinvent. This step goes beyond focusing on products, moving on to replacing ingredients with technical and biological nutrients, and it focuses on viewing products from the perspective of the services they provide and the needs they fulfil for all stakeholders, including customers and the socioecological systems they are part of, in order to reinvent the whole system of production-consumption cycles. 


\section{Box 5.2 CTC design tools and methods}

\section{Broad design guidelines}

- Chapter 6 of Cradle to Cradle: Remaking the Way We Make Things (McDonough \& Braungart, 2002).

- Sections 4, 5 and 6 of 'Cradle-to-cradle design: Creating healthy emissions - a strategy for eco-effective product and system design' (Braungart et al., 2007).

\section{Compliance requirements}

Cradle-to-Cradle Certified Product Standard Version 3.1 (MBDC, 2016).

\section{Tools for creating a CTC business site}

See also www.c2c-centre.com/tools.

- An inventory tool

- Operational frameworks

- $\quad \mathrm{A} \mathrm{C} 2 \mathrm{C}$ communication strategy tool

- Valuation tools

- Material management guidelines

- Diversity guidelines

- Energy assessment guidelines

- A database for nutrient streams

- A development framework

While the above steps provide generic design guidelines for the implementation of the broad CTC vision, the Cradle-to-Cradle Certified Product Standard (MBDC, 2016) presents the compliance requirements for certification in detail.

\subsection{Benefits and limitations}

The potential of CTC design to enable radical innovation and create a mindset change in businesses towards achieving sustainability has been acknowledged as its main value (Bakker, Wever, Teoh, \& Clercq., 2010). It also puts emphasis on regenerative processes, non-human species and future generations. CTC has brought the issue of the toxic substances used in the manufacturing of consumer goods into the open, 
put forward a bold and detailed vision of how production-consumption systems can have positive impacts, rather than simply 'being less bad', and it has established links between materials, products, services and business models. Teoh (2008) has found that designers can easily relate to the visionary and inspiring message of CTC, and CTC guidelines have enabled them to challenge existing company business models. CTC can assist designers in broadening their perspective on sustainability with a 'positive impact' mindset, rather than limiting the potential of their practice by trying to minimise negative impacts as is mostly advocated by eco-efficiency (Bjørn \& Hauschild, 2013). It has also been found that although closing the loops in material systems generally falls outside of the designers' traditional ways of working and requires more effort, it provides new and appreciated opportunities to collaborate with partners in the value chain (de Pauw, Karana, \& Kandachar, 2013). The certification programme has influenced several companies that have then taken significant steps towards reducing the negative impacts of their products.

Nevertheless, it is argued that the emphasis CTC puts on regenerative processes, non-human species and future generations remains at a rhetorical level and that, despite its inspiring vision, CTC is technically not very well justified (Gaziulusoy, 2015) and there are practical limitations to the implementation of this broad vision. Niero, Olsen and Laurent (2018) pointed out that, so far, the implementations of CTC have mainly focused on shifting from a waste paradigm to a resource one, leaving the complementary aspects of the wider vision beyond the scope of implementation. Bach, Minkov and Finkbeiner (2018) found that good environmental performance of CTC certified products is not assured due to the limited assessment scope, which does not take into account all product life-cycle phases and disregards some environmental impacts. Others have also argued that CTC design might shift the focus of design decisions from the entire life cycle of the product to the minimisation or eliminatation of toxic materials; therefore, it might result in the impacts of energy consumption being overlooked (Bakker et al., 2010; LlorachMassana, Farreny, \& Oliver-Solà, 2015; Niero et al., 2018).

This is a particularly significant issue for products which consume energy during the use phase (Llorach-Massana et al., 2015). The disregard for impacts related to energy use in CTC stems from the principle of using renewable energy, which, according to McDonough and Braungart (2002), makes energy consumption irrelevant. Although this principle is logical as part of the CTC vision, in practice such disregard becomes a significant weakness, as providing $100 \%$ of the world's energy demand from renewable resources is currently not possible. Therefore, energy efficiency, optimisation and the measurementof energy-related 
impacts are highly relevant for DfS. In addition, even if $100 \%$ of the world's energy demand was met by renewable resources, energy consumption would still be a relevant factor as unlimited growth in energy use would result in more materials becoming subject to increased shortages (van Dijk, Tenpierik, \& van den Dobbelsteen, 2014).

Van Boeijen, Daalhuizen, van der Schoor, \& Zijlstra (2014) argue that the application of CTC is more difficult for complex products, such as electronic printed circuit boards, which cannot even be recycled. Moreover, the rapid increase in demand since the Second World War for critical materials (including rare earth elements and rare earth metals) used in the components of mass consumer goods has diminished the potential for advanced reuse and recycling even further. So far, CTC has not been able to deliver alternatives to these crucial and critical elements that are required for proper product functionality (Peck, 2016).

In addition, Reijnders (2008) pointed out that the CTC claim that waste and emissions from biological materials are ecologically irrelevant because they decompose and become 'nutrients' is not justified, as increases in the concentrations of biological nutrients have ecological effects and higher-than-normal concentrations may in fact create a human health hazard. In terms of technological nutrients, even if it were possible to establish $100 \%$ efficient cycles with no material quality or quantity loss, these cycles would still need to be fed with new virgin materials in order to feed the promised continuous growth (Bjørn \& Hauschild, 2013). Finally, there are also problems associated with the growth-oriented politics of CTC, which also apply to biomimicry design (discussed in further detail in Chapter 6).

\subsection{Future research directions}

Based on the analysis of the benefits and limitations of CTC, it is evident that there are several ways in which CTC can benefit from future research. The first of these concerns integrating the life-cycle approach and CTC principles both conceptually and methodologically. It is important to acknowledge the complementariness of eco-efficiency (measured by LCAs) and eco-effectiveness rather than treating them as mutually exclusive and contrasting. To address this, several studies have argued for the complementary use of CTC and LCA in design practice (see, e.g., Bjørn \& Hauschild, 2013; Toxopeus, de Koeijer, \& Meij, 2015; Niero et al., 2018). Nevertheless, there have so far been no significant contributions on this front. Future research could focus on developing theories for the conceptual integration of CTC and LCA, and methodological tools for the methodological integration of CTC and LCA. 
The technical recyclability of a material does not necessarily lead to it being recycled in practice, which is dependent on the availability of sufficient volumes on the market and appropriate recycling infrastructure (Bjørn \& Hauschild, 2013). Similarly, the release of biological nutrients is far from being non-problematic (Reijnders, 2008). Therefore, another research direction relates to the auxiliary systems and policies that are required for enabling biological and technical nutrients to be managed as envisioned in the CTC framework.

For designers, CTC is complex, requiring them to either develop additional knowledge and expertise or be supported by external expertise (Tempelman, Pauw, Van Der Grinten, Mul, \& Grevers, 2015). Therefore, another research direction, which is particularly relevant to the scope of this book, relates to the development of supporting tools and mechanisms for practising designers in order to enable them to implement the CTC framework. Moving in this direction, some recent research which frames CTC within the broader concept of the circular economy has formulated more operational design guidelines (see, e.g., den Hollander, 2018; Peck, 2016; Pagh Jensen, 2018).

\section{References}

Ankrah, N. A., Manu, E., Fullen, M., Bentrar, J., Cousin, A., Mess, M., \& Lewald, O. (2018). Implementation of Cradle to Cradle diversity principles in business site development schemes. International Journal of Urban Sustainable Development, 10(1), 92-108. doi:10.1080/ 19463138.2018.1443937

Bach, V., Minkov, N., \& Finkbeiner, M. (2018). Assessing the ability of the Cradle to Cradle Certified ${ }^{\mathrm{TM}}$ Products Program to reliably determine the environmental performance of products. Sustainability, 10(5). doi:10.3390/ su10051562

Bakker, C. A., Wever, R., Teoh, C., \& Clercq, S. D. (2010). Designing cradleto-cradle products: A reality check. International Journal of Sustainable Engineering, 3(1), 2-8. doi:10.1080/19397030903395166

Bjørn, A., \& Hauschild, M. Z. (2013). Absolute versus relative environmental sustainability. Journal of Industrial Ecology, 17(2), 321-332. doi:10.1111/ j.1530-9290.2012.00520.x

Braungart, M., McDonough, W., \& Bollinger, A. (2007). Cradle-to-cradle design: Creating healthy emissions - a strategy for eco-effective product and system design. Journal of Cleaner Production, 15(13-14), 1337-1348. doi:10.1016/j.jclepro.2006.08.003

Chong, S., Chiu, H. L., Liao, Y. C., Hung, S. T., \& Pan, G. T. (2015). Cradle to Cradle ${ }^{\circledR}$ design for 3D printing. Chemical Engineering Transactions, 45, 1669-1674. doi:10.3303/CET1545279 
Contreras-Lisperguer, R., Muñoz-Cerón, E., Aguilera, J., \& Casa, J. D. L. (2017). Cradle-to-cradle approach in the life cycle of silicon solar photovoltaic panels. Journal of Cleaner Production, 168, 51-59. doi:10.1016/ j.jclepro.2017.08.206

den Hollander, M. (2018). Design for managing obsolescence: A design methodology for preserving product integrity in a circular economy. $\mathrm{PhD}$ Thesis. Delft University of Technology, Delft, the Netherlands.

de Pauw, I., Karana, E., \& Kandachar, P. (2013). Cradle to Cradle in product development: A case study of closed-loop design. In A. Nee, B. Song, \& S. K. Ong (Eds.), Re-engineering manufacturing for sustainability (pp. 47-52). Singapore: Springer.

Gaziulusoy, A. İ. (2015). A critical review of approaches available for design and innovation teams through the perspective of sustainability science and system innovation theories. Journal of Cleaner Production, 107, 366-377. doi:10.1016/j.jclepro.2015.01.012

Llorach-Massana, P., Farreny, R., \& Oliver-Solà, J. (2015). Are Cradle to Cradle certified products environmentally preferable? Analysis from an LCA approach. Journal of Cleaner Production, 93, 243-250. doi:10.1016/ j.jclepro.2015.01.032

MBDC. (2016). Cradle to Cradle Certified Product Standard Version 3.1. Cradle to Cradle Products Innovation Institute.

McDonough, W., \& Braungart, M. (2002). Cradle to cradle: Remaking the way we make things (1st ed.). New York: North Point Press.

Niero, M., Olsen, S. I., \& Laurent, A. (2018). Renewable energy and carbon management in the Cradle-to-Cradle certification: Limitations and opportunities. Journal of Industrial Ecology, 22, 760-772. doi:10.1111/jiec.12594

Pagh Jensen, J. (2018). Narrowing, slowing and closing the resource loops Circular Economy in the wind industry. PhD Thesis. Aalborg University, Aalborg, Denmark.

Peck, D. (2016). Prometheus missing: Critical materials and product design. $\mathrm{PhD}$ Thesis. Delft University of Technology, Delft, the Netherlands.

Reijnders, L. (2008). Are emissions or wastes consisting of biological nutrients good or healthy? Journal of Cleaner Production, 16(10), 1138-1141. doi:10.1016/j.jclepro.2008.02.003

Rossi, M., Charon, S., Wing, G., \& Ewell, J. (2008). Design for the next generation: Incorporating Cradle-to-Cradle design into Herman Miller products. Journal of Industrial Ecology, 10(4), 193-210. doi:10.1162/jiec.2006.10.4.193

Steidel, V. (2017). Cradle to cradle: A sustainable approach for the textile chain. Melliand International, 23(3), 162-164.

Tempelman, E., De Pauw, I. C., Van Der Grinten, B., Mul, E. J., \& Grevers, K. (2015). Biomimicry and cradle to cradle in product design: An analysis of current design practice. Journal of Design Research, 13(4), 326-344. doi:10.1504/JDR.2015.074151

Teoh, C., 2008. Should Philips Consumer Lifestyle implement cradle-to-cradle? An investigation and an innovation framework. Master's Thesis. Delft University of Technology, Delft, the Netherlands. 


\section{Cradle-to-cradle design}

Toxopeus, M. E., de Koeijer, B. L. A., \& Meij, A. G. G. H. (2015). Cradle to Cradle: Effective vision vs. efficient practice? Procedia CIRP, 29, 384-389. doi:10.1016/j.procir.2015.02.068

van Boeijen, A., Daalhuizen, J., van der Schoor, R., \& Zijlstra, J. (2014). Delft design guide: Design strategies and methods. Amsterdam, the Netherlands: BIS Publishers.

van Dijk, S., Tenpierik, M., \& van den Dobbelsteen, A. (2014). Continuing the building's cycles: A literature review and analysis of current systems theories in comparison with the theory of Cradle to Cradle. Resources, Conservation and Recycling, 82, 21-34. doi:10.1016/j.resconrec.2013.10.007 


\section{Biomimicry design}

\subsection{Taking inspiration from nature}

Chapter 5 presented and discussed CTC design as one prominent approach that take inspiration from nature. Biomimicry (BM) design or biomimetics (also known as bio-inspired design and bionics [Vincent, 2009]) is another prominent framework that argues for imitating nature's processes as a way of achieving sustainability in production-consumption systems. Mimicking nature or being inspired by analogies from nature is not a new approach in the designers' toolbox. Vincent, Bogatyreva, Bogatyrev, Bowyer and Pahl (2006) provided a detailed list of contemporary inventions that were developed using biomimetic approaches. These include Velcro, which is inspired by the action of the hooked seeds of the burdock plant, robotic control systems, which are inspired by natural neural circuits, and dry adhesive tape, which is inspired by the adhesive mechanism of gecko feet. There is even a whole field of research and practice dedicated to biologically inspired micro-robots (see, e.g., Kim, Steager, \& Julius, 2012). Despite this historical and contextual prevalence of mimicking nature in design, engineering and architecture, it was Janine Benyus who popularised BM design in the context of DfS (Benyus, 2002).

$\mathrm{BM}$ design is defined as 'an intended emulation of nature life solutions for solving contemporary challenges' (Cohen \& Reich, 2016, p. 3). It encourages the observation of the ways in which nature solves problems in order to create novel solutions (Mead \& Jeanrenaud, 2016). The premise of BM design is to use nature as a model, measure and mentor (Benyus, 2002). Using nature as a model involves studying the models and processes within nature and adapting these to solve human problems. Using nature as a measure means adopting an ecological standard by which to judge the 'rightness' of innovations. The rationale behind using nature as an ecological standard is the claim that nature has learned what works and what is appropriate as a result of 3.8 billion 
years of evolution (Benyus, 2002). Using nature as a mentor places an emphasis on learning from nature rather than exploiting it.

Benyus $(2002,2008)$ differentiates between three levels of mimicking nature: mimicking the form, the process and the system (or ecosystem). Other authors have suggested similar levels when discussing knowledge transfer from nature to technology. For example, Schmidt (as cited in Cohen \& Reich, 2016, p. 24) also mentions three levels: (1) structures, forms and materials; (2) functions; and (3) processes and information which omits mimicry at the system level. Sartori, Pal and Chakrabarti (2010), on the other hand, refer to four levels of abstraction from a biological system: parts, organs, attributes and the state of change. Regardless of these nuanced categorisations, these mimicry levels are associated with the degree of sophistication of mimicry approaches, ranging from shallow (reductive) to deep (Volstad \& Boks, 2012). Referring to the categorisation proposed by Benyus (2002), the first level (i.e. mimicking form) is the shallowest approach in BM design. At this level, a natural form is emulated in a technological solution. The second level mimics the processes of nature, dealing with certain functions such as production, cleaning, organisation, renewal and disposal (of materials, parts, whole bodies or structures). The third level (i.e. the deepest level) of BM design considers emulating whole ecosystems.

$\mathrm{BM}$ design can take place bi-directionally, moving from biology to design (solution-driven design) and from design to biology (problemdriven design) (Pandremenos, Vasiliadis, \& Chryssolouris, 2012). In the first case, solutions in biology become an inspiration for creating design ideas, while in the second case, designers consult biology (mainly purpose-built solutions databases) with a specific problem in mind in the hope of being inspired by how nature has solved similar problems. Cohen and Reich (2016) argued that problem-driven BM design might be easier than solution-driven BM design and therefore more prevalent in practice.

\section{Box 6.1 BM design examples}

Japan's 500 Series Shinkansen bullet train was initially 'too noisy' coming out of tunnels. The train was redesigned, inspired by kingfishers. Kingfishers have long, narrow beaks and they dive into water without causing any splash. The redesigned train is not only quieter, but also consumes approximately $15 \%$ less energy and it is $10 \%$ faster. 


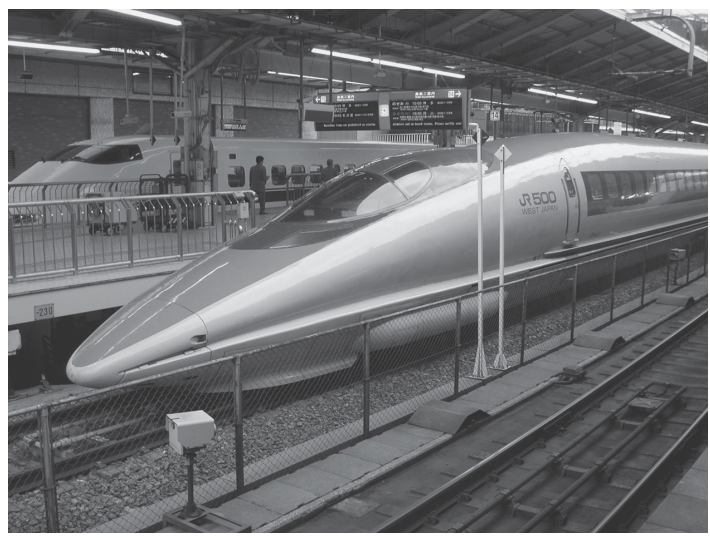

Figure 6.1 The Shinkansen bullet train, Japan Source: Wikimedia Commons CC BY-SA 3.0.

The Supertree Grove in Gardens by the Bay (Singapore) was designed by Grant Associates in collaboration with Atelier One and Atelier Ten. Supertrees comprise four major parts: a reinforced concrete core, a trunk, the planting panels of the living skin and a canopy. There are 18 Supertrees in the grove with heights ranging from 25 to 50 meters. The trees host a large number of plants of different species. Some of the Supertrees are fitted with solar photovoltaic systems that convert sunlight into energy to generate electricity, providing lighting and water technology within the conservatories below.

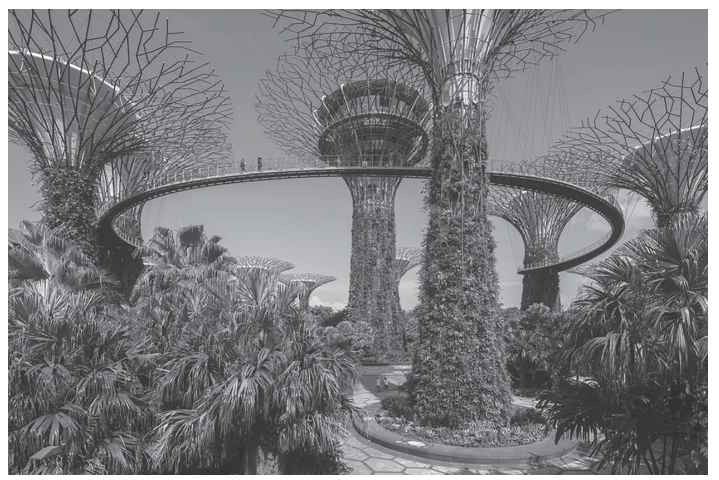

Figure 6.2 The Supertree Grove, Singapore

Source: Photo $@$ Grant Associates, photo credit: Darren Soh. 


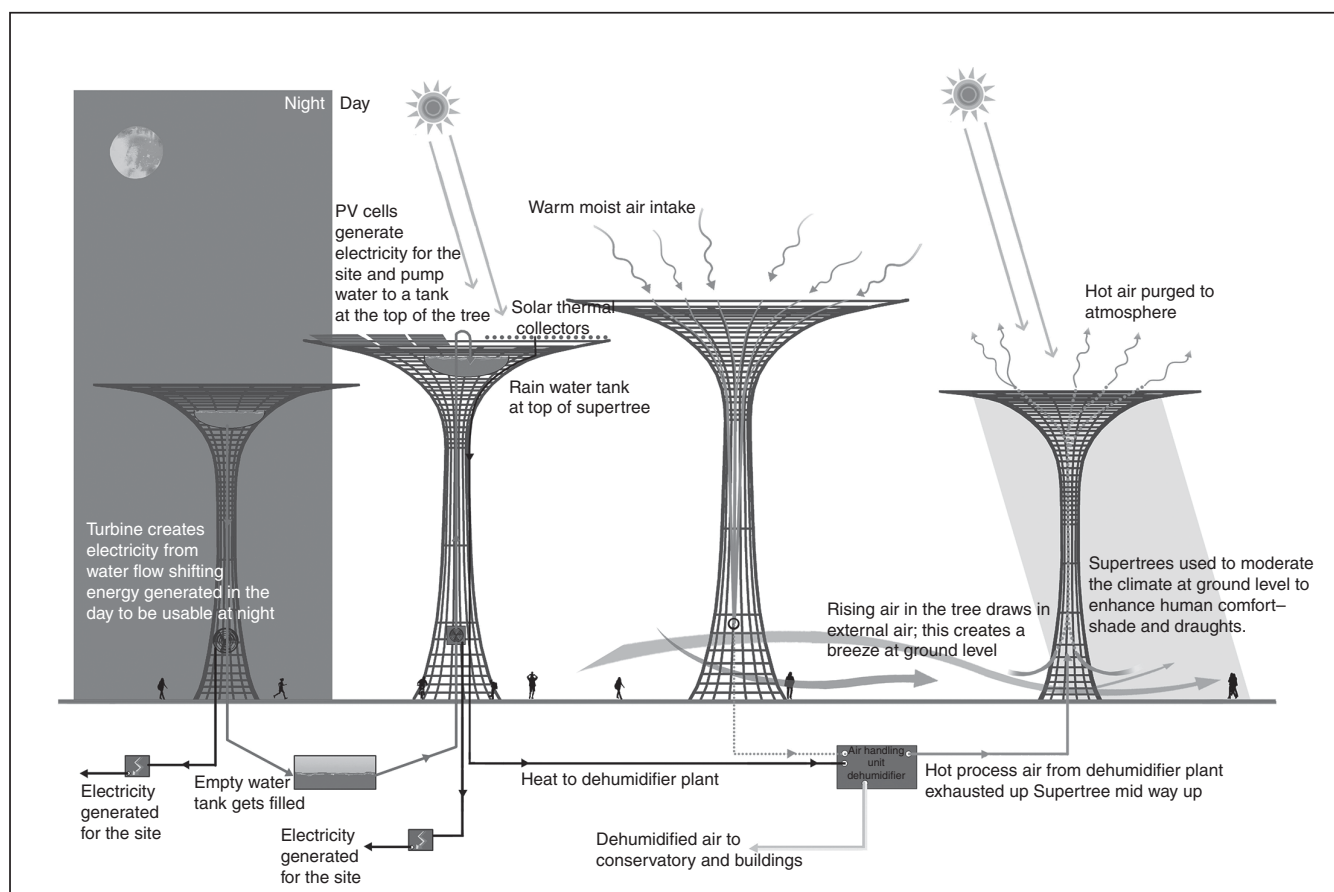

Figure 6.3 Diagram showing Supertrees' design and operation

Source: Image (C) Grant Associates. 


\subsection{Design practice}

With reference to the two possible directions that BM design can take (i.e. from biology to design and from design to biology), there are two generic methodological approaches. These are synthesised from the work of Helms, Vattam and Goel (2009) and Cohen and Reich (2016) and summarised below.

\section{The methodology for biology-to-design BM}

Step 1: The identification of a biological solution (if the designer already has a biological solution in mind, the process starts from Step 2).

Step 2: Defining the biological solution.

Step 3: Extracting a principle (or principles) from the biological solution.

Step 4: Reframing the solution by thinking of its usefulness for humans.

Step 5: Searching for a problem that can be solved by the solution. Step 6: Defining the problem.

Step 7: Application of the principle(s).

\section{The methodology for design-to-biology BM}

Step 1: Defining the problem.

Step 2: Reframing the problem.

Step 3: Searching for a biological solution.

Step 4: Defining the biological solution.

Step 5: Extracting a principle (or principles).

Step 6: Applying a principle (or principles).

These generic methodological approaches are highly simplified, and in real-world applications the processes are less linear and more iterative, requiring evaluation and reflection, more detailed searching for biological solutions that are relevant for the design problem at hand or more ideating for the potential applications of an identified biological solution (Helms et al., 2009; Cohen \& Reich, 2016). 


\section{Box 6.2 BM design methods and tools}

- Idea Inspire 3.0 (Chakrabarti et al., 2017): A web-based tool to assist designers in finding analogical ideas.

- Biomimicry Card Deck (Volstad \& Boks, 2012): A tool to help designers who are new to BM design with ideation that does not require extensive resources.

- Biomimicry Resource Handbook (Baumeister, Tocke, Dwyer, Benyus, \& Ritter, 2014): A handbook that provides advice on how to practise $\mathrm{BM}$, giving examples.

- AskNature (www.asknature.org): A web-based database of solutions from biology and resources that can be used in conjunction with BM design.

\subsection{Benefits and limitations}

BM design has a good track record of yielding innovative solutions in new product development and there is also some evidence that using $\mathrm{BM}$ design to drive sustainable innovation can result in remarkable outcomes. For example, based on a preliminary assessment of product concepts in a company case study, Kennedy and Marting (2016) found that BM design doubled both the intellectual property and the energy savings for just one sixth of the resource commitment while also speeding up front-end innovation. In addition, it has been argued that $\mathrm{BM}$ design can be used in urban contexts with some evidence supporting the successful use of BM design in urban related components (Buck, 2017), however, so far BM design has not been trialled at the level of a complete urban system.

Despite its demonstrated potential for assisting in the generation of innovative solutions, there are several critical perspectives on BM design. First and foremost, the outputs of BM design processes are not per se sustainable (Kennedy, Fecheyr-Lippens, Hsiung, Niewiarowski, \& Kolodziej, 2015). Although mimicking nature is an age-old and valid approach in design and innovation, claiming that innovations that result from mimicking nature are sustainable is misleading (Volstad \& Boks, 2012) because isolating a principle, structure or process from nature and imitating it does not necessarily yield sustainability. As illustrated by Reap, Baumeister and Bras (2005), this is particularly true for 'reductive' BM, which only mimics forms and processes, while BM design at the ecosystem level seems to offer 
more opportunities (in relation to this, refer to the systemic design approach discussed in Chapter 10). In addition, there is not an established system of accountability for BM design in sustainability-oriented innovation, therefore it is unclear how BM design practice relates to sustainability agendas and how sustainability is addressed and assessed by practitioners (Mead \& Jeanrenaud, 2016). Benyus (2002) indicated that the full potential of BM design cannot be realised unless it becomes integrated into an economic system that itself mimics living systems. Currently, BM design is mostly practised through the technical translation of biological functions and its focus is mostly on artefact-level innovation without consideration for integration with ecosystems.

However, even the technical translation approach does not come without problems and the translation of biological functions into the technological domain is not straightforward. Cohen and Reich (2016) identified four constraints in this regard: scalability, material constraints, manufacturing constraints and irrelevant design constraints. They pointed out that some biological mechanisms cannot be readily translated across different scales; for example, what works at the nanoscale may fail at the macroscale. When the biological function relates to material qualities and not to the structure, the emulation of the unique qualities of nature's materials (e.g. spider silk) may not be possible technologically. Similarly, the emulation of the processes of nature (e.g. the self-cleaning of lotus leaves) may not yield equal performance in manufactured artefacts. Finally, some constraints that are relevant for nature (such as the need for living bodies to be adjusted for growth) may not be at all relevant for technological artefacts. In relation to these constraints that are associated with translating biological functions, the practice of BM design is challenging. It is difficult for designers to access the information needed in order to use BM design in an effective and successful way other than through difficult-to-access databases (Volstad \& Boks, 2012). The search stage of finding biological solutions that are relevant for a design problem is difficult with little or no biological training (Buck, 2017). Although in ideal situations the practice would involve the collaboration of designers with biologists in order to overcome these difficulties, such arrangements are not always practical for companies and having to pay for additional consultation might result in an increased cost of innovation.

In addition to these limitations, BM design has also been criticised from both a philosophical perspective and with regard to its politics. Marshall and Lozeva (2009) argued that, theoretically, BM bridges technology and ecology, but in practice it values nature only instrumentally (and not intrinsically). They pointed out that the prime funders of 
large-scale BM research are the defence industry and large corporations, and outputs from BM design have as much capacity for environmental harm as eco-friendliness. They evaluated the current practice of BM design to be technocentric and therefore to be obscuring solutions to problems that are not technological when these might be readily available. They also criticised BM design for not challenging the existing power structures which create unsustainability and favour the market as the main dispersal mode, converting citizens into mere consumers. Similarly, Mathews (2011) raised concerns about the ethical foundations of BM design. She identified two main positions in BM design with regard to ethics: one which conceptualises BM design as a vehicle to save nature and another which sees BM design as a vehicle to replace nature with a 'new nature' of our design, associating the latter with anthropocentric triumphalism. She argued that, in contrast to its proponents, BM design will not create sustainability unless we act not only in imitation of nature but also from within nature, allowing nature to redesign not only our commodities but also our psycho-social patterns.

\subsection{Future research directions}

It is anticipated that BM design (along with the other DfS approaches discussed in this book) will attract increased attention over the coming years, as addressing climate change and other environmental challenges is becoming a major priority for policymakers, businesses and the public in general. Based on the limitations and constraints discussed in the previous section, it is apparent that ongoing discussions about the theoretical, scientific and ethical foundations of BM design and its politics are necessary. This is a task that should be taken seriously, not only by BM theorists and practitioners but also in conjunction with those involved in the broader and evolving conversations about societal values and norms with regard to sustainability. It is important that BM design is not practised in isolation but with reference to the socio-technical and socioecological systems that the outcomes will be embedded in. Marshall and Lozeva (2009), acknowledging the potential of BM design to transform technological patterns, argued that for it to actually contribute to sustainability, it should adopt an ecocentric value base (instead of a technocentric one) and encourage decentralisation, localism and democratic innovation processes. This calls for a restructuring of the field and already implies several research directions, all of which should be undertaken in collaborative research teams, such as teams of BM expert biologists and environmental ethicists. Although it is from this kind of research that the most breakthrough developments in the field are likely 
to happen, providing a detailed analysis of potential future research directions is beyond the scope of this book. Instead, here we elaborate on future directions for research that can be taken up in the short term and without much need for interdisciplinary coordination.

The first of these directions relates to strengthening BM design in such ways as meet its sustainability promise. Faludi (2012) argued that BM design is a concept generator for creating ideas and it can only be used as a metric to suggest what to measure and not how it should be measured. Therefore, one research direction is to investigate how the BM design process can be integrated with sustainability measurement tools. Mead and Jeanrenaud (2016) also emphasised the necessity for practitioners to be explicit about the impact of BM design outputs in relation to sciencebased targets. However, they also highlighted the importance of qualitative ways of assessing impacts, including the potential of BM design to inspire mindsets, values and alternative visions of development. From this, a research direction investigating BM in the context of sustainability transitions arises. Finally, further research is necessary in order to develop and improve the existing methods of solution translation in such a way that they will be easy to use for designers. For example, an initial attempt has been made by Volstad and Boks (2012), who developed a card deck of biological solutions in order to inspire packaging design.

\section{References}

Baumeister, D., Tocke, R., Dwyer, J., Benyus, J. M., \& Ritter, S. (2014). Biomimicry resource handbook: A seed bank of best practices.. Missoula, MT: Biomimicry 3.8.

Benyus, J. M. (2002). Biomimicry: Innovation inspired by nature. New York: Perennial.

Benyus, J. M. (2008). A good place to settle: Biomimicry, biophilia, and the return to nature's inspiration to architecture. In S. R. H. Kellert, H. M. Judith, \& L. Martin (Eds.), Biophilic design: The Theory, science, and practice of bringing buildings to life (pp. 27-42). Hoboken, NJ: Wiley.

Buck, N. T. (2017). The art of imitating life: The potential contribution of biomimicry in shaping the future of our cities. Environment and Planning B: Urban Analytics and City Science, 44(1), 120-140. doi:10.1177/ 0265813515611417

Chakrabarti A., Siddharth L., Dinakar M., Panda M., Palegar N., \& Keshwani S. (2017). Idea Inspire 3.0 - A tool for analogical design. In: A. Chakrabarti \& D. Chakrabarti (Eds.), Proceedings of ICoRD 2017: Research into design for communities, Volume 2 (pp. 475-485), Singapore: Springer.

Cohen, Y. H., \& Reich, Y. (2016). Biomimetic design method for innovation and sustainability. Cham, Switzerland: Springer. 


\section{Biomimicry design}

Faludi, J. (2012). Biomimicry place in green design. Zygote Quarterly, 3(Fall), $120-129$.

Kennedy, E., Fecheyr-Lippens, D., Hsiung, B.-K., Niewiarowski, P. H., \& Kolodziej, M. (2015). Biomimicry: a path to sustainable innovation. Design Issues, 31(3), 66-73. doi:10.1162/DESI_a_00339

Kennedy, E. B., \& Marting, T. A. (2016). Biomimicry: Streamlining the front end of innovation for environmentally sustainable products. ResearchTechnology Management, 59(4), 40-48. doi:10.1080/08956308.2016.1185342

Kim, M., Steager, E., \& Julius, A. (Eds.). (2012). Microbiorobotics: Biologically inspired microscale robotic systems. Oxford, UK: Elsevier.

Helms, M., Vattam, S. S., \& Goel, A. K. (2009). Biologically inspired design: Process and products. Design Studies, 30(5), 606-622. doi:10.1016/ j.destud.2009.04.003

Marshall, A., \& Lozeva, S. (2009). Questioning the theory and practice of biomimicry. International Journal of Design and Nature and Ecodynamics, 4(1), 1-10. doi:10.2495/DNE-V4-N1-1-10

Mathews, F. (2011). Towards a Deeper Philosophy of Biomimicry. Organization \& Environment, 24(4), 364-387. doi:10.1177/108602661142568

Mead, T., \& Jeanrenaud, S. (2016). The elephant in the room: Biomimetics and sustainability? Bioinspired, Biomimetic and Nanobiomaterials, 6(2), 113-121. doi:10.1680/jbibn.16.00012

Pandremenos, J., Vasiliadis, E., \& Chryssolouris, G. (2012). Design architectures in biology. Procedia CIRP, 3, 448-452. doi:10.1016/j.procir.2012.07.077

Reap, J., Baumeister, D., \& Bras, B. (2005). Holism, biomimicry and sustainable engineering. In Proceedings of IMECE2005, ASME International Mechanical Engineering Conference and Exposition, Orlando, USA, 5-11 November.

Sartori, J., Pal, U., \& Chakrabarti, A. (2010). A methodology for supporting "transfer" in biomimetic design. Artificial Intelligence for Engineering Design, Analysis and Manufacturing, 24(4), 483-506. doi:10.1017/ S0890060410000351

Volstad, N. L., \& Boks, C. (2012). On the use of biomimicry as a useful tool for the industrial designer. Sustainable Development, 20(3), 189-199. doi:10.1002/sd.1535

Vincent, J. F. V. (2009). Biomimetics - a review. Proceedings of the Institution of Mechanical Engineers, Part H: Journal of Engineering in Medicine, 223(8), 919-939. doi:10.1243/09544119JEIM561

Vincent, J. F. V., Bogatyreva, O. A., Bogatyrev, N. R., Bowyer, A., \& Pahl, A.K. (2006). Biomimetics: Its practice and theory. Journal of the Royal Society Interface, 3(9), 471-482. doi:10.1098/rsif.2006.0127 


\section{Product-service system design for sustainability}

\subsection{From designing individual products to integrated sets of products and services}

The adoption of design approaches that focus on product innovation (see Chapters 2-6) is crucial in order to reduce the environmental impact of products and production processes. However, although they are fundamental and necessary, these approaches are not on their own sufficient to obtain the radical improvements required to achieve sustainability. In fact, even if these innovations could bring about an improvement in products' environmental performance, it is also true that these improvements are often negatively counterbalanced by an increase in consumption levels (Schmidt-Bleek, 1996; Brookes, 2000). For example, the environmental gain achieved through the improvement of car efficiency (10\% from 1990 to 2004) has been more than offset by the increase in the number of cars and by the related increase (of $30 \%$ ) in the overall distance travelled (EEA, 2008). In addition, another problem is that in traditional business logic, based on the production and sale of products, manufacturers are usually not economically interested in extending product lifespan as much as possible, nor in optimising the consumption of resources along the product's life cycle (UNEP, 2002). Thus, as suggested by Ehrenfeld (2008), product innovation approaches constitute symptomatic solutions which do not address the root of the sustainability problem.

For these reasons, there is a need to move away from a focus on product improvements towards a wider design approach, focused on producing structural changes in the ways in which production and consumption systems are organised. Within this perspective, several researchers have started to look at product-service system (PSS) innovation as a promising approach for sustainability (e.g. Goedkoop, Halen, te Riele, \& P. Rommes, 1999; White, Stoughton, \& Feng, 1999; Stahel, 
2000; Heiskanen \& Jalas, 2000; Mont, 2002). PSSs can be defined as 'a mix of tangible products and intangible services designed and combined so that they are jointly capable of fulfilling final customer needs' (Tukker \& Tischner, 2006). In these business models, sometimes referred to as 'functional economy' (Stahel, 1997), the business focus shifts from the design and sale of products alone to the offer of a bundle of products and services that are jointly capable of satisfying a particular customer demand (UNEP, 2002). In other words, these are value propositions oriented to satisfy users through the delivery of functions instead of products (e.g. from selling heating systems to providing thermal comfort services, or from selling cars to offering mobility services). In this sense, PSSs entail a shift from consumption based on ownership to consumption based on access and sharing.

From a sustainability perspective, the interesting aspect is that PSSs, if properly conceived, can potentially decouple economic value from material and energy consumption (White et al., 1999; Stahel, 2000; Heiskanen \& Jalas, 2000). In fact, since manufacturers retain the ownership of products and deliver performance for their customers, they are economically incentivised to reduce, as much as possible, the material and energy resources (e.g. the costs of maintenance, disposal and manufacturing of new products) needed to provide that performance (Halme, Jasch, \& Sharp, 2004).

Traditionally, PSSs have been classified into three main categories (Hockerts \& Weaver 2002; Tukker, 2004):

- Product-oriented PSSs (see the Patagonia example in Box 7.1) is when a company (or an alliance of companies and stakeholders) sells a product coupled with additional services to add value to the product life cycle. These services can include, for example, maintenance, repairs, upgrading, advice on how to use the product, substitution and product take-back.

- Use-oriented PSSs (see the Riversimple example in Box 7.1) is when a company (or an alliance of companies and stakeholders) offers access to a product (or a set of products) which enables customers to get the results they want. The client obtains the desired utility but does not own the product that provides that utility and only pays for the time the product is actually used. Typical examples include product leasing, product renting/sharing and product pooling.

- Result-oriented PSSs (see the Pay-per-lux example in Box 7.1) is when a company (or an alliance of companies and stakeholders) provides a customised mix of products and services to deliver a specific 'final result' (in other words, an integrated solution to meet 
the customer's needs). The producer maintains ownership of the products and is only paid by the client for providing the agreed results. The customer benefits by being freed from the problems and costs involved in the acquisition, use and maintenance of the equipment and products.

From a design perspective, understanding the need to innovate at a broader level led researchers to explore its design implications. To this end, over the past decade several related research projects have been funded by the European Union (EU). ${ }^{1}$ Clearly, designing a PSS requires a different approach than designing a product. PSSs are in fact inherently complex artefacts composed of products (the tangible elements of the system), services (including the services that make products available and services to manage products in the use and end-of-life phases) and a network of actors (the socio-economic actors needed to produce, deliver and manage the PSS) (Mont, 2002). Designing a PSS means designing these elements simultaneously and requires a shift from product design thinking to system design thinking. It is important to highlight that this broadening of the design scope has also been explored by design researchers outside the sustainability area. Important contributions have also come from design researchers in the field of service and strategic design (see, e.g., Zurlo, 1999; Meroni, 2008).

Initially, design researchers focused on PSS design for eco-efficiency, looking at the economic and environmental dimensions of sustainability (e.g. Brezet, Bijma, Ehrenfeld, \& Silvester, 2001; Manzini, Vezzoli, \& Clark, 2001), and several design methods were developed and tested (see the next section). These have recently been complemented by approaches that focus on the design engineering aspects (for an overview, see Cavalieri \& Pezzotta, 2012), looking at the technical and systematic design and development of PSSs. In this context, researchers have explored methods for the integrated development of products and services (e.g. Aurich, Fuchs, \& Wagenknecht, 2006), methods for the modular design of PSSs (e.g. Wang et al., 2011), computer-aided design systems for PSS engineering (e.g. Sakao, Shimomura, Sundin, \& Comstock, 2009), methods for building collaborative networks (e.g. Zhang, Jiang, Zhu, \& Cao, 2012) and methods to be used more at managerial and strategic levels (e.g. Bocken, Short, Rana, \& Evans, 2013).

Researchers have also looked at integrating the socio-ethical dimension of sustainability in PSS design. For example, Vezzoli developed PSS design guidelines to enable designers to consider aspects such as employment/working conditions, equity and justice in relation to stakeholders, the integration of vulnerable and marginalised people, the 
improvement of social cohesion and the valorisation of local resources (Vezzoli, 2007; Vezzoli et al., 2014). When all three dimensions of sustainability are taken into consideration, we can refer to PSS design for sustainability (Vezzoli, 2007; Vezzoli et al., 2014).

Another area on which design researchers have been focusing is the application of PSS design in low-income contexts, namely PSS design for the bottom of the pyramid (see Chapter 8).

More recently, with the popularisation of the circular economy concept, researchers have started to use the term circular business model (see, e.g. Nußholz, 2017). In this context, Bocken, Pauw, Bakker and van der Grinten (2016) proposed six business model strategies that they grouped into two main categories: strategies for slowing loops and strategies for closing loops. Apart from the new terminology and different classification systems, the concept of circular business models essentially overlaps with PSSs but includes additional broader aspects, such as industrial symbiosis and extending resource value (through collecting otherwise 'wasted' materials/resources and turning these into new forms of value; Bocken et al., 2016).

\subsection{Design practice}

Since the 2000s, several methods and tools have been developed to support the design of eco-efficient and sustainable PSSs (see Box 7.2). The EU-funded project LeNS (Learning Network on Sustainability; 2007-2010; see Vezzoli \& Ceschin, 2011) reviewed and integrated existing PSS design methods into the MSDS (method for system design for sustainability; see Vezzoli, Ceschin, \& Cortesi 2009; Vezzoli et al., 2014). Similarly to the previous methods, the MSDS is organised around four main design stages (Vezzoli, Ceschin, \& Cortesi 2009; Vezzoli et al., 2014):

- Strategic analysis is aimed at obtaining all the background information necessary to facilitate the generation of sustainable PSS innovation ideas. This includes, for example, the analysis of the socio-economic context, the customer and the definition of sustainability design priorities.

- Exploring opportunities is aimed at creating a 'catalogue' of promising strategic and potentially sustainable PSS concept directions and ideas.

- PSS concept design is aimed at selecting the most promising ideas and combining them into coherent concept proposals with details of the business model, the set of products and services that make up the 


\section{Box 7.1 PSS design for sustainability examples}

The outdoor clothing company Patagonia sells all its products with a set of services that are available at any time. These include repairs (free, excluding damage due to wear and tear), returns (with a full refund) and care and maintenance advice. In addition, if the customer no longer wears a piece of clothing, she or he has the option of trading in that product in exchange for credit towards another garment (allowing Patagonia to remanufacture the garment or recycle its materials).

Riversimple is a British company that manufactures hydrogenpowered cars. The cars are not sold to customers. Rather, the company retains ownership and sells mobility as a service. In particular, customers can lease the car by paying a monthly fee that covers the use of the car, maintenance, insurance and the required energy. This means that the company has an economic interest in making a car that lasts as long as possible and is as efficient as possible. (For additional details and images, visit www.riversimple.com.)

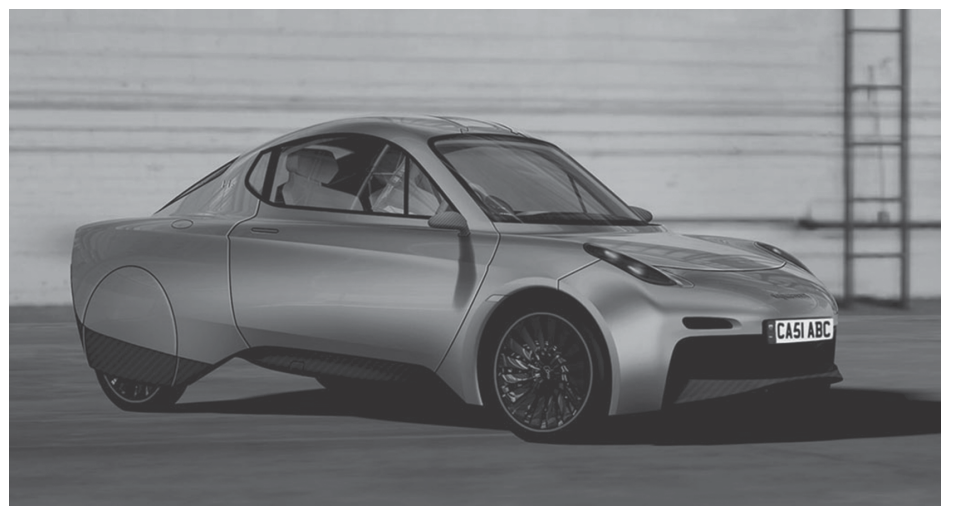

Figure 7.1 The Riversimple car

Source: () Riversimple.

Pay-per-lux (by Philips) is a business-to-business solution that provides lighting as a service. The customer does not own the lighting equipment. They rent the equipment from Philips and pay a flat rate for an agreed amount of light that hits a given surface (measured in lux). The offer includes the design, installation, upgrading, repair and end-of-life collection of the lighting system. Philips retains ownership of the lighting equipment and thus has 
an interest in extending the product lifespan as much as possible. In addition, if customers exceed their expected energy usage, they get cash back from Philips. This creates an economic incentive for Philips to provide customers with the most energy-efficient service possible.

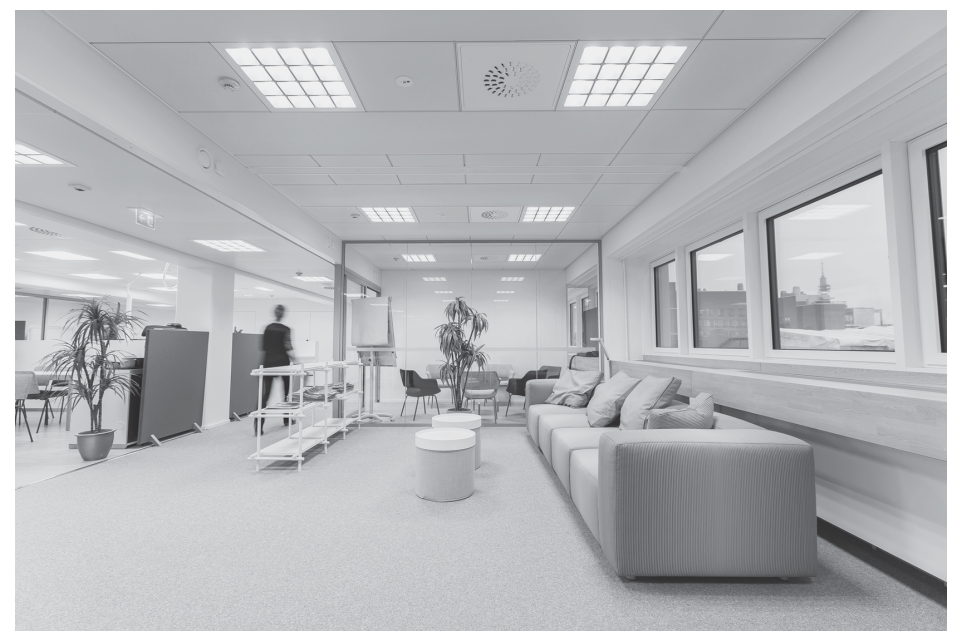

Figure 7.2 The Philips Pay-per-lux lighting solution

Source: (C) Philips.

offer, the socio-economic actors involved in the offer and the environmental, socio-ethical and economic potential of the proposal.

- $\quad$ PSS engineering is aimed at developing the selected concept with the level of detail that is required to enable its implementation.

From a more engineering-focused perspective, attention has recently moved towards the development of methods to support improved design and integration of the product and service components across the whole PSS life cycle (see, e.g., Pezzotta et al., 2018).

The methodological toolbox for eco-efficient and sustainable PSS development is fairly complete. A wide range of tools have been developed in association with the previously mentioned methods (for a comprehensive overview, see Verkuijl, Tischner, \& Tukker, 2006): tools to support creativity and ideas generation, tools to support the 
visualisation of PSSs and facilitate co-design processes (for an overview, see Ceschin et al., 2014) and tools to steer the design process towards sustainable outcomes. Regarding the integration of the sustainability dimension of the PSS design process, tools have been developed to support designers in identifying the sustainability design priorities, generating PSS ideas and assessing the sustainability performance of new concept alternatives.

\section{Box 7.2 PSS design for sustainability methods and tools}

\section{Methods}

- Kathalys: A method for sustainable product-service innovation (Luiten, Knot, \& van der Horst, 2001);

- The DES (design of eco-efficient services) methodology (Brezet et al., 2001);

- MEPSS (methodology for product service system development) (van Halen, Vezzoli, \& Wimmer, 2005);

- MSDS (method for system design for sustainability) (Vezzoli et al. , 2009; Vezzoli et al., 2014; available at www.lensinternational.org);

- PSSLDM (product service system lean design methodology) (Pezzotta et al., 2018).

\section{Visualisation and co-design tools}

What is offered to the customer?

- The advertising poster simulates the future promotional advertising of the PSS (van Halen et al., 2005).

- The offering diagram communicates what the PSS offers to customers through a combination of visual and textual elements (van Halen et al., 2005).

Who are the stakeholders involved?

- The stakeholder system map visualises the socio-economic stakeholders involved in producing and delivering the PSS offering and their interactions (Jégou, Manzini, \& Meroni, 2004). 
- The stakeholder motivation matrix describes the motivations and benefits that each stakeholder has with regard to being involved in the PSS (Jégou, Manzini, \& Meroni, 2004).

How does the PSS solution work?

- The interaction table (storyboard) (van Halen et al., 2005), a service blueprint and an animatic (Vezzoli et al., 2014) visualise the chronological sequence of interactions occurring at both front-desk and back-stage levels.

- PSS solution elements describe the material and immaterial elements required to deliver the PSS offering (Jégou, Manzini, \& Meroni, 2004).

Why should the PSS be implemented?

- The sustainability diagram describes how the PSS achieves certain sustainability goals (Vezzoli \& Ceschin, 2009)

\section{Sustainability-orienting tools and strategies}

- PSS design criteria and guidelines for system eco-efficiency (Vezzoli et al., 2014, Appendix I).

- PSS design criteria and guidelines for social equity and cohesion (Vezzoli et al., 2014, Appendix I).

- Strategies for circular business model design (Bocken et al., 2016).

- The SDO (sustainability design-orienting) toolkit is used to define sustainability-related design priorities, support idea generation and assess sustainability performance (available at www.sdo-lens.polimi.it).

\subsection{Benefits and limitations}

From an environmental point of view, the main benefit of PSSoriented solutions is that (as shown by the examples in Section 7.1) they create a potential economic incentive for stakeholders involved in the PSS to take responsibility for the PSS life cycle and optimise material and energy consumption. Although this does vary depending on the specific characteristics of each PSS, in general terms it makes 
manufacturers design longer-lasting and more energy-efficient products that can be easily repaired, remanufactured and recycled. Of course, in order to exploit this potential, the products included in the PSS have to be properly designed (i.e. with a low environmental impact in the various life-cycle phases). In this sense there is a clear connection between PSS design and the product design approaches discussed in the previous chapters.

It is important to highlight that PSS innovations can also be associated with a series of economic and competitive benefits (for an overview, see Ceschin, 2014). For companies, PSSs can, for example, offer the possibility to find new strategic market opportunities, increase competitiveness, establish longer and stronger relationships with customers and build barriers to entry for potential new competitors.

In addition, compared to conventional product-oriented solutions, PSSs can potentially create enduring socio-ethical benefits. In fact, PSSs are more focused on the context of use and for this reason PSSs could trigger the greater involvement of more local (rather than global) stakeholders, thus fostering and facilitating the reinforcement of local economies (UNEP, 2002). Being more labour and relationship intensive, PSSs can also lead to an increase in local employment and dissemination of competencies (UNEP, 2002). Also, some PSSs do not require payment for the full value of the product, thus they are more accessible for low-income customers who could not afford high initial investments (Tukker, Tischner, \& Verkuijl, 2006).

However, it must be said that not all PSSs deliver sustainability benefits, which must be verified on a case-by-case basis and balanced against unwanted rebound effects and possible increases in the costs of servicing, transportation, disposal and recycling. For example, some PSSs are characterised by high transport intensity, the impact of which might offset the environmental benefits of the system. Another example is the careless behaviour of customers with regard to products that they do not own, which might lead to premature product repair/replacement (Mont, 2002).

Despite the potential to deliver a range of sustainability benefits, the diffusion of PSSs with sustainability characteristics is still very limited (particularly in relation to business-to-consumer PSSs). The reality is that this type of innovation can be complex to implement and bring to the mainstream because it is hindered by a set of barriers (Mont, 2002; Tukker \& Tischner, 2006; Ceschin, 2014; Vezzoli, Ceschin, Diehl, \& Kohtala, 2015): cultural barriers (e.g. the cultural shift necessary to value ownerless offers as opposed to owning products), corporate barriers (e.g. the need to implement changes in 
corporate culture and organisation) and regulative barriers (e.g. lack of internalisation of the environmental and social costs in market prices).

\subsection{Future research directions}

Most of the future research directions are aimed at overcoming the previously mentioned implementation barriers. Firstly, as highlighted by Vezzoli et al. (2015), more in-depth studies on user behaviour in relation to sustainable PSSs are needed in order to understand what factors influence user satisfaction, as well as how to measure and evaluate this satisfaction. In this respect, increased attention is paid to developing a deeper understanding of the use of PSSs and the identify factors and mechanisms that may enable or constrain their adoption (see, e.g., Mylan, 2015). The role that socio-cultural factors play in user acceptance should also be investigated (see, e.g., Piscicelli, Cooper, \& Fisher, 2015). Another aspect that should be further investigated is the influence of symbolic value and user identity in PSS acceptance (see, e.g., Catulli, Cook, \& Potter, 2017), with potential synergies with emotionally durable design (see Chapter 3 ). This knowledge would be valuable in order to integrate it into existing design approaches and methods and thus inform the design process with regard to PSS solutions that are more likely to be accepted by users.

Since the implementation of sustainable PSSs might sometimes require socio-technical system changes, another research priority is to better understand the process of the introduction and diffusion of these innovations and how it can be more effectively designed, managed and oriented. In this respect, some researchers have started to draw insights from system innovation and transition theories and integrate them into PSS design (see, e.g., Ceschin, 2012, 2013, 2014; Joore \& Brezet, 2015), while others have been investigating the role that can be played by socio-technical experiments and living labs (Ceschin, 2012, 2013, 2014; Liedtke, Baedeker. Hasselkuß, Rohn, \& Grinewitschus, 2015). This research focus is strictly linked to the DfST approach (see Chapter 11).

With the advent of new manufacturing paradigms - such as Industry 4.0, distributed manufacturing and additive manufacturing - it has become crucial to investigate how these paradigms might change how sustainable PSSs are designed, delivered and managed. For example, Petrulaityte, Ceschin, Pei and Harrison (2018) have developed nearfuture scenarios for how distributed manufacturing can improve PSSs.

Finally, as highlighted by Tukker (2015), there is also a need for more research on assessing the benefits of implemented PSSs. It is essential to 
move towards the adoption of quantitative research methods in order to quantify and detail the environmental and economic benefits of different PSSs in different markets. This understanding would be valuable as it would better inform design processes.

\section{Note}

1 ProSecCo (Product-Service Co-design; EU funded 2002-2004), HiCS (Highly Customerized Solutions; EU funded 2001-2004) (see Manzini, Collina, \& Evans, 2004), MEPSS (Methodology for Product Service System) development (EU funded 2002-2005) (see van Halen, Vezzoli, \& Wimmer, 2005), SusProNet (Sustainable Product-Service Co-design Network; EU funded 2002-2005) (see Tukker \& Tischner, 2006) and LeNS (Learning Network on Sustainability; EU funded 2007-2010) (see Vezzoli \& Ceschin, 2011).

\section{References}

Aurich, J. C., Fuchs, C., \& Wagenknecht, C. (2006). Life cycle oriented design of technical product-service systems. Journal of Cleaner Production, 14(17), $1480-1494$.

Bocken, N. M. P., de Pauw, I., Bakker, C., \& van der Grinten, B. (2016). Product design and business model strategies for a circular economy, Journal of Industrial and Production Engineering, 33(5), 308-320. doi:10.1080/ 21681015.2016.1172124

Bocken, N., Short, S., Rana, P., \& Evans, S. (2013). A value mapping tool for sustainable business modelling. Corporate Governance, 13(5), 482-497.

Brezet, H., Bijma, A. S., Ehrenfeld, J., \& Silvester, S. (2001). The design of ecoefficient services: Methods, tools and review of the case study based "Designing Eco-efficient Services" project. Report for Dutch Ministries of Environment (VROM). The Hague, the Netherlands: VROM.

Brookes, L. (2000). Energy efficiency fallacies revisited. Energy Policy, 28(6/7), $355-366$.

Catulli, M., Cook, M., \& Potter, S. (2017). Consuming use orientated product service systems: A consumer culture theory perspective. Journal of Cleaner Production, 141, 1186-1193. doi:10.1016/j.jclepro.2016.09.187

Cavalieri, S., \& Pezzotta, G. (2012). Product-service systems engineering: State of the art and research challenges. Computers in Industry, 63(4), 278-288.

Ceschin, F. (2012). The introduction and scaling up of sustainable product-service systems: A new role for strategic design for sustainability. Doctoral dissertation. Politecnico di Milano, Milan, Italy.

Ceschin, F. (2013). Critical factors for implementing and diffusing sustainable product-service systems: Insights from innovation studies and companies' experiences. Journal of Cleaner Production, 45, 74-88.

Ceschin, F. (2014). Sustainable product-service systems: Between strategic design and transition studies. London, UK: Springer. 
Ceschin, F., Resta, B., Vezzoli, C., \& Gaiardelli, P. (2014). Communicating product-service system business models. Paper presented at the 19th DMI: Academic Design Management Conference "Design Management in an Era of Disruption", London, UK, 2-4 September.

Ehrenfeld, J. H. (2008). Sustainability by design: A subversive strategy for transforming our consumer culture. New Haven, CT: Yale University Press.

European Environmental Agency (EEA) (2008). Beyond transport policy exploring and managing the external drivers of transport demand: Illustrative case studies from Europe. EEA Technical report, 12.

Goedkoop, M., van Halen, C., te Riele, H., \& P. Rommes (1999). Product services systems, ecological and economic basics. Report 1999/36. The Hague, the Netherlands: VROM.

Halme, M., Jasch, C., \& Sharp, M. (2004). Sustainable homeservices? Towards household services that enhance ecological, social and economic sustainability. Ecological Economics, 51(1/2), 125-138.

Heiskanen, E., \& Jalas, M. (2000). Dematerialisation through services: a review and evaluation of the debate. Helsinki, Finland: Ministry of the Environment, Environmental Protection Department.

Hockerts, K., \& Weaver, N. (2002). Towards a theory of sustainable product service systems - what are the dependent and independent variables of S-PSS? In Proceedings of the INSEAD-CMER Research Workshop "Sustainable Product Service Systems - Key Definitions and Concepts", Fontainebleau, France, 9 May.

Jégou, F., Manzini, E., \& Meroni, A. (2004). Design plan: A design tool-box to facilitate solution oriented partnerships. In E. Manzini, L. Collina, \& S. Evans (Eds.), Solution oriented partnership (pp. 107-118). Cranfield, UK: Cranfield University.

Joore, P., \& Brezet, H. (2015). A multilevel design model: The mutual relationship between product-service system development and societal change processes, Journal of Cleaner Production, 97, 92-105.

Liedtke, C., Baedeker. C., Hasselkuß, M., Rohn, H., \& Grinewitschus, V. (2015). User-integrated innovation in Sustainable LivingLabs: An experimental infrastructure for researching and developing sustainable product service systems. Journal of Cleaner Production, 97, 106-116.

Luiten, H., Knot, M., \& van der Horst, T. (2001). Sustainable product-service systems: The Kathalys method. In Proceedings of the Second International Symposium on Environmentally Conscious Design and Inverse Manufacturing, Tokyo, Japan, 12-15 December (pp. 190-197).

Manzini, E., Collina, L., \& Evans, S. (2004). Solution oriented partnership. Cranfield, UK: Cranfield University.

Manzini, E., Vezzoli, C., \& Clark, G. (2001). Product service systems: Using an existing concept as a new approach to sustainability. Journal of Design Resesearch, 1(2), 27-40.

Meroni, A. (2008). Strategic design: Where are we now? Reflection around the foundations of a recent discipline. Strategic Design Research Journal, 1(1), 31-38. 
Mont, O. (2002). Clarifying the concept of product-service system. Journal of Cleaner Production, 10(3), 237-245.

Mylan, J. (2015). Understanding the diffusion of sustainable product-service systems: Insights from the sociology of consumption and practice theory. Journal of Cleaner Production, 97, 13-20.

Nußholz, J. L. K. (2017). Circular business models: Defining a concept and framing an emerging research field. Sustainability, 9(10), 1810. doi.org/ $10.3390 / \mathrm{su} 9101810$

Petrulaityte, A., Ceschin, F., Pei, E., \& Harrison, D. (2018). A design tool to apply distributed manufacturing principles to sustainable product-service system development. In Proceedings of the Design Research Society (DRS) 2018, Vol. 5, Limerick, Ireland, 25-28 July (pp. 1986-2002).

Pezzotta, G., Sassanelli, C., Pirola, F., Sala, R., Rossi, M., Fotia, S., ... Mourtzis, D. (2018). The product service system lean design methodology (PSSLDM): Integrating product and service components along the whole PSS lifecycle. Journal of Manufacturing Technology Management, 29(8), 1270-1295.

Piscicelli, L., Cooper, T., \& Fisher, T. (2015). The roles of values in collaborative consumption: Insights from a product-service system for lending and borrowing in the UK. Journal of Cleaner Production, 97: 21-29.

Sakao, T., Shimomura, Y., Sundin, E., \& Comstock, M. (2009). Modeling design objects in CAD system for service/product engineering. ComputerAided Design, 41, 197-213.

Schmidt-Bleek, F. (1996). MIPS Book or the Fossil Makers - Factor 10 and More. Basel, Switzerland: Birkhäuser. Retrieved from www.factor10-institute.org/ files/the_fossil_makers/FossilMakers_Intro.pdf.

Stahel, W. R. (1997). The functional economy: Cultural and organizational change. In D. J. Richards (Ed.), The industrial green game (pp. 91-100). Washington, DC: National Academy Press.

Stahel, W. R. (2000). From manufacturing industry to a service economy, from selling products to selling the performance of products. Geneva, Switzerland: Product-Life Institute.

Tukker, A. (2004). Eight types of product-service system: Eight ways to sustainability? Experiences from SusProNet. Business Strategy and the Environment, 13, 246-260.

Tukker, A. (2015). Product services for a resource-efficient and circular economy: A review. Journal of Cleaner Production, 97, 76-91.

Tukker, A., \& Tischner, U. (Eds.). (2006). New business for Old Europe: Product services, sustainability and competitiveness. Sheffield, UK: Greenleaf Publishing.

Tukker, A., Tischner, U., \& Verkuijl, M. (2006). Product-services and sustainability. In A. Tukker \& U. Tischner (Eds.), New business for Old Europe: Product services, sustainability and competitiveness. Sheffield, UK: Greenleaf Publishing.

UNEP (2002). Product-service systems and sustainability: Opportunities for sustainable solutions. Paris, France: United Nations Environmental Programme 
(UNEP), Division of Technology Industry and Economics, Production and Consumption Branch.

Van Halen, C., Vezzoli, C., \& Wimmer, R. (Eds.). (2005). Methodology for product service system innovation: How to develop clean, clever and competitive strategies in companies. Assen, the Netherlands: Van Gorcum.

Verkuijl, M., Tischner, U., \& Tukker, A. (2006). The toolbox for productservice development. In A. Tukker \& U. Tischner (Eds.), New business for Old Europe: Product services, sustainability and competitiveness. Sheffield, UK: Greenleaf Publishing.

Vezzoli, C. (2007). System design for sustainability: Theory, methods and tools for a sustainable "satisfaction-system" design. Rimini, Italy: Maggioli Editore.

Vezzoli, C., \& Ceschin, F. (2009). Sustainable scenarios for upstream waste reduction in the food chain. In I. Hülsen \& E. Ohnesorge (Eds.), Food Science Research and Technology (pp. 65-110), New York: Nova Publishers.

Vezzoli, C., \& Ceschin, F. (2011). The learning network on sustainability: an e-mechanism for the development and diffusion of teaching materials and tools on design for sustainability in an open-source and copy left ethos. International Journal of Management in Education, 5(1), 22-43.

Vezzoli, C., Ceschin, F., \& Cortesi, S. (2009). Metodi e strumenti per il Life Cycle Design: Come progettare prodotti a basso impatto ambientale. Rimini, Italy: Maggioli Editore.

Vezzoli, C., Ceschin, F., Diehl, J. C., \& Kohtala, C. (2015). New design challenges to widely implement 'Sustainable Product-Service Systems'. Journal of Cleaner Production, 97, 1-12.

Vezzoli, C., Kohtala, C., Srinivasan, A., Xin, L., Fusakul, M., Sateesh, D., \& Diehl, J. C. (2014). Product-service system design for sustainability. Sheffield, UK: Greenleaf Publishing.

Wang, P. P., Ming, X. G., Li, D., Kong, F. B., Wang, L., \& Wu, Z. Y. (2011). Modular development of product service systems. Concurrent Engineering: Research and Applications, 19(1), 85-96.

White, A. L., Stoughton, M., \& Feng, L. (1999). Servicizing: The quiet transition to extended product responsibility. Boston, MA: Tellus Institute.

Zhang, F., Jiang, P., Zhu, Q., \& Cao, W. (2012). Modeling and analyzing of an enterprise collaboration network supported by service-oriented manufacturing. Proceedings of the Institution of Mechanical Engineers, Part B: Journal of Engineering Manufacture, 226(9), 1579-1593.

Zurlo, F. (1999), Un modello di lettura per il design strategico: La relazione tra design e strategia nell'impresa contemporanea. Doctoral dissertation. Politecnico di Milano, Milan, Italy. 


\section{Design for the base of the pyramid}

\subsection{Addressing the needs of low-income people}

In the second half of the 2000s, in line with what was advocated by Papanek (1972), some design researchers began to address the social aspects of sustainability, with a particular focus on low-income people and communities, namely those forming the base of the pyramid (BoP). The BoP is the poorest portion of the global population who live with an annual income below a certain purchasing power parity (PPP) threshold. Authors have proposed various PPP thresholds (London, 2007), with several researchers setting it at \$2 per day (Karnani, 2011). However, as noted by London (2007), PPP measures should be seen as empirical approximations that cannot capture the multi-faceted dimensions of the BoP. In fact, in addition to lacking the income required to satisfy basic needs, the BoP is characterised by a lack of access to basic services (such as public health, education and sanitation) and by social, cultural and political exclusion (Karnani, 2011).

Prahalad and Hart argued that the traditional development aid strategy has not been effective in solving the problem of poverty faced by the BoP (Prahalad, 2004; Prahalad \& Hart, 2002). To tackle these issues they suggest a market-based perspective: companies should look at unexplored business opportunities in low-income markets and treat the poor as consumers and not as victims. As a result, companies could realise profit and, at the same time, bring prosperity by allowing low-income people access to better and cheaper products and services (Prahalad \& Hart, 2002). In this context, two broad approaches have been proposed (Rangan, Quelch, Herrero, \& Barton, 2007): the BoP as consumers, wherein the business focus is on selling products and/or services to those at the $\mathrm{BoP}$; and the $\mathrm{BoP}$ as producers, where the business focus is on sourcing products and/or services from those at the BoP. 
The claim that poverty can be alleviated by simply targeting the poor as consumers has raised criticism. To begin with, some authors argued that companies' successes have been inflated in several case studies reported in Pralahad's famous book, The Fortune at the Bottom of the Pyramid (see, e.g., Karnani, 2006; Jaiswal, 2008). Others have highlighted the moral dilemma formed from the fact that BoP approaches do not differentiate between satisfying essential needs (such as nutrition and health) and offering non-essential goods (Karnani, 2006; Jaiswal, 2008). In this sense the risk is that BoP strategies simply become a tool to turn the poor into consumers (Karnani, 2006; Jaiswal, 2008).

In response to these criticisms, some authors have proposed moving from the first-generation of $\mathrm{BoP}$ strategies (seeing the BoP as consumers and seeing the BoP as producers) to the second-generation of BoP strategies (Simanis \& Hart, 2008). This second generation sees the BoP as business partners who are to be empowered, enabled and involved in the process of business co-creation (ibid.). This involves moving from simply selling to the poor to co-creating solutions with communities and stakeholders at the BoP that are capable of producing mutual value. Beyond this approach, Gupta stated that being at the base of the economic pyramid does not mean lacking knowledge and that people living in low-income contexts should be seen as a source of ideas and innovations (Gupta, 2016). His position is that it is necessary to support the creativity that already exists at the grass-roots level by providing incubation and development support, guidance on patenting and intellectual property rights, microventure funding and entrepreneurship advice, as well as by collecting, cross-pollinating and replicating ideas (ibid.) (In this respect, consider the activities undertaken by the Honey Bee Network, currently active in more than 75 countries.)

From a design perspective, the designer and design philosopher Victor Papanek was among the first to initiate the discussion on the role of design in supporting the needs of people in low-income countries (Papanek, 1972). His view was that design should focus on basic individual and community daily life problems, addressed by lowtech solutions based on the use of locally available resources (ibid.). This perspective was enriched and complemented by the Ahmedabad Declaration of Industrial Design and Development (National Institute of Design, 1979). As pointed out by Margolin (2007), while the declaration recognised that design in low-income countries had to use indigenous traditions, skills and materials, it also put forward that design should be used as an economic development resource and that it should exploit the power of science and technology. Later in the 1980s, Papanek's position began to change, starting to question the role of 
Western designers in low-income countries (Madge, 1993). Along the same lines, Bonsiepe argued for the need to move away from design for low-income countries towards design in and by low-income countries (Bonsiepe, 1977).

More recently, the design debate has become more articulated, focusing in particular on developing principles, approaches and tools for design for the BoP (DfBoP). In this respect an important contribution has come in particular from the Delft University of Technology, which initiated a programme for master's degree projects on DfBoP in 2001 (see, e.g., Kandachar, de Jong, \& Diehl, 2009), which formed the basis for collecting design cases and elaborating on research outcomes. The main challenge faced by designers is that, even thought there may be considerable knowledge and know-how in product design in industrialised countries, much of this is not directly applicable in low-income contexts (Crul \& Diehl, 2008). In fact, designing and developing solutions for the BoP requires addressing specific issues that are different from those in high-income markets (Jagtap, Larsson, \& Kandachar, 2013; Jagtap, Larsson, Warell, Santhanakrishnan, \& Jagtap, 2015). These issues include a lack of market information about the BoP (e.g., what low-income people need, what capabilities they can offer), an underdeveloped or inappropriate regulatory environment, slow bureaucracy and corruption, inadequate infrastructures (e.g. roads, electricity, water), low literacy and educational levels, and limited access to credit (Jagtap \& Kandachar, 2010; Jagtap et al., 2015).

Because of these issues, developing solutions for the BoP requires that designers adopt a different approach to how design requirements are defined and addressed and use different skills (dos Santos, Sampaio, Giacomini da Silva, \& Costa, 2014). Gomez Castillo, Diehl, \& Brezet (2012) have grouped these requirements into four main interrelated clusters:

- Desirability. It is crucial to gain a deep understanding of the socio-cultural context in which users live in order to identify user problems, needs and desires. Thus, several authors have suggested that the adoption of a user-centred approach is essential (Smith, 2007; Kandachar \& Halme, 2008; IDEO, 2009), in particular in order to engage users in co-design and co-creation processes to address the entire design problem from problem definition to solution prototyping (Gomez Castillo et al., 2012). Overall, this means designing for, with and within the targeted communities, which poses important challenges for the designer, especially in relation to 
being accepted by communities, building mutual trust and creating a meaningful and sustained engagement with them.

- Feasibility. It should not be assumed that technologies developed for high-income markets are suitable for BoP contexts (Kandachar \& Halme, 2008). Thus, technological feasibility should be assessed on a case-by-case basis, depending on the specific socioeconomic contextual conditions and taking into consideration issues such as manufacturing capacity and locally available resources (Fisher, 2007).

- Viability. From a financial perspective, affordability (customer willingness and ability to pay), distribution channels (for delivering solutions to BoP communities) and the creation of local income generation capacity (in order to empower local actors and stimulate entrepreneurship) represent other important factors that need to be carefully considered in BoP projects (Prahalad, 2004; Smith, 2007).

- Sustainability. Projects must take into consideration the environmental and social impacts, looking at each stage from design to implementation. On this specific matter, UNEP (2006) have proposed a systematic guide for integrating sustainability in design projects in low- and middle-income contexts.

Looking at the evolution of $\mathrm{DfBoP}$, it seems that, analogously to the overall evolution of DfS, it has gradually expanded the scope of interventions ranging from products to business models and complex socio-ethical aspects. In fact, after an initial emphasis on product design (see, e.g., UNEP, 2006; Crul \& Diehl, 2008; Viswanathan \& Sridharan, 2012), the design research focus on the BoP has moved to productservice system (PSS) design (see, e.g., Moe \& Boks, 2010; Schafer, Parks, \& Rai, 2011; dos Santos et al., 2014). The assumption is that PSS innovations "may act as business opportunities to facilitate the process of social-economic development in emerging and low-income contexts by jumping over or by-passing the stage of individual consumption/ ownership of mass produced goods - towards a 'satisfaction-based' and low-resource intensive advanced service economy' (UNEP, 2002). Even if some research suggests that this is not a likely option (see, e.g., the work on the Brazilian context by Shafer, Jaeger-Erben and dos Santos, 2011), by innovating at a business model level, a PSS design approach is considered to offer wider opportunities for addressing the complex set of requirements that characterise BoP projects and for developing solutions capable of meeting the three sustainability dimensions.

More recently, scholars have explored the importance of social innovation and social entrepreneurship in the context of BoP (e.g. Goyala, Sergib, \& Jaiswala, 2015; Michelini, 2012), with a particular emphasis on bottom-up approaches and on investigating the role of 
users and communities as co-creators (Chakrabarti \& Mason, 2014) and innovators (Gupta, 2016). Some researchers have also emphasised the strategic role designers can play in developing comprehensive community development plans, including skills assessment, training programmes and entrepreneurial models (see, e.g., Mandar, Punekar, $\&$ Shende, 2016). In relation to social innovation, of particular relevance is the 2008 UNEP 'Creative Communities for Sustainable Lifestyles' project (aimed at identifying best practices and making design and policy recommendations for grass-roots social innovations in low-income countries) and the activities of the Design for Social Innovation for Sustainability (DESIS) network on community-based innovations in informal low-income contexts (see, e.g., Cipolla, Melo, \& Manizini, 2013).

\section{Box 8.1 DfBoP examples}

SafariSeat (designed by Janna Deeble in the development of his major project at Brunel University London) is a low-cost, allterrain wheelchair for rural communities in low-income countries. The wheelchair integrates a simple, patented mechanism to keep all four wheels on the ground at the same time. All the components are built from bicycle parts and locally sourced materials. The project also includes an open-source toolkit that enables local workshops to build SafariSeats with basic metalwork skills. (Additional information can be found at www.safariseat.org.)

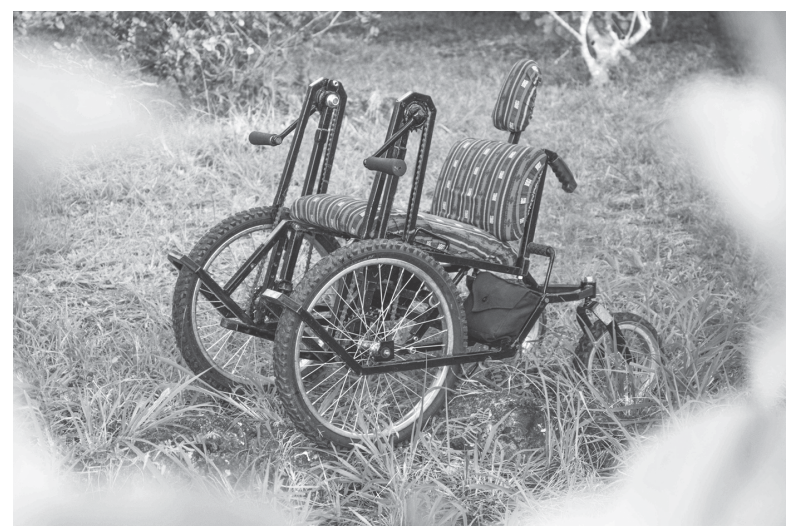

Figure 8.1 The SafariSeat all-terrain wheelchair Source: (C) Freddy Deeble. 


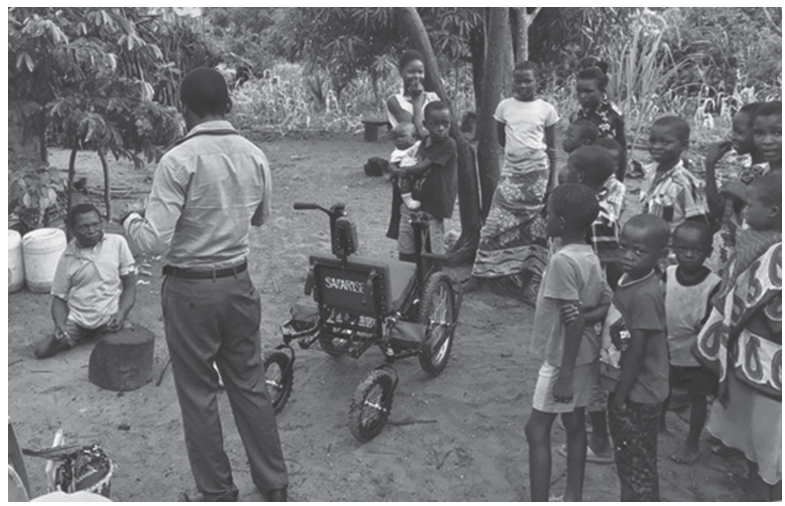

Figure 8.2 The SafariSeat all-terrain wheelchair: one of the co-design sessions held to test and improve the product

Source: (C) Freddy Deeble.

The Sun Shines for All is a company that offers a home solar energy PSS package (with energy-using products) for leasing. It provides customers with a contract that includes installation, maintenance, battery replacement after three years and take-back services. Users pay an initial deposit and a monthly leasing fee according to the system size and the number of lights installed. The provider, who retains ownership of the systems and appliances, trains and employs local technicians who perform the maintenance, repair and take-back services.

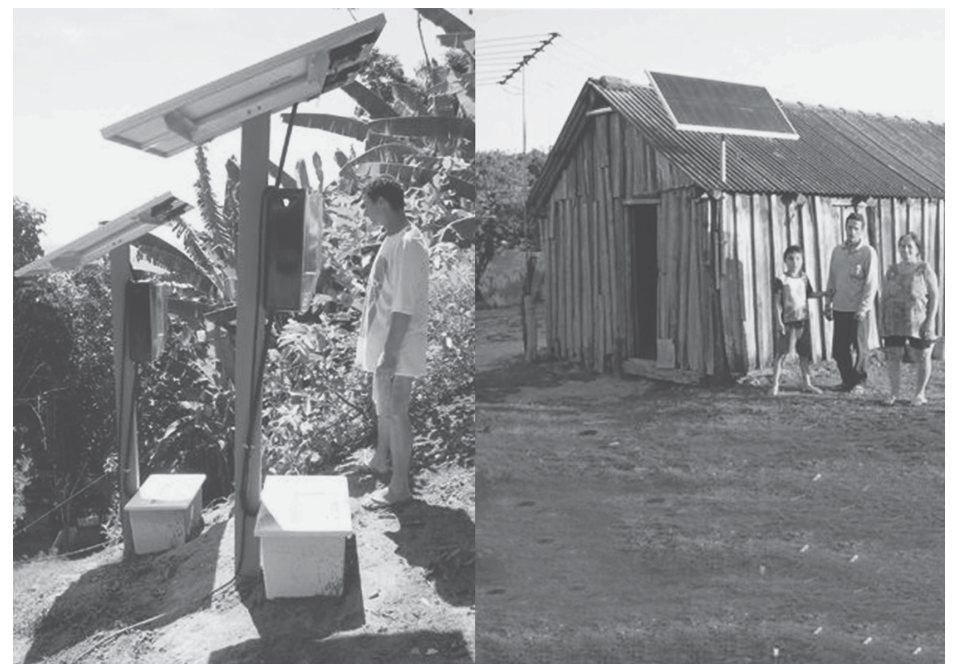

Figure 8.3 The Sun Shines for All solar enery package Source: (C) Fabio Rosa. 
Mitti Cool (designed by Mansukhbhai Prajapati) is a natural refrigerator made from clay, which is suitable for storing vegetables and fruit and for cooling water. The refrigerator provides natural cooling without requiring any electricity. It works on the principle of evaporation: water from the upper chambers drips down the sides and evaporates, taking away heat from the inside and keeping the chambers cool. Mansukhbhai Prajapati is a potter living in rural Gujarat (India) who has no formal qualifications. This is an example of how a grass-roots innovation from an inventor without a formal education can, with proper funding and incubation support (in this case from the Honey Bee Network and the Indian National Innovation Foundation), become a commercial success.

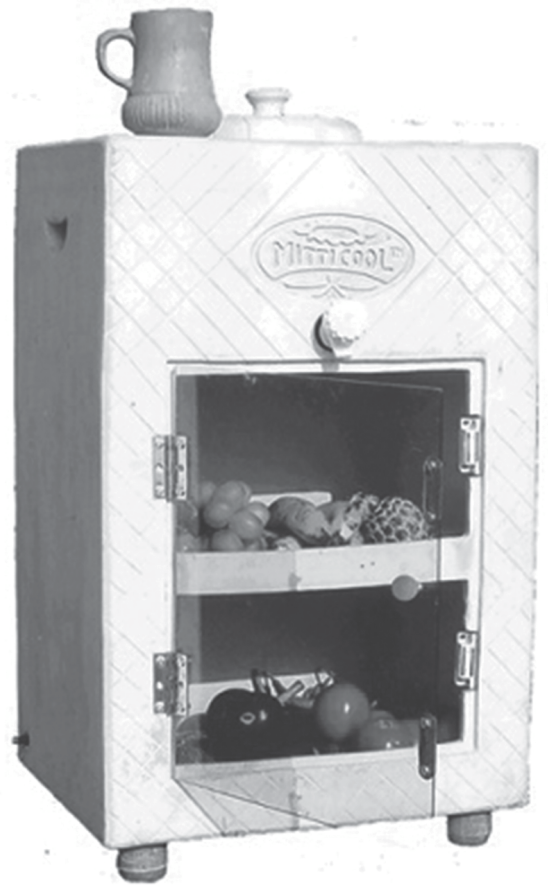

Figure 8.4 The Mitti Cool refrigerator Source: (C) Mitti Cool Clay Creation. 


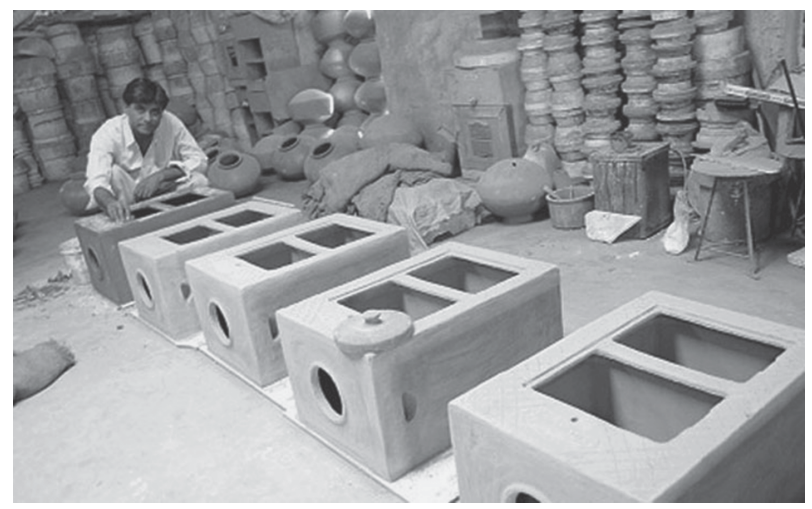

Figure 8.5 Mansukhbhai Prajapati, the inventor of the Mitti Cool refrigerator

Source: (C) Mitticool Clay Creation.

\subsection{Design practice}

From a methodological perspective, a number of manuals and tools have been proposed in recent years, providing a set of diverse and complementary approaches. The DfBoP methodologies which have been most adopted are described in the following publications.

Design for Sustainability: A Practical Approach for Developing Economies (UNEP, 2006) presents a set of methods and tools with which product ecodesign principles can be applied in low- and middleincome contexts. It adopts existing ecodesign tools, as well as adapted and new ecodesign tools. It proposes two main innovation paths: redesign, for redesigning existing products made by a company with a sustainability perspective, and benchmarking, for designing new products, taking inspiration from local and international competitors. Among the presented methodologies, this is the only one that specifically addresses sustainability aspects, but only from a product perspective.

The Field Guide to Human-Centered Design (IDEO, 2015) is the evolution of the Human Centered Design Toolkit (IDEO, 2009) and provides guidance and tools regarding how to apply human-centred design innovation processes, structured in three main stages: inspiration, 
ideation and implementation. However, this methodology does not include any sustainability considerations, methods or tools.

Base of the Pyramid Protocol (Simanis \& Hart, 2008) targets corporations and supports them in the process of business co-creation. This is structured in three main stages: pre-field processes, in-field processes (opening up, building the ecosystem and enterprise creation) and scaling out. The key aspect of this approach is that it sees local stakeholders as business partners and its final goal is to co-create mutual value for all of them. Also, it is not restricted to product innovation alone. However, as highlighted by Gomez Castillo et al. (2012), it is difficult to put it into practice since it does not include practical tools for implementing the process.

The Market Creation Toolbox (Larsen \& Flensborg, 2011) is not particularly focused on supporting idea generation but rather on providing guidance for how to bring an idea to the market. In this respect, it can be used in the later stages of a design process (i.e. prototyping, testing and implementation) in order to complement other BoP methodologies. Similarly to the previous two methodologies, the market creation toolbox does not include considerations about sustainability aspects.

Gomez Castillo et al. (2012) proposed a design methodological framework that integrates the complementary aspects offered by these approaches and the related tools and techniques. The result is a design process that encompasses five iterative stages (see Figure 8.6):

1. Preparation: defining team members, design goals and objectives, project partners, and the project time schedule;

2. Contextualisation: understanding people and their contexts, identifying design opportunities, and co-generating and assessing ideas with users and stakeholders;

3. Concept development: selecting the most promising ideas and combining/developing them into design concepts, and prototyping, testing and evaluating the initial solutions with users and stakeholders;

4. Implementation: developing a full business model of the most feasible and viable solution and implementing small-scale implementation tests for continuous learning;

5. Managing: considering all the implications related to bringing the solution to the market (e.g. stakeholder value chain, distribution systems, maintenance network etc.). 


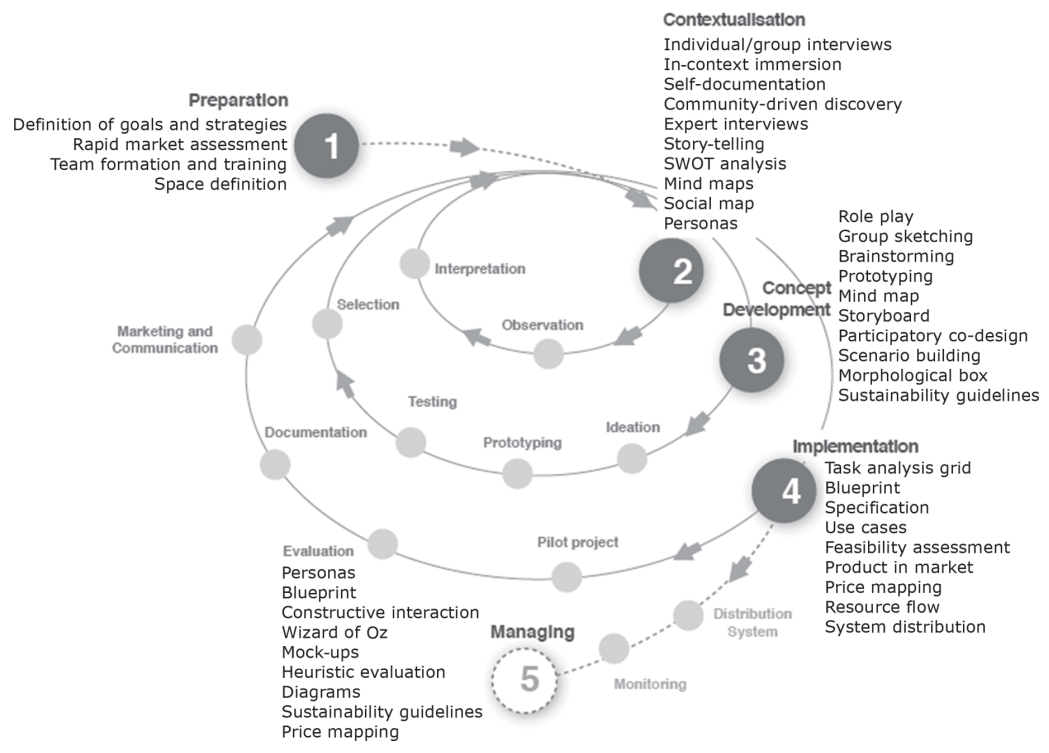

Figure 8.6 The design methodological framework proposed by Gomez Castillo et al.

Source: Gomez Castillo et al. (2012).

\section{Box 8.2 DfBoP methods and tools}

- Design for Sustainability: A Practical Approach for Developing Economies (UNEP, 2006). Available at www.d4s-de.org/ manual/d4stotalmanual.pdf.

- $\quad$ The Field Guide to Human-Centered Design (IDEO, 2015). Available at www.designkit.org//resources/1.

- $\quad$ The Base of the Pyramid Protocol (Simanis \& Hart, 2008). Available at https://stuartlhart.com/sites/stuartlhart.com/ files/BoPProtoco12ndEdition2008_0.pdf.

- Market Creation Toolbox (Larsen \& Flensborg, 2011). Available at https://di.dk/SiteCollectionDocuments/DIBD/ BOP-Learning\%20Lab/TOOLBOX.pdf.

- BoP design methodological framework (Gomez Castillo et al. 2012). Available at www.researchgate.net/publication/ 257927083_Design_Considerations_for_Base_of_the_ Pyramid_BoP_Projects. 


\subsection{Benefits and limitations}

As discussed above, DfBoP has focused on applying some DfS approaches (namely product ecodesign, PSS design and design for social innovation) in low- and middle-income contexts. As such, the main benefits and limitations of these DfS approaches (see Sections 2.3, 7.3 and 9.3) are also valid for DfBoP.

In relation to specific aspects of $\mathrm{DfBoP}$, a common criticism is that many $\mathrm{BoP}$ projects tended to address design problems merely from a technical perspective, failing to properly consider user needs or social and cultural values (Madge, 1993). This was particularly true for early $\mathrm{BoP}$ projects, but with the integration of human-centred design approaches into design processes (see, e.g., the IDEO's human-centred design field guide; IDEO, 2015), this problem has been played down.

It has also been argued that the BoP approach is essentially a market tool for multinational enterprises aimed at transforming the poor into consumers (Karnani, 2006; Jaiswal, 2008). Again, this might have been accurate for some early BoP ventures, which adopted the so-called BoP as a consumer strategy (see, e.g., Prahalad, 2004). More recently, the focus has moved to co-creating value with local stakeholders (the $B o P$ as partners strategy; Simanis \& Hart, 2008).

Another criticism is related to the fact that DfBoP has mainly been developed from a Eurocentric perspective (e.g. a strong contribution came from the Delft University of Technology). However, although it is true that some European universities did play an important role, it is also true that key publications on the topic published in the last 10 years have been authored by academics who are representative of different regions of the world. DfBoP is also sometimes criticised when applied by designers from Western countries (see, e.g., Schultz et al., 2018). It is true that some organisations, such as Design Without Borders (see Skjerven, 2017) have operated in low-income contexts, mainly through Western designers, but it should be noted that this was initially due to a lack of professionally trained local designers. It is also important to highlight that the focus now is much more on enabling and empowering local designers rather than delivering solutions. Still, debate is ongoing about the extent to which this is done from a Western design perspective to the detriment of indigenous knowledge and values. To find out more about the debate on what has been called decolonising design, refer to, e.g., Schultz et al. (2018).

\subsection{Future research directions}

Looking at how research on DfBoP has evolved over the years, it is possible to identify three main trends. Firstly, there has been a widening 
of the design scope: DfBoP has moved from product design to PSS design and, more recently, to design for social innovation. Secondly, there has been a shift in research from how to design and market solutions in low- and middle-income contexts to how to enable and empower local stakeholders to independently carry out design innovation processes. Thirdly, there has been a shift from design research led by Western universities to design research led by institutions in low- and middle-income countries or conducted in collaboration with Western universities.

Future research will focus on understanding how DfBoP can be integrated with other design approaches. In addition to product, PSS and social innovation design, all DfS approaches could potentially be adapted for BoP contexts. We expect that in the future DfBoP will actually overlap with all the other DfS approaches and will focus on understanding how different approaches can be applied in low- and middle-income contexts.

Another aspect to be further investigated is related to the process of enabling and empowering local designers and stakeholders to address specific design challenges. For example, this might mean developing design toolkits to be used by local designers and companies, or fostering the innovation and entrepreneurship skills of people living in lowincome contexts (as done, for example, by Gupta, 2016).

Finally, another potential research direction is to understand how lessons learned in BoP contexts can be applied in high-income countries. Low- and middle-income contexts and the related socio-economic problems can in fact also be found in high-income countries, and solutions implemented in $\mathrm{BoP}$ countries might also be adapted for these contexts.

\section{References}

Bonsiepe, G. (1977). Precariousness and ambiguity: Industrial design in dependent countries. In J. Bicknell \& L. McQuiston (Eds.), Design for need: The social contribution of design. Oxford, UK: Pergamon Press.

Chakrabarti, R., \& Mason, K. (2014). Designing better markets for people at the bottom of the pyramid: Bottom-up market design. In S. Geiger, D. Harrison, H. Kjellberg, \& A. Mallard (Eds.), Concerned markets: Economic ordering for multiple values. Cheltenham, UK: Edward Elgar Publishing.

Cipolla, C., Melo, P., \& Manizini, E. (2013). Collaborative services in informal settlements: A social innovation case in a pacified favela in Rio de Janeiro. Paper presented at NESTA Social Frontiers: The Next Edge of Social Innovation Research Conference, Glasgow Caledonian University London, London, UK, 14-15 November. 
Crul, M., \& Diehl, J. C. (2008). Design for sustainability (D4S): Manual and tools for developing countries. In Proceedings of the 7th Annual ASEE Global Colloquium on Engineering Education, Cape Town, South Africa, 1923 October.

dos Santos, A., Sampaio, C. P., Giacomini da Silva, J. S., \& Costa, J. (2014). Assessing the use of Product-Service Systems as a strategy to foster sustainability in an emerging context. Product: Management \& Development, 12(2), 99-113. doi:10.4322/pmd.2014.012

Fisher, M. (2007). Design to kickstart incomes. In C. Smith (Ed.), Design for the other 90\%. New York: Cooper-Hewitt, National Design Museum.

Gomez Castillo, L., Diehl, J. C., \& Brezet, J. C. (2012). Design considerations for base of the pyramid (BoP) projects. In Proceedings of the Cumulus Conference, Helsinki, Finland, 24-26 May. Retrieved from www.researchgate.net/publication/257927083_Design_Considerations_for_ Base_of_the_Pyramid_BoP_Projects.

Goyala, S., Sergib, B. S., \& Jaiswala, M. (2015). How to design and implement social business models for base-of-the-pyramid (BoP) markets? European Journal of Development Research, 27, 850-867. doi:10.1057/ejdr.2014.71

Gupta, A. K. (2016). Grassroots innovation: Minds on the margin are not marginal minds. Gurgaon, India: Penguin Books India.

IDEO (2009). Human-centered design toolkit. IDEO. Retrieved from www.ideo. com/work/human-centered-design-toolkit.

IDEO (2015). The field guide to human-centered design. IDEO. Retrieved from www.designkit.org//resources/1

Jagtap, S., \& Kandachar, P. (2010). Representing interventions from the base of the pyramid. Journal of Sustainable Development, 3(4), 58-73.

Jagtap, S., Larsson, A., \& Kandachar, P. (2013). Design and development of products and services at the base of the pyramid: A review of issues and solutions. International Journal of Sustainable Society, 5(3), 207-231.

Jagtap, S., Larsson, A., Warell, A., Santhanakrishnan, D., \& Jagtap, S. (2015). Design for the BOP and the TOP: Requirements handling behaviour of designers. In A. Chakrabarti (Ed.), Proceedings of ICoRD'15: Research into design across boundaries, Vol. 2 (pp. 375-385). New Delhi, India: Springer India.

Jaiswal, A. K. (2008). The fortune at the bottom or the middle of the pyramid? Innovations: Technology, Governance, Globalization, 3(1), 85-100.

Kandachar, P., de Jong, I., \& Diehl, J.C. (Eds.). (2009). Designing for emerging markets: Design of products and services. Delft, the Netherlands: Delft University of Technology.

Kandachar, P., \& Halme, M. (Eds.). (2008). Sustainability challenges and solutions at the base of the pyramid: Business, technology and the poor. Sheffield, UK: Greenleaf Publishing.

Karnani, A. (2006). The misfortune at the bottom of the pyramid. Greener Management International, 51(Autumn), 99-110.

Karnani, A. (2011). Fighting poverty together: Rethinking strategies for business, governments, and civil society to reduce poverty. New York: Palgrave Macmillan. 
Larsen, M. L., \& Flensborg, A. (2011). Market creation toolbox: Your guide to entering developing markets. Copenhagen, Denmark: DI International Business Development. Retrieved from https://di.dk/SiteCollection Documents/DIBD/BOP-Learning\%20Lab/TOOLBOX.pdf.

London, T. (2007). A base-of-the-pyramid perspective on poverty alleviation. Growing Inclusive Markets Working Paper Series. Washington, DC: United Nations Development Program.

Madge, P. (1993). Design, ecology, technology: A historiographical review. Journal of Design History, 6(3), 149-166.

Mandar, R., Punekar, R. M., \& Shende, A. (2016). Design of an entrepreneurial model in product development and strategy for marketing of handicraft products in the northeast of India. In Proceedings of the 10th International Conference on Design History and Studies (ICDHS 2016), Taipei, Taiwan, 26-28 October.

Margolin, V. (2007). Design for development: Towards a history. Design Studies, 28, 111-115. doi:10.1016/j.destud.2006.11.008

Michelini, L. (2012). Social innovation and new business models: Creating shared value in low-income markets. Berlin, Germany: Springer.

Moe, H. P., \& Boks, C. (2010). Product service systems and the base of the pyramid: A telecommunications perspective. In Proceedings of the 2nd CIRP IPS2 Conference, Linköping, Sweden, 14-15 April.

National Institute of Design (1979). Ahmedabad declaration on industrial design for development and major recommendation for the promotion of industrial design for development. Ahmedabad, India: National Institute of Design.

Papanek, V. (1972). Design for the real world. London, UK: Penguin.

Prahalad, C. K. (2004). The fortune at the bottom of the pyramid: Eradicating poverty through profits. Upper Saddle River, NJ: Wharton School Publishing.

Prahalad, C. K., \& Hart, S. L. (2002). The fortune at the bottom of the pyramid. Strategy+Business, 26, 2-14.

Rangan, V. K., Quelch, J. A., Herrero, G., \& Barton, B. (2007). Business solutions for the global poor: Creating social and economic value. San Francisco, CA: Jossey-Bass.

Schafer, C., Parks, R., \& Rai, R. (2011). Design for emerging bottom of the pyramid markets: a product service system (PSS) based approach. In Proceedings of the ASME 2011 International Design Engineering Technical Conferences \& Computers and Information in Engineering Conference IDETC/CIE 2011, Washington, DC, 28-31 August.

Shafer, M., Jaeger-Erben, M., \& dos Santos, A. (2011). Leapfrogging to sustainable consumption? An explorative survey of consumption habits and orientations in Southern Brazil. Journal of Consumer Policy, 34(1), 175-196.

Schultz, T., Abdulla, D., Ansari, A., Canlı, E., Keshavarz, M., Kiem, M., ... Vieira de Oliveira, P. J. S. (2018). what is at stake with decolonizing design? A roundtable. Design and Culture, 10(1), 81-101. doi:10.1080/ 17547075.2018.1434368

Simanis, E., \& Hart, S. (2008). The Base of the Pyramid Protocol: Toward Next Generation BoP Strategy. 2nd ed., Ithaca, NY: Cornell University. 
Retrieved from https://stuartlhart.com/sites/stuartlhart.com/files/ BoPProtocol2ndEdition2008_0.pdf.

Skjerven, A. (2017). Design without borders: Ideologies, realities, and results. Design Issues, 33(1), 17-29.

Smith, C. (2007). Design for the other 90\%. New York: Cooper-Hewitt, National Design Museum.

UNEP (2002). Product-service systems and sustainability: Opportunities for sustainable solutions. Paris, France: United Nations Environmental Programme, Division of Technology Industry and Economics, Production and Consumption Branch.

UNEP (2006). Design for sustainability: A practical approach for developing countries. Paris, France: United Nations Environmental Programme. Retrieved from www.d4s-de.org/manual/d4stotalmanual.pdf.

Viswanathan, M., \& Sridharan, S. (2012). Product development for the BoP: Insights on concept and prototype development from university-based student projects in India. Journal of Product Innovation Management, 29(1), 5269. doi:10.1111/j.1540-5885.2011.00878.x 


\section{Design for social innovation}

\subsection{Supporting communities in place-based innovations}

In a general sense, social innovation is as old as civilisation itself and its history can be traced back to cooperative and social business movements of the Victorian era (McGowan \& Westley, 2015). Although social innovation has been studied in business and innovation studies, and more recently in design, what it means precisely is still a topic of discussion.

Hockerts and Wüstenhagen (2010) stated that social innovation may refer to product and process innovations with a social purpose and argued that innovations that concern the BoP are therefore a subgroup of social innovations (see Chapter 8). In addition, in business and management literature the term social innovation has been used to refer to a range of innovation activities, including those that aim to launch and improve social enterprises, company-internal activities (social intrapreneurship) and business/social sector collaboration (corporate social innovation) (Boons \& Lüdeke-Freund, 2013). Technocentric formulations of the concept referred to social innovation as a set of (technological) innovations that aim to solve social problems (Schaltegger \& Wagner, 2008), such as poverty and access to safe drinking water. Those who put emphasis on social change instead argued that social innovations target behavioural change and social well-being and, avoiding a technocentric formulation, defined social innovation as a creative recombination of existing assets (Manzini, 2007, 2014). Some sociologists defined social innovation as new configurations of social practices intentionally undertaken to address social needs that are left unmet by established practices and therefore framed it as a new paradigm of innovation instead of a separate innovation category (van der Have \& Rubalcaba, 2016). Along the same lines, Tracey and Stott (2017) referred to social innovation as alternative ways of organising and innovating, ostensibly designed to 
address the most deep-rooted problems of society. In the words of van Wijk, Zietsma, Dorado, de Bakker, and Martí (2018) social innovation describes 'the agentic, relational, situated, and multilevel process to develop, promote, and implement novel solutions to social problems' (p. 3). This places an emphasis on the role of social innovation in generating significant change in institutional contexts. Social innovation has also been defined as a learning process that generates behavioural change (Murray, Caulier-Grice, \& Mulgan, 2010; Manzini, 2015).

The diversity of definitions implies that social innovation covers a broad range of activities; however, the defining factor is that it aims to address socially relevant issues. Social innovation actors are mostly the owners of the problems they are addressing and they operate on a bottom-up and self-organised basis. The outputs of social innovation processes may cover one or more categories including products, services, strategies, ideas, new organisational forms and social movements, as well as new approaches to the delivery of public services (Chick, 2012). However, in this chapter the focus is on the process of social innovation as opposed to its outputs, as this focus is aligned with how social innovation is understood and handled in the field of design. As discussed in earlier chapters, the DfS field has traditionally focused on improving the environmental performance of products. In the meantime, two developments have occurred in the broader relevant fields; first, emphasis on sustainability as a systemic property has increased, and second, the scope of design research and practice has broadened beyond market-oriented industrial implementations. This has given rise to an interest among design researchers and practitioners in the social aspects of sustainability. Design for social innovation (DfSI) now has a history that is slightly over a decade long. In DfSI the main emphasis has been on the role played by people and communities in creating change within their own local environment and circumstances. 'Creative communities' (Meroni, 2007) is in fact an often-used term to indicate that social innovations usually emerge from the inventiveness and creativity of ordinary people and communities (sometimes in collaboration with grass-roots technicians and entrepreneurs, local institutions and civic society organisations) (Jégou \& Manzini, 2008). According to Mazé (2014), design is increasingly engaged with the complexity and dynamics of provision and co-production of social services and services such as habitation, education, care, mobility and food services. Manzini (2014) defined DfSI as 'a constellation of design initiatives geared toward making social innovation more probable, effective, long-lasting, and apt to spread' (p. 65) and pointed out that it can be part of the top-down approach (driven by experts, decision makers and political 
activists), the bottom-up approach (driven by local communities) or the hybrid approach (a combination of the two).

After an initial emphasis on collecting and analysing cases of social innovation (see, e.g., Meroni, 2007), the focus of design researchers moved towards exploring the role of designers (see, e.g., Jégou \& Manzini, 2008) and the development of social innovation toolkits (see, e.g., Murray et al., 2010). Currently, the focus is mainly on investigating how designers can support and facilitate the process of replication and scaling up (see, e.g., Hillgren, Seravalli, \& Emilson; 2011; Manzini \& Rizzo, 2011; Morelli et al., 2017).

\section{Box 9.1 DfSI examples}

\section{Prendi in Casa Uno Studente (Host a Student)}

Analysing their 2004 survey on studying and living in Milan, Meglio Milano - a non-profit organisation aiming to improve life in the city of Milan - realised that there were two distinct yet compatible issues: a high percentage of university students in Milan were from outside of the city and needed affordable accommodation, and about 320,000 residents in the city were aged 65 or older and living in homes too large for their needs. The Prendi in Casa Uno Studente project facilitates the co-habitation of self-sufficient retirees with spare rooms and young non-residents in need of accommodation in Milan. The guests do not pay rent in real terms but contribute to household expenses (with a reimbursement of 250-280 euros per month), collaborate with the host in everyday matters and provide some company without compromising their autonomy. Meglio Milano developed a set of tools to enable compatible host-guest matches, thus ensuring that the relationships were mutually beneficial and non-problematic. For a more detailed analysis of this project, see the work of Manzini (2015) and Meroni (2007).

\section{Nappi Naapuri (Nifty Neighbour)}

Nappi Naapuri is a Finnish online platform that enables people to connect with other people in their neighbourhoods in order to exchange help (with matters such as dog sitting), to share resources (such as tools, books or excess food) and to find friends for their children. The platform does not dictate any specific categories on which the interaction should be based. Rather, it enables people living 
close by to form communities and get to know each other on their own terms and based on their own needs, while assisting with the utilisation of un(der)used resources. The platform was established by Yhteismaa ('common ground' in English), a non-profit organisation based in Helsinki which aims to contribute to a participatory culture and co-creation by developing projects, events and services with a social purpose. Nappi Naapuri is one of Yhteismaa's social purpose projects and currently has approximately 20,000 members.

\section{Open Food Network}

Open Food Network is a project of the non-profit, registered charity Open Food Foundation (Australia), which was established in 2012 with the aim of developing, accumulating and protecting open-source knowledge, code, applications and platforms for fair and sustainable food systems. Open Food Network is an opensource (hosted on GitHub) online platform that directly connects food producers and food hubs with buyers. The prototype of the Open Food Network was launched in September 2013 in Victoria, Australia. Since then, local networks have been developed in the UK, Canada, France and Scandinavia; networks in India, USA and South Africa are also currently being developed. These networks extend to and adapt the original Open Food Network software to suit the local needs.

\subsection{Design practice}

As DfSI refers to the different ways in which design can play a role in social innovation projects alongside other competencies and actors, there are no rule-of-thumb approaches that are specific to this field. DfSI projects may use one or a combination of the problem framing, research and solution-development approaches that are commonly used in different design fields including, but not limited to, product design, participatory and collaborative design, strategic design, service design, urban design and game design (see, e.g., Cairns, 2017; Selloni \& Corubolo, 2017; Yang \& Sung, 2016). As several social innovation projects are either facilitated through online platforms or have a digital component, user experience design has also entered this list (see, e.g., Dinant, Floch, Vilarinho, \& Oliveira, 2017). The important point in bringing together tools and methods in DfSI projects is to develop a systemic understanding of the problem and its context, given that social 


\section{Box 9.2 DfSI tools and methods}

\section{The Young Foundation's The Open Book of Social Innovation}

This toolkit (Murray, Caulier-Grice, \& Mulgan, 2010) divides the process of social innovation into six generic phases (prompts, proposals, prototypes, the sustaining phase, the scaling phase and the systemic change phase) and introduces a total of 527 tools that can be used in different projects across these six stages. Even if only some of these are design tools, all of them can be relevant for practising designers who are taking part in social innovation projects. The book can be downloaded from https://youngfoundation.org/ publications/the-open-book-of-social-innovation/.

\section{Nesta's DIY (Development Impact \& You) toolkit}

Specifically targeting social innovators working in development projects, this toolkit (published by the UK innovation foundation Nesta, in collaboration with the Rockefeller Foundation in the USA) provides a collection of 30 design-led tools to trigger and support social innovation (Nesta, 2014). The book can be downloaded from https://diytoolkit.org/ in English and eight other languages.

\section{The European Social Innovation Toolkit 2018}

This toolkit is prepared by Kennisland, a foundation based in the Netherlands, and Nesta in partnership with other organisations working in the area of social innovation (European Commission, 2018). It is based on the six generic phases of social innovation proposed in The Open Book of Social Innovation (see above). However, it is concise, it has external links to several tools and it also includes new tools that came about after the publication of The Open Book of Social Innovation. The book can be downloaded from www.kl.nl/en/publications/the-european-social-innovationtoolkit-2018/.

innovation projects deal with complex dynamics and multiple stakeholder groups.

Cairns (2017) argued that some forms of participatory and collaborative design only engage with the 'users' at specific points in the design project and 'by invitation only'. He places emphasis on the fact that, in DfSI projects, the user communities (who 'own' the problem being addressed) should instead be embedded in social innovation projects throughout the 
whole process, from conceptualisation to implementation, on an ongoing basis. Through this approach, which he refers to as 'collaborative realisation', the user community will gain ownership of the solution that is codeveloped by them. He identifies and explains six interrelated principles of collaborative realisation between designers and user communities:

1. The problem lies within the domain of the user community and is owned by its members.

2. The user community must recognise and accept that their experience with the problem may be limited, their thinking may be bounded and their vision might be limited to their own context.

3. The professional designer holds a critical role in bringing to the table relevant disciplinary expertise and comparative examples of successful design solutions.

4. The project team must comprise all the expert contributors (both users as experts on their problem and designers as professional experts) in a collaboration with non-hierarchical respect.

5. Such a non-hierarchical organisation of the design team and process should not imply that equality of value is attached to the generated options.

6. The selection of the solution to be implemented should be based on the potential for delivering maximum value to the end-user community by generating meaning for its members.

\subsection{Benefits and limitations}

Social innovation focuses on socially relevant issues that are not addressed through established mechanisms. It is fuelled by a mindset oriented to the creative recombination of existing assets through the development and scaling of new social practices and organisational forms, or by means of enabling infrastructures and platforms. Therefore, it might complement approaches in DfS that are top-down, productcentred and environmental-impact focused. In addition, as social innovation is also a learning process that can bring about behavioural change, it is highly relevant and preparatory for the wider transformational changes required for achieving sustainability (see Chapter 11).

Even if social innovations are often driven by communities who own problems, professional designers can play a significant role in promoting and supporting social innovations (Manzini, 2015). They can contribute by making the social innovations more visible and tangible (e.g. by increasing people's awareness), more effective and attractive (e.g. by improving the experience of the people involved) and by supporting 
their replication (scaling out) and connection (scaling up) (Manzini, 2015). While systemic thinking and more conventional design skills (such as visualisation and prototyping) are considered strengths of the design approach in achieving social innovation, concerns have been raised about the naivety of designers proposing superficial solutions and the high cost of design services (Hillgren et al., 2011). These are valid criticisms and part of a broader discussion about the changes needed in professional design culture and design education in order to remain socially relevant in a post-industrial era, a fundamental characteristic of which is intensifying social and environmental crises.

Another criticism of DfSI relates to the lack of reflection on the alignment of means and goals, stemming from its tendency to focus on the design processes rather than the outcomes. In social innovation projects, the intentions of empowering actors go hand in hand with processes of disempowerment and political struggle; as a result, actors lose their sense of impact, competence, meaning and choice in effecting their desired change (Avelino et al., 2017). Von Busch and Palmås (2016) argued that having social means in innovation processes does not necessarily lead to socially desirable outcomes. They carried out a detailed analysis of a highly regarded, archetypal example of social innovation (microfinance) in order to highlight the anti-social, anti-political and anti-inventive effects it had and suggested that designers move away from the idealism of 'what-if scenarios' and question whose perspective remains dominant in a process of participation. Along similar lines, Mazé (2014) pointed out that designing for social innovation necessarily involves political questions about the role of design. Through the analysis of three cases she argued that the micropolitics of social innovation projects require questions about the distribution of resources, power and risk within a community (in addition to between communities and other social actors). Finally, Del Gaudio (2019) pointed out that new practices in design have often been informed by old epistemological bases, and design researchers and practitioners have not completely moved away from the dominant functionalist, rationalist and industrial traditions. Therefore, the real essence of acting in the social field has not been embraced, which has prevented design from making significant changes in society.

\subsection{Future research directions}

Based on the current discourse on DfSI, four themes emerge as directions for future research. The first of these is the continuation of research on the roles that can be played by design in social innovation projects. The 
complex contextual backdrops of social innovation projects - which include communities and other social actors, as well as the artefacts through which innovation takes place - blur the boundaries between design undertaken by non-professionals as a fundamental human cognitive capacity and design undertaken by professional designers based on capacities developed through training. Manzini (2015) attempted to delineate these as diffuse design and expert design. However, in projects of a complex nature, involving many stakeholders, it has been observed that it is not easy to observe the two in isolation as they tend to take place simultaneously and in resonance with each other (Gaziulusoy \& Ryan, 2017). This demands treating design as an activity with its own agency. Therefore, in trying to articulate the roles design can play, one direction would be to delineate the role of professional designers, as such research would have implications for design education and practice. On the other hand, another direction would be to research what is brought to the table by the agency of design, without necessarily putting emphasis on boundaries between diffuse and expert design.

The second theme for future research relates to the evaluation of and reflection on the involvement of design in social innovation projects. This calls for extended engagement with the communities that designers have collaborated with; these run beyond the project timelines and have a specific focus on reflecting on the longer-term impacts of involvement in social innovation projects. Such engagements are challenging given that the funds allocated for involvement do not generally cover evaluation periods; however, this can be tackled if it is possible to make evaluation part of the initial project plans.

The third theme for future research relates to bringing in learning from design disciplines - such as participatory design and service design - which have a legacy of working in collaboration with stakeholders. There is already ongoing work on how approaches in these disciplines can be used to support DfSI. The decades-long knowledge accumulation in participatory and collaborative design is particularly significant with regard to reflecting on issues of power, representation and politics in the participatory processes of innovation (see, e.g., Light \& Akama, 2012; 2014). In addition to participatory and collaborative design, the emerging fields of design research and practice, such as speculative design and decolonising design, can bring in new and critical perspectives to DfSI.

The final theme is related to understanding how designers can trigger, support and speed up the replication and scaling up of social innovations (see, e.g., Hillgren et al., 2011; Manzini \& Rizzo, 2011; Morelli et al., 2017), which is linked to the topics discussed in 
Chapter 11. Some strategies have already been proposed, for example, community-oriented toolkits, which can enable groups of people to apply (and adapt to specific contextual conditions) social innovation ideas; social franchising, through which a body can offer (to other organisations or groups of people) an idea of social innovation and support in implementing and managing it; and connecting a multiplicity of local projects in a coordinated framework that works to trigger changes at a larger territorial scale (Manzini, 2015). However, empirical research is needed to validate these strategies and, more generally, deepen their theoretical and practical aspects. Examples of attempts to tackle these challenges are available from the TRANSIT project (www.transitsocialinnovation.eu/home), which proposed a theory on how social innovation can lead to transformative institutional changes, and from the Transition project (transitionproject.eu/), which is aimed at supporting the scaling up of social innovations across Europe by developing a network of incubators.

\section{References}

Avelino, F., Wittmayer, J. M., Pel, B., Weaver, P., Dumitru, A., Haxeltine, A., ... O'Riordan, T. (2017). Transformative social innovation and (dis) empowerment. Technological Forecasting and Social Change. doi:10.1016/ j.techfore.2017.05.002

Boons, F., \& Lüdeke-Freund, F. (2013). Business models for sustainable innovation: State-of-the-art and steps towards a research agenda. Journal of Cleaner Production, 45, 9-19. doi:10.1016/j.jclepro.2012.07.007

Cairns, G. (2017). Can design inform effective social innovation? Design Journal, 20(6), 725-734. doi:10.1080/14606925.2017.1370658

Chick, A. (2012). Design for social innovation: Emerging principles and approaches. Iridescent, 2(1), 78-90. doi:10.1080/19235003.2012.11428505

Del Gaudio, C. (2019). Rethinking the designer's role in the collective reimagination of societies: A necessary reinterpretation of design for social innovation. In O. Devisch, L. Huybrechts, \& R. D. Ridder (Eds.), Participatory design theory: Using technology and social media to foster civic engagement. Abingdon, UK: Routledge.

Dinant, I., Floch, J., Vilarinho, T., \& Oliveira, M. (2017). Designing a digital social innovation platform: From case studies to concepts. In I. Kompatsiaris, J. Cave, A. Satsiou, G. Carle, \& A. Passani (Eds.), Lecture Notes in Computer Science: Vol. 10673. Internet Science: Proceedings of INSCI 2017 (pp. 101118). Cham, Switzerland: Springer.

European Commission. (2018). European Social Innovation Toolkit 2018. European Social Innovation Competition. Retrieved from www.kl.nl/en/ publications/the-european-social-innovation-toolkit-2018. 
Gaziulusoy, A. İ., \& Ryan, C. (2017). Roles of design in sustainability transitions projects: A case study of Visions and Pathways 2040 project from Australia. Journal of Cleaner Production, 162, 1297-1307. doi:10.1016/ j.jclepro.2017.06.122

Hillgren, P. A., Seravalli, A., \& Emilson, A. (2011). Prototyping and infrastructuring in design for social innovation. CoDesign, 7(3-4), 169-183. doi:10.1080/15710882.2011.630474

Hockerts, K., \& Wüstenhagen, R. (2010). Greening Goliaths versus emerging Davids: Theorizing about the role of incumbents and new entrants in sustainable entrepreneurship. Journal of Business Venturing, 25(5), 481-492. doi:10.1016/j.jbusvent.2009.07.005

Jégou, F., \& Manzini, E. (2008). Collaborative services: Social innovation and design for sustainability. Milan, Italy: Edizioni POLI.design.

Light, A., \& Akama, Y. (2012). The human touch: Participatory practice and the role of facilitation in designing with communities. Paper presented at the 12th Participatory Design Conference, Roskilde, Denmark, 12-16 August.

Light, A., \& Akama, Y. (2014). Structuring future social relations: The politics of care in participatory practice. Paper presented at the 13th Participatory Design Conference, Windhoek, Namibia, 6-10 October.

McGowan, K., \& Westley, F. (2015). At the root of change: The history of social innovation. In A. Nicholls, J. Simon, M. Gabriel, \& C. Whelan (Eds.), New Frontiers in Social Innovation Research (pp. 52-68). Basingstoke, UK: Palgrave Macmillan.

Manzini, E. (2007). Design research for sustainable social innovation. In R. Michel (Ed.), Design research now: Essays and selected projects (pp. 233245). Basel, Switzerland: Birkhäuser Verlag AG.

Manzini, E. (2014). Making things happen: Social innovation and design. Design Issues, 30(1), 57-66. doi:10.1162/DESI_a_00248

Manzini, E. (2015). Design, when everybody designs: An introduction to social innovation. Cambridge, MA: MIT Press.

Manzini, E., \& Rizzo, F. (2011). Small projects/large changes: Participatory design as an open participated process. CoDesign, 7(3-4), 199-215. doi:10.1080/15710882.2011.630472

Mazé, R. (2014). Our common future? Political questions for designing social innovation. Paper presented at the Design Research Society Conference 2014, Umeå, Sweden, 16-19 June.

Meroni, A. (Ed.). (2007). Creative communities: People inventing sustainable ways of living. Milan, Italy: Edizioni POLI.design.

Morelli, N., Aguilar, M., Concilio, G., Götzen, A. D., Mulder, I., Pedersen, J., \& Torntoft, L. K. (2017). Framing design to support social innovation: The Open4Citizens project. The Design Journal, 20(sup1), S3171-S3184. doi:10.1080/14606925.2017.1352823

Murray, R., Caulier-Grice, J., \& Mulgan, G. (2010). The open book of social innovation. London, UK: The Young Foundation. Retrieved from https:// youngfoundation.org/publications/the-open-book-of-social-innovation/. 


\section{Design for social innovation}

Nesta. (2014). DIY toolkit: Practical Tools to trigger and support social innovation. London, UK: Nesta. Retrieved from https://diytoolkit.org/.

Schaltegger, S., \& Wagner, M. (2008). Types of sustainable entrepreneurship and conditions for sustainability innovation: From the administration of a technical challenge to the management of an entrepreneurial opportunity. In R. Wüstenhagen, J. Hamschmidt, S. Sharma, \& M. Starik (Eds.), Sustainable innovation and entrepreneurship (pp. 27-48). Cheltenham, UK: Edward Elgar Publishing.

Selloni, D., \& Corubolo, M. (2017). Design for social enterprises: How design thinking can support social innovation within social enterprises. Design Journal, 20(6), 775-794. doi:10.1080/14606925.2017.1372931

Tracey, P., \& Stott, N. (2017). Social innovation: A window on alternative ways of organizing and innovating. Innovation, 19(1), 51-60. doi:10.1080/ 14479338.2016.1268924

van der Have, R. P., \& Rubalcaba, L. (2016). Social innovation research: An emerging area of innovation studies? Research Policy, 45(9), 1923-1935. doi:10.1016/j.respol.2016.06.010

van Wijk, J., Zietsma, C., Dorado, S., de Bakker, F. G. A., \& Martí, I. (2018). Social innovation: Integrating Micro, meso, and macro level insights from institutional theory. Business \& Society, 58(5), 887-918. doi:10.1177/ 0007650318789104

von Busch, O., \& Palmås, K. (2016). Social means do not justify corruptible ends: A Realist perspective of social innovation and design. She Ji: The Journal of Design, Economics, and Innovation, 2(4), 275-287. doi:10.1016/ j.sheji.2017.07.002

Yang, C. F., \& Sung, T. J. (2016). Service design for social innovation through participatory action research. International Journal of Design, 10(1), 21-36. 


\section{Systemic design}

\subsection{Creating sustainable productive systems at a territorial scale}

As previously discussed in Chapter 7, in the early 2000s design researchers began to reflect on the need to broaden the design focus, moving away from narrow interventions in individual products towards interventions in production and consumption systems. Systemic design (SD; see examples in Box 10.1) is an approach that sprang from the debate around the need and opportunities to integrate system thinking in design. In the words of Barbero and Toso,

the Systemic Design approach seeks to create not just industrial products, but complex industrial systems. It aims to implement sustainable productive systems in which material and energy flows are designed so that waste from one productive process becomes input to other processes, preventing waste from being released into the environment.

(Barbero \& Toso, 2010, p. 68)

$\mathrm{SD}$ is an approach that combines elements of BM and CTC (see Chapters 5 and 6) with the territorial and systemic focus of industrial ecology. Industrial ecology is a multidisciplinary field of study that seeks to understand and improve industrial systems, with a focus on their material and energy flows and the related effects on the environment (Lifset \& Graedel, 2002).

$\mathrm{SD}$ in fact adopts a territorial approach, looking at local socioeconomic actors, assets and resources with the aim of creating synergistic linkages among productive agricultural and industrial processes, natural processes and the surrounding territory (Barbero \& Fassio, 2011). In more detail, this approach allows one to design/plan the flows of material, energy and information from one element of the system (e.g. a 


\section{4}

productive activity) to another, reducing the waste flow by transforming the outputs of each system element into an input (an opportunity) for another system element (Bistagnino, 2009). This virtuous collaboration among stakeholders is intended to result in new and locally based value chains (Barbero, 2011).

SD was conceptualised by Bistagnino (2009) and further developed by the Systemic Design research group at the Politecnico di Torino, Italy. Five main principles are the basis of this approach (Bistagnino, 2011, 2017):

- Output (waste) becomes an input (a resource). This is the key principle of SD and, similarly to the CTC 'waste equals food' concept, refers to moving from a linear to a circular production-consumption model (i.e. from a model in which waste is considered a problem to one in which waste is viewed as a raw material for another process), an economic model that would ideally create a continuous flow of material, energy and information from and to different socioeconomic actors.

- Relations generate the system. Generally speaking, a system is composed of a set of knots and the connections between them. In the SD approach, the knots are constituted by the various socio-economic stakeholders in a particular geographical area, and connections are represented by the flow of materials, energy and information between these stakeholders. SD focuses on designing the complexity of these relations between socio-economic actors and flows.

- The system is self-generating. SD aims to develop systems that, like biological systems, are characterised by self-regulation and have a dynamic ability to respond to internal and external changes. In other words, open systems are capable of evolving in response to the changes taking place within their context.

- Actions are local. Systems should prioritise the use of local resources. These include natural resources and material and energy flows from productive activities, as well as social and cultural resources from the territory. This results in locally based systems that are potentially capable of promoting and fostering local economic development, as well as preserving the heritage of the material culture.

- The human being is at the centre of the project. SD puts the relationships between the person, the community and the local context at the core of the project. SD starts from the 'human' dimension in order to inform the development of systems of places, communities, practices and processes that are capable of safeguarding local culture, knowledge and know-how. In other words, SD integrates the 
technical aspects of redesigning flows of material and energy with the socio-cultural aspects of promoting local communities and culture.

SD deals with highly complex systems. In fact, SD solutions involve and interlink elements of the biosphere (e.g. natural resources), sociosphere (e.g. local knowledge and practices) and technosphere (e.g. material and energy flows). This means that not only do a large number of variables need to be considered but it is also necessary to adopt an interdisciplinary approach (Peruccio, 2017). In terms of design skills, this entails a significant change because it requires systemic thinking and a holistic approach in order to manage the complexity related to the multiplicity of factors and interactions that come into play.

\subsection{Design practice}

The SD approach has been applied in several projects focusing on a variety of areas, including agricultural and food networks (see, e.g., Barbero \& Toso, 2010; Ceppa, 2010), industrial processes, water treatment (see, e.g., Toso \& Re, 2014; Toso, 2015), exhibitions and fairs (Fassio, 2017) and energy systems (see, e.g., Barbero, 2010). Bistagnino (2009, 2011) provides an extensive description of these and other projects where the SD approach has been applied.

A comprehensive design methodology has been developed to support the practical application of SD. It consists of the following five main steps (Bistagnino, 2009; Barbero, 2017a; Battistoni \& Barbero, 2017):

1. Holistic diagnosis of the territory. Desk and field research are used to understand the current situation of the context on which the project focuses. Firstly, on a wider scale, the analysis aims to gather data related to the economic, social (e.g. material culture, local history and traditional know-how) and environmental aspects (e.g. local resources) of the territory. Secondly, depending on the scope of the project, the analysis focuses on a particular set of production processes in order to identify the quality and quantity of material, energy and financial flows which come into and out from each process. Visual maps (see, e.g., Figure 10.1) are used as a tool to collect and communicate this complex set of flows.

2. Best practice analysis. This stage aims to collect and analyse a range of best practices that tackle similar challenges to those addressed by the project. Best practices can be related to a variety of different contexts, and the focus is on understanding to what extent elements of these practices can be transferred and adapted in relation to the 


\section{Box 10.1 SD examples}

\section{SD to reuse coffee waste}

The Politecnico di Torino, in collaboration with Lavazza, has implemented a solution that reuses coffee waste as an input for agricultural production. A new productive and value chain was conceived in which coffee waste can be reused as a source of lipids and waxes for pharmaceutical production, a substrate for farming mushrooms, and a medium in which to grow worms for vermicomposting. This entails a shift from a system in which coffee waste is a cost to a system which not only reduces disposal costs but also generates income from new activities.

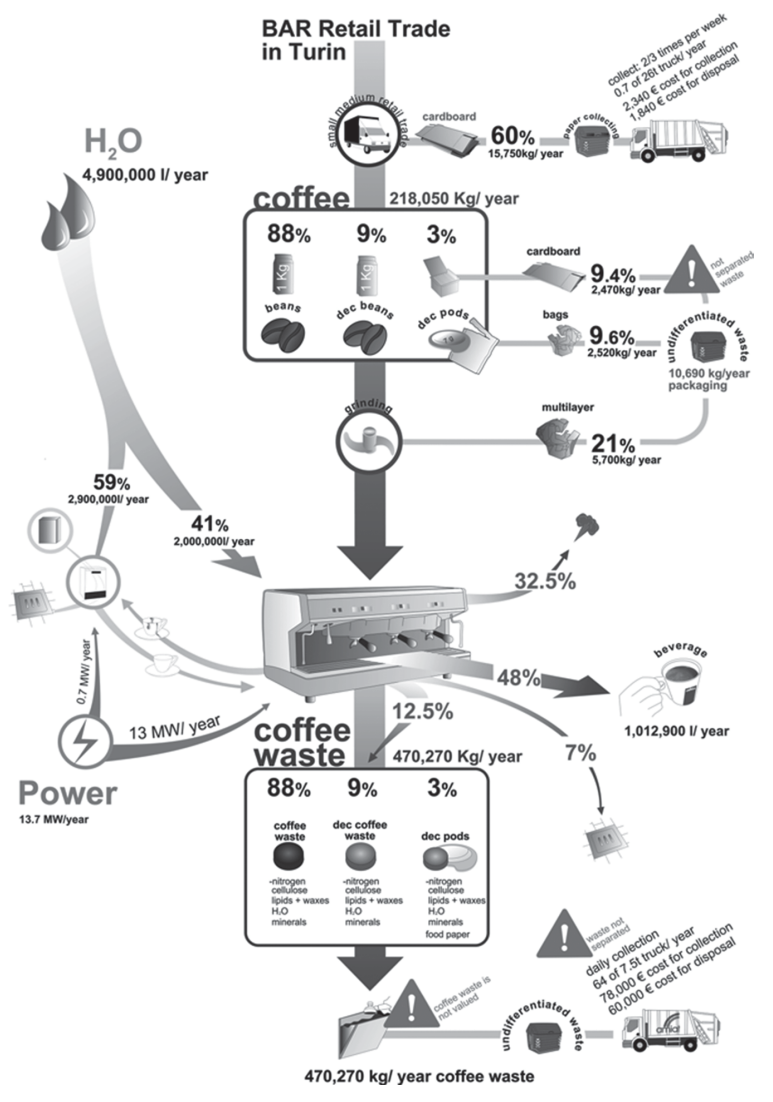

Figure 10.1 Visual representation of the current productive and value chain for coffee waste

Source: Barbero \& Toso (2010). 


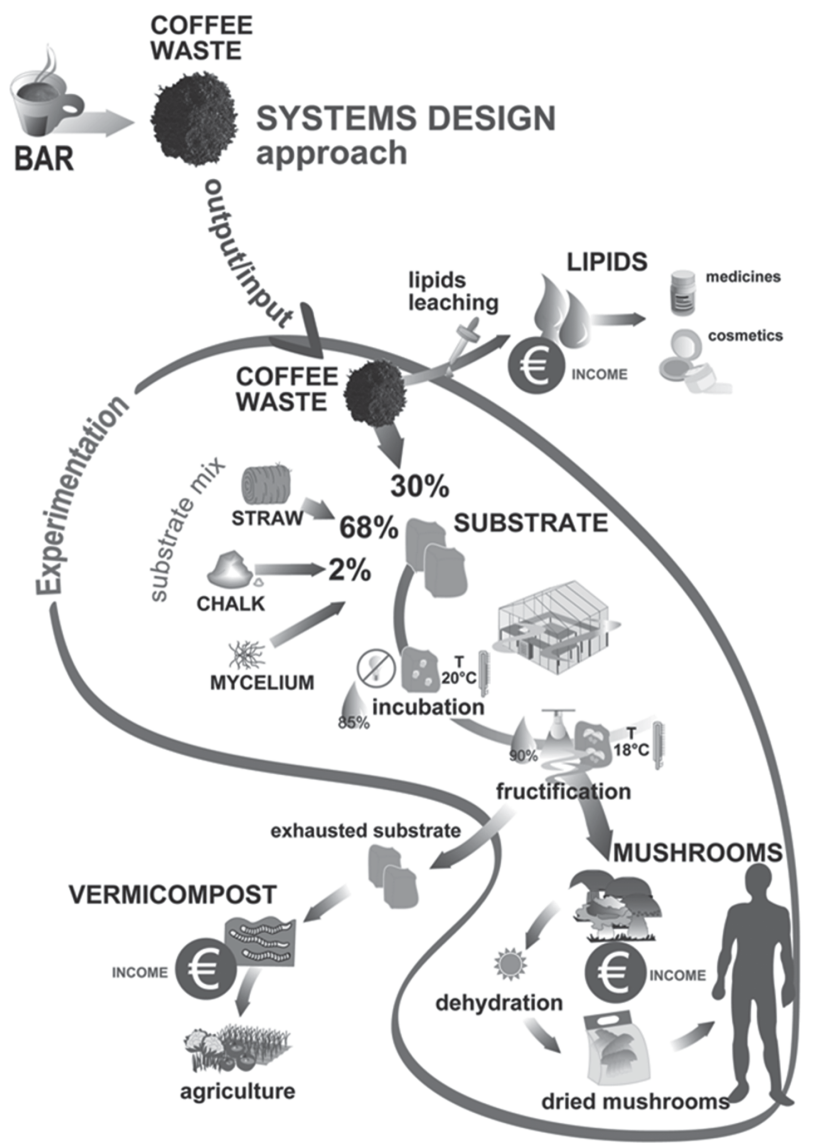

Figure 10.2 Visual representation of the new productive and value chain for coffee waste

Source: Barbero \& Toso (2010).

\section{Rethinking water flows within the house system}

Dario Toso $(2015,2017)$ has applied the SD approach to developing a household water purification system that adopts membrane-less and chemical-free water treatment technologies in order to reduce the amount of water needed and eliminate harmful by-products. This technology exploits the exclusion zone (an interfacial water region that has a lower concentration of solutes than the bulk water) to purify the water without the need for a physical filter. 


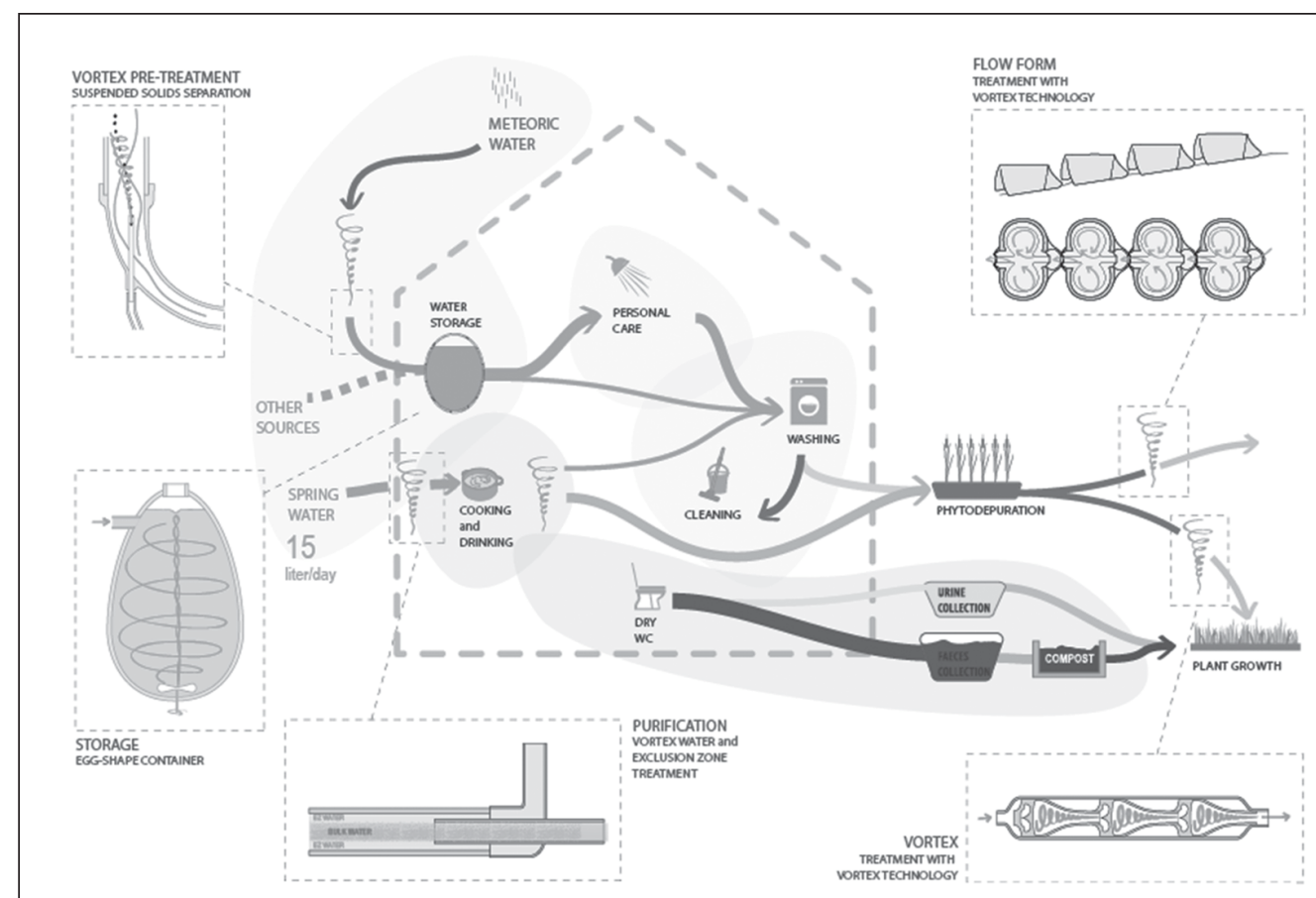

Figure 10.3 Visual representation of the designed household water purification system Source: Toso (2015). 
project context. Again, visual maps can be used to represent these best practices.

3. Problem identification. The visual map developed in the first stage is used to identify the current problems of the existing production processes. These might include, for example, the identification of environmental aspects (such as waste flows, the use of non-local resources and unexploited heat) and even social aspects (such as the loss of cultural heritage).

4. Solution development. This stage entails a continuous and iterative process of ideation, development and validation, based on the following substeps:

a. From problems to opportunities. Building upon the identified problems, and considering the collected best practices, this step aims to identify ways of transforming problems into opportunities to leverage changes in the local production system. This is done by looking at output flows (and then, for example, converting a waste flow from a production process into a resource for another production process) and input flows (and then, for example, converting a non-local resource into a local one).

b. Definition of the new systemic production model. This substep focuses on selecting and combining the identified opportunities into a new coherent systemic production model. This proposal considers not only the complex range of input and output flows (environmental, economic and social) but also the socio-economic actors involved and their interactions. Visual maps are again used to communicate the different features of the production model (see, e.g., Figure 10.2).

c. Definition of the outcomes generated. The development of a new systemic production model is coupled with preliminary studies and simulations of the benefits that the new model can potentially generate for the whole local territory. This includes environmental, economic, social and cultural aspects.

5. Implementation. The final step is the implementation of the solution following its preliminary validation in the previous stage. The implementation allows for assumptions about the potential benefits of the solution to be verified by collecting real data. Through a continuous cycle from stages 1 to 5 , real data are used to identify and apply changes to the systemic production model. 


\section{Box 10.2 SD methods and tools}

SD methods and principles are described in the work of Bistagnino (2009, 2011). Additional considerations and exemplifications of the method can be found in the work of Battistoni and Barbero (2017).

In terms of design tools, visualisation tools have been specifically developed to support practitioners. These tools portray the actors, resources, material, energy and information flows of a given productive system. Essentially, these tools enable the visualisation of complex sets of data and support participatory design processes. They can be used for a number of different purposes, for example, visualising a current production system and its criticalities, visualising a new systemic production model or visualising the outcomes and benefits derived from a new model. Examples of how the tool has been used can be found in the work of Bistagnino (2009, 2011), Barbero and Toso (2010) and Battistoni and Barbero (2017), as well as at www.systemsdesign.polito.it/.

\subsection{Benefits and limitations}

Essentially, the main environmental benefit that the SD approach can bring about is the development of productive processes and systems that minimise the amount of wasted material and energy sources. This is achieved by designing resource flows so that waste from one productive process becomes an input for other processes and by preventing the release of waste into the environment.

It is important to highlight that this is done by adopting a territorial approach. This means that SD aims at developing locally based productive systems that prioritise the use of a range of local resources: natural resources, material and energy flows from local productive activities, and social and cultural resources (including the available competencies and socio-economic actors already settled in an area). This means that the outcome of an SD project cannot be replicated as such in another geographical area due to differences in the locally available resources. By developing locally based systems, SD can potentially bring about a set of environmental, social and economic benefits. From an environmental point of view, the use of local resources avoids/reduces the impact related to transporting these resources. From a social and economic perspective, SD solutions entail the involvement of more local, rather than global, socio-economic actors. As a result, this could potentially increase local employment and the local dissemination of skills and competencies, as 
well as favouring the preservation of local cultural heritage. Overall, this could potentially foster a local economic and social development.

In addition, as highlighted by Peruccio (2017), since SD operates at a local level, it addresses the needs of a specific target group rather than a global target market. As a consequence, SD solutions can be tailored to the particular (cultural and ethical) needs of the local people and socioeconomic stakeholders.

In terms of limitations, the weaknesses highlighted for CTC design also apply to SD (see Section 5.3). In addition to these weaknesses, the main problem is that SD is mainly focused on production processes and production systems, without addressing the issue of reducing individual consumption. Even if the approach is helpful in designing and creating local material and energy networks that are more efficient, it does not affect consumer demand for products and services. In other words, it optimises an existing (industrial and/or agricultural) productive system, but it does not change people's consumption behaviour and habits. The risk is that the environmental improvement, generated by a systemic production model, might be negatively counterbalanced by an increase in consumption levels. It is for this reason that SD should be combined with other design approaches, for example, PSS design for sustainability (see Chapter 7) or design for social innovation (see Chapter 9), which are both aimed at changing consumption patterns.

Another aspect to be considered is the appropriate balance between local and non-local activities. SD focuses on local productive processes and emphasises the use of local resources, but economy-of-scale factors should be taken into account. In fact, even if SD deals with eco-efficacy instead of eco-efficiency, with a focus on resilience and flexibility, it could be that large non-local productive processes would bring about higher efficiency gains compared to small local productive processes, potentially resulting in lower environmental impacts. At the moment, it is not clear how the SD approach enables designers to make this type of decision.

\subsection{Future research directions}

Most of the applications of the SD approach are related to the agrofood sector, followed by a few applications in projects focusing on exhibitions, fairs and behaviour change. To the authors' knowledge, at the moment there are only a very limited number of applications related to the manufacturing industry (see, e.g., Campagnaro, 2008). Thus, it would be interesting to expand the sectors of application in order to understand the implications of adopting SD in addressing a diverse range of challenges. This could help to better comprehend the strengths 
and limitations of the approach, as well as the implications for designers of applying the approach in different sectors.

It is also important to understand how SD should or could be combined with other design approaches. As explained in the previous section, one of the limitations of SD is that it does not directly address consumption patterns and behaviour. Thus, it seems promising to investigate how SD could be coupled with those design approaches that can have an impact on patterns of consumption - namely PSS design for sustainability (see Chapter 7), design for sustainable behaviour (see Chapter 4) and design for social innovation (see Chapter 9) - and explore how these could complement one another and be synergistically integrated. For example, in relation to social innovation, Campagnaro, D'Urzo and Pezzi (2017) have investigated how an SD approach can be used to detect social inclusion and marginalisation.

Another area on which design researchers are currently focusing is the relation between SD and policymaking. As previously explained, SD seeks to develop complex and locally based industrial systems, which by definition could have important implications at a territorial/regional scale. For this reason, it is clear that regulatory frameworks and policies play an important role in supporting or hindering this type of innovation. As a result, it would be interesting to better understand how to create innovation ecosystems capable of supporting SD innovations. In this respect, some initial works (see, e.g., the EU-funded project called RETRACE; Barbero, 2017b; Barbero \& Bicocca, 2017) have begun to identify some future research goals. These include the following: to raise awareness and properly communicate the benefits of SD to politicians and policymakers; to develop policy road maps, policy briefs and recommendations; and (more generally) to enable policy practitioners to adopt SD strategies and approaches (e.g. through methodological tools) at a territorial and cross-sectoral level.

\section{References}

Barbero, S. (2010). Local bio-energy promotes distributed economy for sustainable development: Systemic design approach and case-studies. Design Principles and Practices, 4(4), 21-29.

Barbero, S. (2011). Systemic design for the development of local distributed economies. Doctoral dissertation. Politecnico di Torino, Turin, Italy.

Barbero, S. (2017a). Systemic design as effective methodology for the transition to circular economy. In S. Barbero (Ed.), Systemic design method guide for policymaking: A circular Europe on the way (pp. 75-82). Turin, Italy: Umberto Allemandi.

Barbero, S. (Ed.). (2017b). Systemic design method guide for policymaking: A circular Europe on the way. Turin, Italy: Umberto Allemandi. 
Barbero, S., \& Bicocca, M. (2017). Systemic design approach in policymaking for sustainable territorial development. The Design Journal, 20(sup1), S3496-S3506. doi:10.1080/14606925.2017.1352853

Barbero, S. and Fassio, F. (2011) Energy and food production with a systemic approach. Environmental Quality Management, 21(2): 57-74.

Barbero, S., \& Toso, D. (2010). Systemic design of a productive chain: Reusing coffee waste as an input to agricultural production. Environmental Quality Management, 19(3), 67-77.

Battistoni, C., \& Barbero, S. (2017). Systemic design, from the content to the structure of education: New educational model. The Design Journal, 20(sup1), 1336-1354. doi:10.1080/14606925.2017.1352661

Bistagnino, L. (2009). Design sistemico: Progettare la sostenibilità produttiva e ambientale. Bra, Italy: Slow Food Editore.

Bistagnino, L. (2011). Systemic design: Designing the productive and environmental sustainability. Bra, Italy: Slow Food Editore.

Bistagnino, L. (2017). Systemic design: Methodology and principles. In S. Barbero (Ed.), Systemic design method guide for policymaking: A circular Europe on the way (pp. 75-82). Turin, Italy: Umberto Allemandi.

Campagnaro, C. (2008). Cinque miliardi di sfere: Design sistemico e produzione metallurgica. Milan, Italy: Casa Editrice Ambrosiana.

Campagnaro, C., D’Urzo, M., \& Pezzi, G. (2017). Systemic design and social marginalization: Mapping and assessment of projects for the empowerment of people experiencing social exclusion. In Proceedings of Relating Systems Thinking and Design (RSD6) 2017 Symposium, Oslo, Norway, 1820 October.

Ceppa, C. (2010). Thinking by connections and the dynamics of nature for food production. In E. Lichtfouse (Ed.), Alternative Farming Systems, Biotechnology, Drought Stress and Ecological Fertilisation (pp. 1-14). Dordrecht, the Netherlands: Springer.

Fassio, F. (2017). Food events as complex cultural systems for territorial reconnection: The case study of Terra Madre Salone Del Gusto. Agroecology and Sustainable Food Systems, 41(8), 907-920. doi:10.1080/ 21683565.2017.1322660

Lifset, R., \& Graedel, T. E. (2002). Industrial ecology: Goals and definitions. In R. U. Ayres \& L. W. Ayres (Eds.), A Handbook of Industrial Ecology. Cheltenham, UK: Edward Elgar Publishing.

Peruccio, P. P. (2017). Systemic design: A historical perspective. In S. Barbero (Ed.), Systemic design method guide for policymaking: A circular Europe on the way (pp. 68-74). Turin, Italy: Umberto Allemandi.

Toso D. (2015). Visione sistemica dell'acqua. Doctoral dissertation. Politecnico di Torino, Turin, Italy.

Toso D. (2017). The systemic design approach for understanding the water social behavior. In Proceedings of Relating Systems Thinking and Design (RSD6) 2017 Symposium, Oslo, Norway, 18-20 October.

Toso, D., \& Re, T. (2014). Systemic design applied to water treatment for domestic purposes. WIT Transactions on the Built Environment, 139, 209-217. 


\section{Design for sustainability transitions}

\subsection{Transforming socio-technical systems and lifestyles through design}

While the design profession was in the early phases of engaging with environmental issues (and later social issues) through frameworks such as green design and ecodesign (see Chapter 2) in the 1990s, there was an emerging focus on the transformation of socio-technical systems for sustainability. Early and well-known projects included the Dutch National Inter-Ministerial Programme for Sustainable Technology Development (STD) (1993-2001) and the EU-funded Strategies Towards the Sustainable Household (SusHouse) Project (1998-2000). Both projects were concerned with sustainable need fulfilment with a long-term approach (Quist \& Vergragt, 2006). The former focused on policy development, aiming to influence sustainable innovations (Weaver, Jansen, van Grootveld, van Spiegel, \& Vergragt, 2000), and the latter focused on developing 'design-orienting scenarios' to influence sustainable technological and social innovations (Green \& Vergragt, 2002). These projects adopted a 50-year timeframe, consistent with the time period needed for radical innovations, and used a backcasting approach (Weaver et al., 2000). Both of these projects focused not only on influencing technological innovations but also social, institutional and organisational innovations (Vergragt \& van Grootveld, 1994; Weaver et al., 2000). Although these projects focused on different types of innovations in the wider socio-cultural context, the understanding about the formation of these innovations was linear and one-way rather than co-evolutionary, and the whole approach was technocentric (Gaziulusoy \& Boyle, 2008).

Around the same time, some fundamental theories that aimed to understand and influence the ways in which innovation in socio-technical systems occur were being developed. Among these were strategic niche management (Hoogma, Kemp, Schot, \& Truffer, 2002; Kemp, Schot, 
\& Hoogma, 1998), constructive technology assessment (Rip, Misa, \& Schot, 1995) and transition management (TM) (Rotmans, Kemp, \& Van Asselt, 2001). Building on these contributions, the multi-level perspective (MLP) on system innovations was developed as an analytical and theoretical model to explain the dynamics of transitions from one sociotechnical system to another (Kemp, 1994; Kemp, Rip, \& Schot, 2001). Following the early development of the model, the MLP was refined and clarified by Geels (2005a; 2005b) and Geels and Schot (2007; see Box 11.1). TM has subsequently been developed further and elaborated on as a new way of governing socio-technical system change (Loorbach, 2010). Both of the earlier projects, STD and SusHouse, and the development of theories on system innovations and transitions created a ground in the design field for cross-fertilisation.

A need for more systemic approaches targeting 'cultural change' in society, rather than focusing solely on technological interventions in production-consumption systems, was signalled by some design scholars as far back as first half of the 1990s (see, e.g., Ryan, Hosken, \& Greene, 1992, p. 21). Brezet (1997), on the other hand, was the first scholar to mention system innovations in the context of design. He identified four types of ecodesign innovations (consistent with the terminology and sole environmental focus of the period) with increasing potential for improvement: product improvement, product redesign, function innovation and system innovation. He referred to system innovations as changes that are required in infrastructure and organisations as the result of new products and services. The first conference held on design and sustainability transitions was the Changing the Change conference in Turin, Italy (Cipolla \& Peruccio, 2008). The conference highlighted that radical change in lifestyles and ways of meeting needs was required and that sustainability had to become the meta-objective for all design research activity. As indicative examples of the content presented at this conference, Ryan (2008) argued for design visioning for paradigm change, Vezzoli, Ceschin and Kemp (2008) established a link between design and TM, and Boehnert (2008) discussed what designers can learn from the Transition Towns movement.

Between 2010 and 2012, the first PhD studies that established a link between design and sustainability transitions were completed. Gaziulusoy's (2010) work was situated at the intersection of sustainability science, system innovations and transitions theories, and design theory (see also Gaziulusoy \& Brezet, 2015). Joore (2010), on the other hand, situated his work tightly within industrial design engineering, exploring the mutual influence of new products and societal change processes. Ceschin (2012a) situated his work within the maturing research area of 


\section{Box 11.1 The MLP of system innovations}

The MLP model portrays the dynamic nature of system innovations through a layered structure. It has three levels: the socio-technical landscape, the socio-technical regime and niche innovations. The landscape (macro) level provides an overview of the overall socio-technical setting. Landscapes mostly consist of long-term changes and factors (deep cultural patterns, macro-economic and macro-political developments) that do not change (or change only very slowly) and sometimes of rapid external shocks (Van Driel $\&$ Schot, 2005). They cannot be changed by actors in the short term (Geels \& Schot, 2007). The landscape level stimulates and exerts top-down pressure upon the socio-technical regime. The regime (meso) level represents the rules of dominant scientific, technological, business and market activity. This level is stable and reinforces the prevailing socio-technical systems, thus often demonstrating activities that are barriers for change. The niche (micro) level is the level of experimentation for the conception of new technologies, organisational models and social and cultural practices, as well as being the level of institutional innovations. This level has a loose structure compared to the upper levels, and is less likely to be subject to market and regulatory influences. The coordination between niche-level actors is also less often compared to the coordination between regime actors.

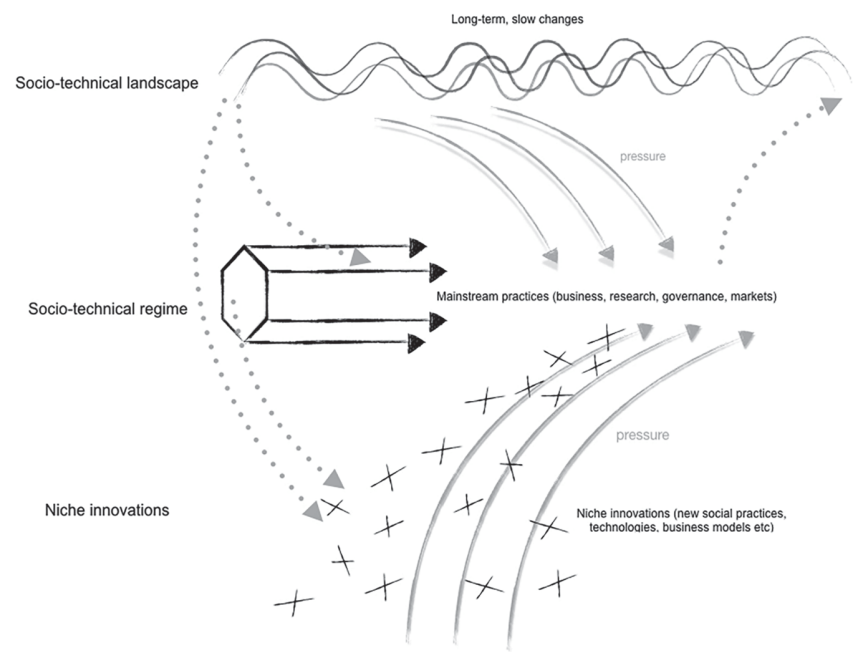

Figure 11.1 The MLP of system innovations model

Source: Adapted from Geels (2005a, 2005b) and Geels \& Schot (2007). 
sustainable PSSs (SPSSs) and argued that SPSSs can be considered as system innovations as they require changes in user practices, organisational structures, regulatory frameworks and culture. These three PhD studies were similar in the sense that they all referred to and used the MLP of system innovations (Geels, 2005b) and other models and theories of system innovations and transitions literature in constructing their theoretical/conceptual frameworks. They also focused on product (understood in a broad sense) development and each demonstrated in their own way how the work of designers is, or can be, linked to societal change processes for sustainability. Kossoff (2011), on the other hand, followed a very different path. He argued that it is everyday life that needs to be sustainable. He referred to the contexts within which most pre-industrial societies satisfied their needs as the domains of everyday life and argued that the relative sustainability of those societies stemmed from their control over the satisfaction of needs in holistic ways (rather than the top-down control of needs satisfaction found in modern societies). His understanding of design - particularly transition design - was that it should be the activity of everyone and should constitute facilitating the emergence of nested domains of everyday life and making them whole.

Building on the work of Kossoff (2011), Irwin (2015b) proposed a transition design framework for design education, research and practice. She situated transition design as an emerging area at the end of a design continuum, following service design and design for social innovation, thereby making links between transition design and other new areas of design for sustainability. In 2012, the School of Design at Carnegie Mellon University began to implement curricula formulated using transition design as an umbrella framework across all levels of design education (Irwin, 2015a). Although theories and practices for design in sustainability transition processes had been being developed for two decades, it was Irwin and her colleagues who popularised it within the broader community of design academics and practitioners.

Design for sustainability transitions (DfST) (or transition design, as popularised by Irwin, 2015b; see examples in Box 11.2), focuses on the transformation of socio-technical systems through technological, social, organisational and institutional innovations. In this regard, DfST embodies design for PSSs, which aims to transform productionconsumption systems through business model innovation (see Chapter 7), and design for social innovation, which aims to assist with social change without seeing technological change as a pre-determinant of this (see Chapter 9). More recently, DfST has begun to be focused on cities (see, e.g., Ryan, 2013a, 2013b; Ryan, Gaziulusoy, McCormick, 
\& Trudgeon, 2016a), which are essentially socio-technical systems. This focus on cities - as distinct from conventional sustainable urban design and planning, which focus on urban form, urban growth, liveability, walkability, energy reduction and place-making separately and distinctively from sustainable architecture, which focuses on individual buildings - is grounded in the theoretical framings of cities as complex adaptive systems (see, e.g., Bettencourt \& West, 2010; Portugali, 2012). Framing cities as complex adaptive systems requires an understanding of the the interrelationships between technologies, ecosystems, social and cultural practices, and city governance in design decisions (Marshall, 2012). In order to achieve this, DfST integrates different theoretical domains that might be relevant to cities and utilises a multiplicity of supportive design approaches, such as speculative design, design futures, and collaborative and participatory design.

\subsection{Design practice}

In the context of sustainability transitions, it is important to design a multiplicity of interconnected and diverse experiments, iteratively implemented over long periods of time, in order to generate changes in large and complex systems (Manzini \& Rizzo, 2011; Ceschin, 2014a). Sustainability transitions are design challenges with creative,

\section{Box 11.2 DfST examples}

\section{Visions and Pathways 2040: the Visions, Scenarios and Pathways for Low-Carbon Resilient Futures in Australian Cities project}

In this project a series of transdisciplinary and participatory design and futures methods were used to develop visions and scenarios for low-carbon and resilient city futures and to engage the stakeholders in project framing and execution. Through designled visioning (Ryan et al., 2016a; Gaziulusoy \& Ryan, 2017b), a series of 'glimpses of the future' - snapshots of desirable, lowcarbon and resilient futures for Australian cities - across different city-system levels (whole cities, precincts and neighbourhoods, products and services) were produced. These glimpses were then used to facilitate strategic conversations among stakeholders in order to inform the development of four distinct future scenarios and transition pathways (Ryan et al., 2016b; Candy, Larsen, Twomey, McGrail, \& Ryan, 2017). 

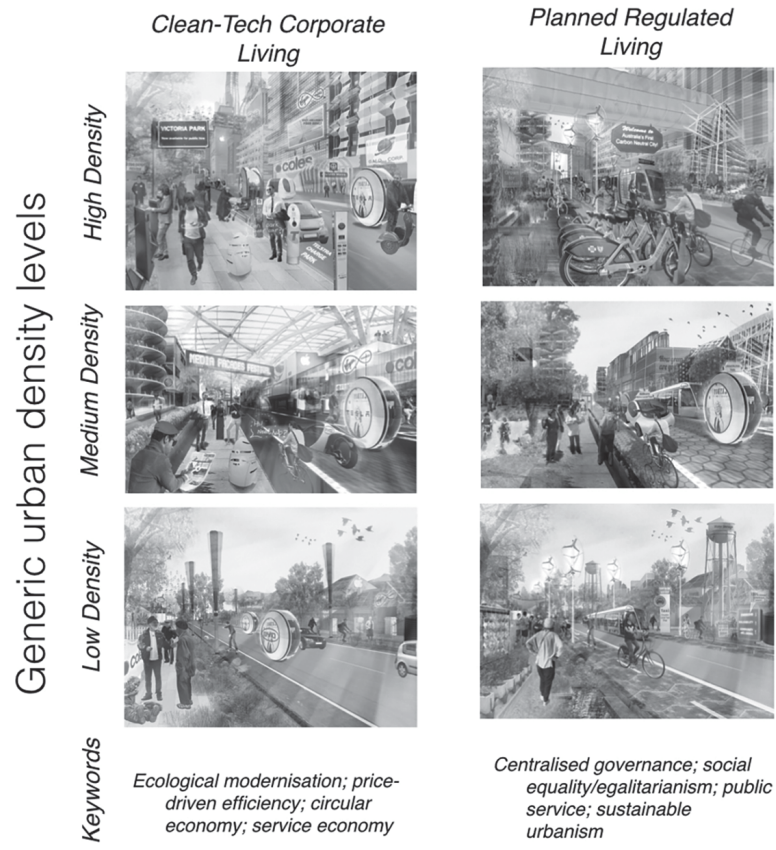

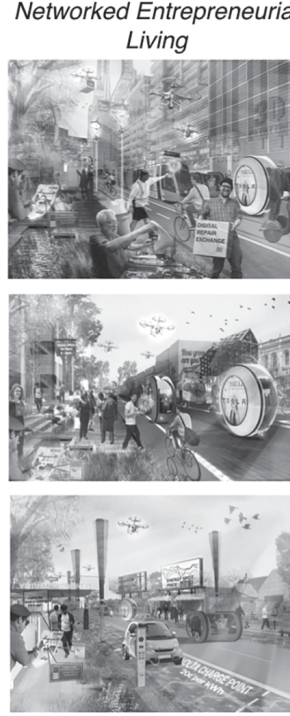
Peer-to-peer; collaborative economy; micro-businesses; freelance workers; diversity and creativity

Community Balanced Living
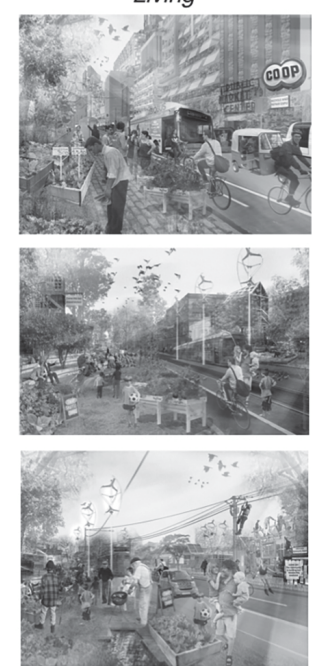

Localisation; well-being; balanced living; alternative forms of
enterprises and exchange; caring for the commons

Figure 11.2 Visualisations of the four scenarios produced in the Visions and Pathways 2040 project Source: Images $\odot$ Amy Bracks, VEIL and the Cooperative Research Centre for Low Carbon Living. 


\section{Redesigning transition arenas for mid-range planning in the Smart Energy Transitions project, Finland}

$\mathrm{TM}$ is one of the key theoretical frameworks used in sustainability transitions projects. TM is practised through the transition arenas, multi-stakeholder and collaborative platforms through which new policy pathways are created. In the context of the Smart Energy Transitions project, the transition arena process was redesigned to address the implementation difficulties associated with the ambitious agenda of transition arenas (Hyysalo et al., 2019). The redesigned version focused on interim goals, mid-range change pathways and the development of a toolset that allowed participants to directly create pathways.

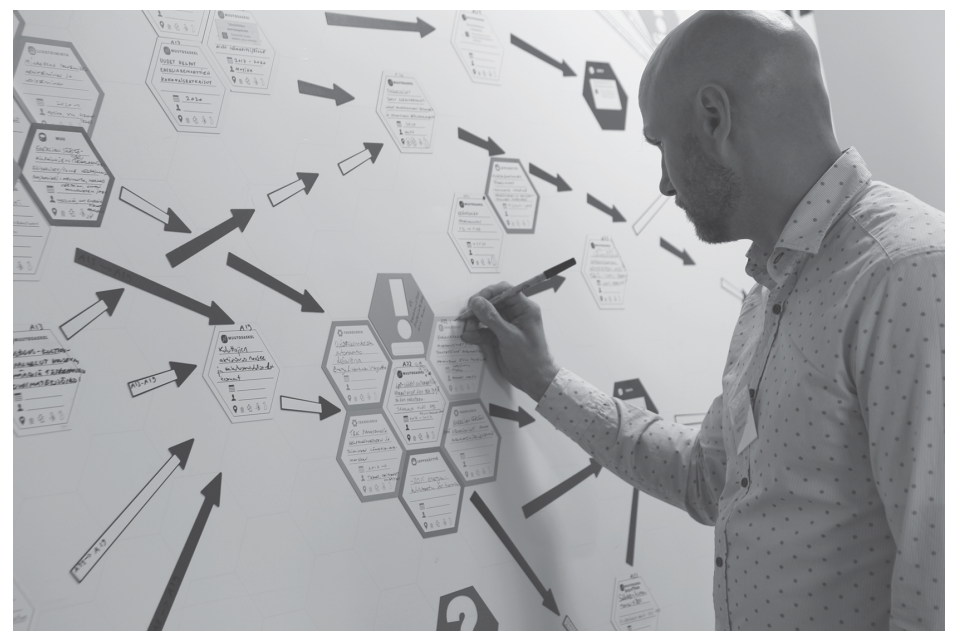

Figure 11.3 A pathway development workshop for mid-range planning during the Smart Energy Transitions project

Source: Images courtesy of Sampsa Hyysalo, Tatu Marttila and Sofi Perikangas, licensed under CC BY 4.0.

technical and political dimensions (Gaziulusoy \& Ryan, 2017b). It is important to note here that design, in the context of transitions, should be understood more broadly than how it is framed by the traditional (although expanding) boundaries of the design profession. For example, Dewberry and Johnson (2010) argued that in the context of transitions, policymaking is designing sustainable futures and there is a 
need to consider design activity at any level of socio-technical systems in relation to design activity at all other levels. Also, there is a need to acknowledge that design can be diffuse (undertaken by anyone as a natural human cognitive capacity) or expert-led (undertaken by design professionals) (Manzini, 2015). The boundaries between diffuse design and expert design are particularly blurred in transition processes. For example, a group of scholars have been studying how users have become innovators of and played roles in energy transitions in Finland (Heiskanen, Hyysalo, Jalas, Juntunen, \& Lovio, 2014; Hyysalo, Johnson, $\&$ Juntunen, 2017). Therefore, the practice of design in the context of sustainability transitions covers a wide range of activities which may be undertaken by a variety of actors, not just by professionally trained designers. Due to the complexity of transition projects, more often than not these activities are undertaken by actors who wish to bring about change in collaboration with each other, which may or may not involve professional designers. In addition, the activities undertaken by professionally trained designers in the context of transitions cover traditional as well as new or emerging designer tasks and yield both tangible and intangible outcomes (Gaziulusoy \& Ryan, 2017a). The design outcomes generated during transition projects may cover outcomes associated with all four orders of design (i.e. communication, construction, strategic planning and systemic integration) and may include signs, symbols, images, physical objects, activities, services, processes, systems, environments, ideas and values, as theorised by Buchanan (1998).

Despite the rather broad scope of the design activity relevant to sustainability transition projects, there are some methods, tools and frameworks (see examples in Box 11.3) that have been developed by design researchers that are specifically related to designing transition experiments or assisting designers and design teams to actively influence transitions. For example, Gaziulusoy (2010) (see also Gaziulusoy, Boyle, \& McDowall, 2013) developed an operational tool for the use of design and innovation teams in order to align their day-to-day decisions and strategic outlook with unfolding and upcoming sustainability transitions. This operational tool - which employs a scenario method - integrates explorative and normative (backcasting) scenario approaches in order to causally link the present reality with future aspiration. Ceschin (2012a, 2014b) developed a very elaborate toolset for practising designers. This toolset included tools to formalise SPSS concept visions, tools to develop and formalise transition strategies, tools to manage the network of actors, and tools to monitor and evaluate the transition process. He also proposed designing experiments as labs, windows and agents of change (Ceschin, 2014a, 2015). Other 


\section{Design for sustainability transitions}

researchers have written about 'synergising' or 'acupunctural planning' (Jégou, 2011; Meroni, 2007, 2008), 'urban eco-acupuncture' (Ryan, 2013a, 2013b) and design visioning (Ryan et al., 2016). Recently Baek, Meroni and Manzini (2015) proposed and tested a framework for a socio-technical approach to designing community resilience. A significant contribution has also been achieved by Hyysalo, Perikangas, Marttila and Auvinen (2018) and Hyysalo et al. (2019) who have redesigned the transition arena process (the main practical tool in TM) which enables the direct co-creation of mid-range transition pathways by the participants themselves.

\subsection{Benefits and limitations}

A design-led approach in sustainability transition projects is aligned with the experimentation that is necessary to transform systems. Therefore, designers who uptake design for sustainability transitions are able to play several roles (Gaziulusoy \& Ryan, 2017a) in the operational, tactical and strategic activities that are part of transition projects (Loorbach, 2010). The theories, frameworks and tools associated with DfST can also assist with encouraging the necessary long-term thinking needed for achieving sustainability transitions in private, public and civil organisations, as well as being able to assist with the transformation of design education.

However, DfST is a high-level approach on its own. Unless it is supported by design approaches that are focused on the creation of specific design outcomes, including - but not limited to - product design, service design and policy design, it is only able to contribute to the communication of high-level outcomes through visualisations and perhaps play a role in the identification of intervention points in systems and the design of transition experiments. DfST can specify and conceptualise the new values, new technologies, new social practices and new lifestyles that are necessary in sustainable sociotechnical systems and assist in the democratic deliberation of transition paths and alternative futures. However, to be able to realise the actual transformation of socio-technical systems there is a need for more traditional design approaches, as well as the integration of knowledge from several other knowledge bodies, including - but not limited to - engineering, social sciences, urban planning and public policy.

Finally, after two decades of development and practice, mostly within academic circles, and as DfST penetrates into commercial design practice, there is a danger of it becoming the new 'design thinking', 


\section{Box 11.3 DfST methods and tools}

Gaziulusoy's (2010) double-flow scenario method combines tools that are familiar to companies and design teams (organisational vision development, risk assessment, stakeholder analysis, explorative [foresight] scenarios, product concept generation) with other (new and established) tools that companies and design teams are likely to be less familiar with (the development of a sustainability model, societal vision development, reflecting on organisational functions within society, systems analysis, normative [backcasting] scenarios).

Ceschin's (2012b) handbook for the scaling up of PSSs in the context of sustainability transitions combines four clusters of established and new PSS design tools. These clusters involve tools for formalising PSS concept visions (a PSS offering diagram, a PSS value chain map, a storyboard, PSS elements and a sustainability diagram), tools for developing and formalising transition strategies (a transition path canvas, a transition path storyboard, a transition path table, socio-technical experiment design guidelines and scaling up guidelines), tools for managing the network of actors (an actor map, an actor table, a key issues and alternative options map, and a context opportunities and barriers map) and tools for monitoring and evaluating the transition process (an experiment evolution framework and a scaling-up evaluation framework).

Joore and Brezet's (2015) multi-level design model (MDM) explains the relationships between PSS development and societal change processes. The MDM distinguishes four typical design phases (product design, PSS design, system design and vision development) and four typical system levels (product-technology, product-service, socio-technical and societal) on which design and innovation processes may take place. The MDM provides two functionalities: one is a cyclic and iterative design approach to link product, PSS and societal change processes, and the second is a hierarchical systems approach whereby a similar description of the design, change or transition process is applied to each aggregation level.

The mid-range transition pathway creation toolset (MTPT) of Hyysalo et al. $(2018,2019)$ introduced insights from collaborative design research to transition arena processes and tools. The MTPT equips diverse groups of front-runner actors with the means to 
envision and collaboratively construct pathways for accelerated systems change in a mid-range, 10-20-year timespan. The toolset is comprised of large metallic boards and magnetic, pre-categorised elements for small-group path construction, as well as a digital platform for further refinement. The toolset has been used to further Finnish energy transitions, on both the city and the national scale, with regard to the use of water-based resources and setting biodiversity goals. With the MTPT, the participants - typically the most knowledgeable people on the domain issues - can take the main ownership of the pathway construction without going via systems analysts.

that is, being reduced to a process model and commercially exploited by 'Post-it design consultancies' as yet another tool for incremental change, rather than pushing the boundaries of mainstream sociotechnical and socio-political practices and imaginaries. Such co-option would undermine the very essence and spirit of design being involved in sustainability transition projects. Any project labelled as a DfST or transition design project which does not include a radical rethinking of institutional and organisational models, redesigning of socio-technical systems and reimagining of socio-ecological relations would result in transformative opportunities being lost.

\subsection{Future research directions}

DfST as an emergent area would benefit from further theoretical development informed by empirical research. Although there is a dearth of sustainability transitions projects which explicitly reference design theory or practice, the plethora of completed and ongoing projects provide a fertile ground for analysis of the roles and agency of design in transition projects. Design researchers should also seek opportunities to participate in transition research consortiums in order to gain a more active involvement both in fertilising these projects with design theory and practice and in utilising them as case studies in order to expand the current boundaries of DfST.

It would also be interesting to investigate how some nascent DfS approaches - for example, design for conviviality (Lizarralde \& Tyl, 2018), design for resilience (Baek et al., 2015) and design for cohabitation (Smith, Bardzell, \& Bardzell, 2017) - could be supported by 
and contribute to the theory and practice of DfST. Both the established DfS approaches presented in earlier chapters of this book and the above-mentioned emerging approaches are 'small' approaches in the sense that their focus is either systemically narrow or thematically limited. Nevertheless, the former set can assist with achieving visions at different systemic scales and the latter set, as new ways of designing, can inform visions of new systems.

The foundational theories that underlie early contributions in DfST cover complex adaptive systems theories, sustainability science, system innovations and transitions theories, social practice theory and environmental ethics. These are essential theories for informing the future of design practice and they can play a role in sustainability transitions. Nevertheless, this emerging field can and should also learn from other theories that are currently informing design and penetrating its zone of comfort. For example, design in general should shake off the dominance of human-centredness in theory and practice as it is a necessary but too anthropocentric foundation to lead design practice into the future on its own. DfST should develop ways to give voice to the voiceless, both in its epistemology and methodology, as the essential aim should be to create just futures as well as sustainable ones. For this purpose, DfS in general and DfST specifically can learn from feminist theory, animal studies, degrowth studies, post-humanist ethnography, political ecology and the literature on the decolonising methodology. Some of this literature has been integrated into design in recent years though pioneering contributions (see, e.g., Avila, 2017; Forlano, 2016; Galloway, 2016; Garduño García, 2017; Gaziulusoy \& Houtbeckers, 2018; Jönsson \& Lenskjold, 2014; Keinonen, 2017; Schalk, Kristiansson, \& Mazé, 2017; Tlostanova, 2017; Veselova \& Gaziulusoy, 2019). There is an urgency to further explore the implications of this literature in design, and derive insights and lessons for the development of DfST theory and practice. However, this endeavour should not be one-sided; it is necessary that this array of design scholarship should become aware of the relevance of their research (and practice) with regard to sustainability transitions. For example, a recent systematic review on transition intermediaries found that many intermediary actors who play important roles in transition processes (who often operate at the interface of the niche and regime levels) are unaware of their intermediation (Kivimaa, Boon, Hyysalo, \& Klerkx, 2019). It is therefore possible that there are more interconnections between design research and practice and sustainability transitions than are visible to the eye. This calls for design 
researchers to begin framing their work with references to transitions literature and practice.

\section{References}

Avila, M. (2017). Ecologizing, decolonizing: An artefactual perspective. Paper presented at the NORDES 2017 Conference: Design + Power, Oslo, Norway, 15-17 June.

Baek, J. S., Meroni, A., \& Manzini, E. (2015). A socio-technical approach to design for community resilience: A framework for analysis and design goal forming. Design Studies, 40, 60-84. doi:10.1016/j.destud.2015.06.004

Bettencourt, L., \& West, G. (2010). A unified theory of urban living. Nature, 467(7318), 912-913.

Boehnert, J. (2008). Design and transition: What designers can learn from the transition movement. Paper presented at the Changing the Change: Design Visions, Proposals and Tools conference, Turin, Italy, 10-12 July.

Brezet, H. (1997). Dynamics in ecodesign practice. Industry and Environment, 20(1-2), 21-24.

Buchanan, R. (1998). Branzi's dilemma: Design in contemporary culture. Design Issues, 14(1), 3-20.

Candy, S., Larsen, K., Twomey, P., McGrail, S., \& Ryan, C. (2017). Pathways 2040. Results from Visions and Pathways 2040: Scenarios and pathways to low carbon living. Melbourne, Australia: Victorian Eco-innovation Lab.

Ceschin, F. (2012a). The introduction and scaling up of sustainable productservice systems: A new role for strategic design for sustainability. PhD Thesis. Politecnico di Milano, Milan, Italy.

Ceschin, F. (2012b). The introduction and scaling-up of sustainable ProductService Systems: Unpublished handbook based on the PhD Thesis The introduction and scaling up of sustainable product-service systems: A new role for strategic design for sustainability. Politecnico di Milano, Milan, Italy.

Ceschin, F. (2014a). How the design of socio-technical experiments can enable radical changes for sustainability. International Journal of Design, $8(3), 1-21$.

Ceschin, F. (2014b). Sustainable product-service systems: Between strategic design and transition studies. London, UK: Springer. doi:10.1007/ 978-3-319-03795-0.

Ceschin, F. (2015). The role of socio-technical experiments in introducing sustainable product-service system innovations. In R. Agarwal, W. Selen, G. Roos, \& R. Green (Eds.), The Handbook of Service Innovation (pp. 373-401). London, UK: Springer. doi:10.1007/978-1-4471-6590-3-18.

Cipolla, C., \& Peruccio, P. P. (Ed.). (2008). Proceedings of the Changing the Change: Design Visions, Proposals and Tools International Conference, Turin, Italy, 10-12 July.

Dewberry, E., \& Johnson, J. (2010). Design interventions, prediction and science in the sustainable transition of large, complex systems. Keynote presentation 
at the 2nd International Conference on Design Engineering and Science (ICDES2010), Tokyo, Japan, 17-19 November.

Forlano, L. (2016). Decentering the human in the design of collaborative cities. Design Issues, 32(3), 42-54. doi:10.1162/DESI_a_00398

Galloway, A. (2016). More-than-human lab: Creative ethnography after human exceptionalism. In L. Hjorth, H. Horst, A. Galloway, \& G. Bel (Eds.), The Routledge companion to digital ethnography (pp. 470-477). New York: Routledge.

Garduño García, C. (2017). Design as freedom. PhD Thesis. Aalto University, Helsinki, Finland.

Gaziulusoy, A. İ. (2010). System innovation for sustainability: A scenario method and a workshop process for product development teams. PhD Thesis. University of Auckland, Auckland, New Zealand.

Gaziulusoy, A. İ., \& Boyle, C. (2008). Addressing the problems of linking present and future and measuring sustainability in developing sustainable technologies: A proposal for a risk-based double-flow scenario methodology. Paper presented at the 7th International Symposium on Tools and Methods of Competitive Engineering, İzmir, Turkey, 21-25 April.

Gaziulusoy, A. İ., Boyle, C., \& McDowall, R. (2013). System innovation for sustainability: A systemic double-flow scenario method for companies. Journal of Cleaner Production, 45, 104-116. doi: 10.1016/j.jclepro.2012.05.013

Gaziulusoy, A. İ., \& Brezet, H. (2015). Design for system innovations and transitions: A conceptual framework integrating insights from sustainability science and theories of system innovations and transitions. Journal of Cleaner Production, 108, 558-568. doi:10.1016/j.jclepro.2015.06.066

Gaziulusoy, A. İ., \& Houtbeckers, E. (2018). Convergences: Design for sustainability transitions and degrowth. Paper presented at the 6th International Degrowth Conference, Malmö, Sweden, 21-25 August.

Gaziulusoy, A. İ., \& Ryan, C. (2017a). Roles of design in sustainability transitions projects: A case study of Visions and Pathways 2040 project from Australia. Journal of Cleaner Production, 162, 1297-1307. doi:10.1016/ j.jclepro.2017.06.122

Gaziulusoy, A. İ., \& Ryan, C. (2017b). Shifting conversations for sustainability transitions using participatory design visioning. The Design Journal, 20(sup1), S1916-S1926. doi:10.1080/14606925.2017.1352709

Geels, F. W. (2005a). Processes and patterns in transitions and system innovations: Refining the co-evolutionary multi-level perspective. Technological Forecasting and Social Change, 72(6), 681-696.

Geels, F. W. (2005b). Technological transitions and system innovations: A coevolutionary and socio-technical analysis. Cheltenham, UK: Edward Elgar Publishing.

Geels, F. W., \& Schot, J. (2007). Typology of sociotechnical transition pathways. Research Policy, 36(3), 399-417.

Green, K., \& Vergragt, P. (2002). Towards sustainable households: A methodology for developing sustainable technological and social innovations. Futures, 34(5), 381-400. 
Heiskanen, E., Hyysalo, S., Jalas, M., Juntunen, J. K., \& Lovio, R. (2014). User involvement and radical innovation: The case of heat pumps in Finland. In S. Juninger \& P. Christensen (Eds.), Highways and byways of radical innovation: The perspective of design. Kolding, Denmark: Kolding Design School.

Hoogma, R., Kemp, R., Schot, J., \& Truffer, B. (2002). Experimenting for sustainable transport: The approach of strategic niche management. London, UK: Routledge.

Hyysalo, S., Johnson, M., \& Juntunen, J. K. (2017). The diffusion of consumer innovation in sustainable energy technologies. Journal of Cleaner Production, 162(Supplement), S70-S82. doi:10.1016/j.jclepro.2016.09.045

Hyysalo, S., Lukkarinen, J., Kivimaa, P., Lovio, R., Temmes, A., Hildén, M., ... Pantsar, M. (2019). Developing policy pathways: Redesigning transition arenas for mid-range planning. Sustainability, 11(3). doi:10.3390/su11030603

Hyysalo, S., Perikangas, S., Marttila, T., \& Auvinen, K. (2018). Catalysing pathway creation for transition governance. Paper presented at the Design Research Society 2018, Limerick, Ireland, 25-28 June.

Irwin, T. (2015b). Redesigning a design program: How Carnegie Mellon University is developing a design curricula for the 21 st century. Solutions, , 6(1), 91-100.

Irwin, T. (2015a). Transition design: A proposal for a new area of design practice, study, and research. Design and Culture, 7(2), 229-246. doi:10.1080/ 17547075.2015.1051829

Jégou, F. (2011). Social innovations and regional acupuncture towards sustainability. Chinese Journal of Design, 214, 56-61.

Joore, P. (2010). New to improve: The mutual influence between new products and societal change processes. PhD Thesis, Technical University of Delft, Delft, the Netherlands.

Joore, P., \& Brezet, H. (2015). A multilevel design model: The mutual relationship between product-service system development and societal change processes. Journal of Cleaner Production, 97, 92-105.

Jönsson, L., \& Lenskjold, T. U. (2014). A foray into not-quite companion species: Design experiments with urban-animals as significant others. Artifact, 3(2), 1-7.

Keinonen, T. (2017). Designers, users and justice. London, UK: Bloomsbury Academic.

Kemp, R. (1994). Technology and the transition to environmental sustainability: The problem of technological regime shifts. Futures, 26(10), 1023-1046.

Kemp, R., Rip, A., \& Schot, J. (2001). Constructing transition paths through the management of niches. In R. Garud \& P. Karnøe (Eds.), Path dependence and creation (pp. 269-299). Mahwah, NJ: Lawrence Erlbaum Associates.

Kemp, R., Schot, J., \& Hoogma, R. (1998). Regime shifts to sustainability through processes of niche formation: The approach of strategic niche management. Technology analysis and strategic management, 10(2), 175-195. 
Kivimaa, P., Boon, W., Hyysalo, S., \& Klerkx, L. (2019). Towards a typology of intermediaries in sustainability transitions: A systematic review and a research agenda. Research Policy, 48(4), 1062-1075. doi:10.1016/ j.respol.2018.10.006

Kossoff, G. (2011). Holism and the reconstitution of everyday life: A framework for transition to a sustainable society. PhD Thesis, University of Dundee, Dundee, UK.

Lizarralde, I., \& Tyl, B. (2018). A framework for the integration of the conviviality concept in the design process. Journal of Cleaner Production, 17661777. doi:10.1016/j.jclepro.2017.03.108

Loorbach, D. (2010). Transition management for sustainable development: A prescriptive, complexity-based governance framework. Governance, 23(1), 161-183.

Manzini, E. (2015). Design, when everybody designs: An introduction to social innovation. Cambridge, MA: MIT Press.

Manzini, E., \& Rizzo, F. (2011). Small projects/large changes: Participatory design as an open participated process. CoDesign, 7(3-4), 199-215. doi:10.1080/15710882.2011.630472

Marshall, S. (2012). Planning, design and the complexity of cities. In J. Portugali, H. Meyer, E. Stolk, \& E. Tan (Eds.), Complexity theories of cities have come of age: An overview with implications to urban planning and design (pp. 191206). Berlin, Germany: Springer.

Meroni, A. (Ed.). (2007). Creative communities: People inventing sustainable ways of living. Milan, Italy: Edizioni Polidesign.

Meroni, A. (2008). Strategic design to take care of the territory: Networking creative communities to link people and places in a scenario of sustainable development. Keynote presentation at the $8^{\circ}$ Congresso Brasileiro de Pesquisa e Desenvolvimento em Design, São Paulo, Brazil, 8-11 October.

Portugali, J. (2012). Complexity theories of cities: Implications to urban planning. In J. Portugali, H. Meyer, E. Stolk, \& E. Tan (Eds.), Complexity theories of cities have come of age: An overview with implications to urban planning and design (pp. 221-244). Berlin, Germany: Springer.

Quist, J., \& Vergragt, P. (2006). Past and future of backcasting: The shift to stakeholder participation and a proposal for a methodological framework. Futures, 38(9), 1027-1045.

Rip, A., Misa, T. J., \& Schot, J. (Eds.). (1995). Managing technology in society: The approach of constructive technology assessment. London, UK: Thomson Learning.

Rotmans, J., Kemp, R., \& van Asselt, M. (2001). More evolution than revolution: Transition management in public policy. Foresight, 3(1), 15-31.

Ryan, C. (2008). The Melbourne 2032 Project: Design visions as a mechanism for (sustainable) paradigm change. Paper presented at the Changing the Change: Design Visions, Proposals and Tools conference, Turin, Italy, 10-12 July. 
Ryan, C. (2013a). Critical agendas: Designing for sustainability from products and systems. In S. Walker, \& J. Giard (Eds.), The Handbook of Design for Sustainability. London, UK: Bloomsbury.

Ryan, C. (2013b). Eco-acupuncture: Designing and facilitating pathways for urban transformation, for a resilient low-carbon future. Journal of Cleaner Production, 50, 189-199.

Ryan, C., Gaziulusoy, İ., McCormick, K., \& Trudgeon, M. (2016a). virtual city experimentation: A critical role for design visioning. In J. Evans, A. Karvonen, \& R. Raven (Eds.), The Experimental City. London, UK: Routledge.

Ryan, C. J., Hosken, M., \& Greene, D. (1992). EcoDesign: Design and the response to the greening of the international market. Design Studies, 13(1), 3-22. doi:10.1016/0142-694X(92)80002-G

Ryan, C., Twomey, P., Gaziulusoy, A. İ., McGrail, S., \& Chandler, P. (2016b). Scenarios 2040: Results from the second year of Visions and Pathways 2040: Scenarios of low carbon living. Melbourne, Australia: Victorian Eco-innovation Lab.

Schalk, M., Kristiansson, T., \& Mazé, R. (2017). Feminist futures of spatial practice: Materialism, activism, dialogues, pedagogies, projections. Baunach, Germany: Spurbuchverlag.

Smith, N., Bardzell, S., \& Bardzell, J. (2017). Designing for cohabitation: Naturecultures, hybrids, and decentering the human in design. Paper presented at the 2017 CHI Conference on Human Factors in Computing Systems, Denver, CO, 6-11 May.

Tlostanova, M. (2017). On decolonizing design. Design Philosophy Papers, 15(1), 51-61. doi:10.1080/14487136.2017.1301017

Van Driel, H., \& Schot, J. (2005). Radical innovation as a multilevel process: Introducing floating grain elevators in the Port of Rotterdam. Technology and Culture, 46(1), 51-76.

Vergragt, P. J., \& van Grootveld, G. (1994). Sustainable technology development in the Netherlands: The first phase of the Dutch STD program. Journal of Cleaner Production, 2(3/4), 133-139.

Veselova, E., \& Gaziulusoy, A. İ. (2019). Implications of the bioinclusive ethic on collaborative and participatory design. Paper presented at the 13th European Academy of Design Conference, Dundee, UK, 10-12 April.

Vezzoli, C., Ceschin, F., \& Kemp, R. (2008). Designing transition paths for the diffusion of sustainable system innovations: A new potential role for design in transition management? Paper presented at the Changing the Change: Design Visions, Proposals and Tools conference, Turin, Italy, 10-12 July.

Weaver, P., Jansen, L., van Grootveld, G., van Spiegel, E., \& Vergragt, P. (2000). Sustainable Technology Development. Sheffield, UK: Greenleaf Publishing. 


\section{Reflections on the past, present and future of design for sustainability}

\subsection{A framework to capture DfS approaches}

In Chapters 2-11 we provided an analysis of the main design for sustainability (DfS) approaches (see Table 12.1 for an overview). In this chapter we organise and categorise these approaches and put forward a unified innovation framework that is capable of coherently integrating them and synthesising the DfS field and its evolution.

In a recent review of sustainability-oriented innovations, Adams, Jeanrenaud, Bessant, Denyer and Overy (2016) showed that these innovations have evolved from a narrow technical and product-centric focus towards a focus on system-level changes. They also identified two important dimensions that characterise this evolution:

- The technology/people dimension: the evolution from a technically focused and incremental view of innovation towards innovations in which sustainability is seen as a socio-technical challenge wherein user practices and behaviour play a fundamental role.

- The insular/systemic dimension: the evolution from innovations which address the firm's internal issues towards a focus on making changes to the wider socio-economic systems that lie beyond the firm's immediate stakeholders and boundaries.

Drawing on these dimensions, Adams et al. (2016) proposed an initial framework with which to demonstrate how the field of sustainabilityoriented innovations has evolved. Our understanding of the DfS field shows alignment with the findings of Adams et al. (2016), as we have also observed a shift towards the adoption of systemic approaches as 
Table 12.1 An overview of the DfS approaches in chronological order of their development

\begin{tabular}{|c|c|c|c|}
\hline DfS approach & Focus & $\begin{array}{l}\text { The innovation } \\
\text { level }(s) \text { addressed }\end{array}$ & $\begin{array}{l}\text { Initial research } \\
\text { contributions }\end{array}$ \\
\hline $\begin{array}{l}\text { Green design } \\
\text { (Chapter } 2)\end{array}$ & $\begin{array}{l}\text { Lowering environmental } \\
\text { impact through } \\
\text { redesigning individual } \\
\text { qualities/aspects of } \\
\text { products }\end{array}$ & $\begin{array}{l}\text { - The material/ } \\
\text { component level }\end{array}$ & $\begin{array}{l}\text { The first half } \\
\text { of the } \\
1990 \mathrm{~s}\end{array}$ \\
\hline $\begin{array}{l}\text { Product } \\
\text { ecodesign } \\
(\text { Chapter } 2)\end{array}$ & $\begin{array}{l}\text { Lowering the } \\
\text { environmental impact } \\
\text { of products by focusing } \\
\text { on the whole life cycle, } \\
\text { from the extraction of } \\
\text { raw materials to final } \\
\text { disposal }\end{array}$ & - The product level & $\begin{array}{l}\text { The second } \\
\text { half of the } \\
\text { 1990s }\end{array}$ \\
\hline $\begin{array}{l}\text { Biomimicry } \\
\text { (BM) } \\
\text { (Chapter 6) }\end{array}$ & $\begin{array}{l}\text { Mimicking the models } \\
\text { and processes of } \\
\text { nature to tackle design } \\
\text { challenges }\end{array}$ & $\begin{array}{l}\text { - The material/ } \\
\text { component level } \\
\text { - The product level }\end{array}$ & $\begin{array}{l}\text { The second } \\
\text { half of the } \\
\text { 1990s }\end{array}$ \\
\hline $\begin{array}{l}\text { Cradle-to-cradle } \\
\text { (CTC) design } \\
\text { (Chapter 5) }\end{array}$ & $\begin{array}{l}\text { Creating regenerative } \\
\text { systems characterised } \\
\text { by closed loops of } \\
\text { technical 'nutrients' and } \\
\text { open loops of biological } \\
\text { 'nutrients' }\end{array}$ & $\begin{array}{l}\text { - The material/ } \\
\text { component } \\
\text { level } \\
\text { - The product level } \\
\text { - The product- } \\
\text { service system } \\
\text { (PSS) level }\end{array}$ & $\begin{array}{l}\text { The first half } \\
\text { of the } \\
2000 \text { s }\end{array}$ \\
\hline $\begin{array}{l}\text { Product-service } \\
\text { system } \\
\text { (PSS) design } \\
\text { (Chapter 7) }\end{array}$ & $\begin{array}{l}\text { PSS design for eco- } \\
\text { efficiency: Designing } \\
\text { product-service offers } \\
\text { and business models } \\
\text { where providers are } \\
\text { economically pushed to } \\
\text { optimise/reduce resource } \\
\text { consumption. } \\
\text { PSS design for } \\
\text { sustainability: As } \\
\text { above, but also } \\
\text { integrating socio-ethical } \\
\text { aspects. }\end{array}$ & $\begin{array}{l}\text { - The PSS level } \\
\text { - The spatio-social } \\
\text { level }\end{array}$ & $\begin{array}{l}\text { The first half } \\
\text { of the } \\
2000 \text { s }\end{array}$ \\
\hline $\begin{array}{l}\text { Emotionally } \\
\text { durable } \\
\text { design (EDD) } \\
\text { (Chapter 3) }\end{array}$ & $\begin{array}{l}\text { Strengthening and } \\
\text { extending over time the } \\
\text { emotional attachment } \\
\text { between the user and the } \\
\text { product }\end{array}$ & $\begin{array}{l}\text { - The material/ } \\
\text { component level } \\
\text { - The product level }\end{array}$ & $\begin{array}{l}\text { The second } \\
\text { half of the } \\
2000 \text { s }\end{array}$ \\
\hline
\end{tabular}




\begin{tabular}{|c|c|c|c|}
\hline DfS approach & Focus & $\begin{array}{l}\text { The innovation } \\
\text { level }(s) \text { addressed }\end{array}$ & $\begin{array}{l}\text { Initial research } \\
\text { contributions }\end{array}$ \\
\hline $\begin{array}{l}\text { Design for } \\
\text { sustainable } \\
\text { behaviour } \\
\text { (DfSB) } \\
\text { (Chapter 4) }\end{array}$ & $\begin{array}{l}\text { Making people } \\
\text { adopt a desired } \\
\text { sustainable behaviour } \\
\text { and abandon an } \\
\text { unwanted, unsustainable } \\
\text { behaviour }\end{array}$ & $\begin{array}{l}\text { - The product } \\
\text { level } \\
\text { - The PSS level } \\
\text { - The spatio-social } \\
\text { level }\end{array}$ & $\begin{array}{l}\text { The second } \\
\text { half of the } \\
2000 \text { s }\end{array}$ \\
\hline $\begin{array}{l}\text { Design for the } \\
\text { base of the } \\
\text { pyramid } \\
\text { (DfBoP) } \\
\text { (Chapter 8) }\end{array}$ & $\begin{array}{l}\text { Developing solutions } \\
\text { with which to address } \\
\text { the needs of low-income } \\
\text { people }\end{array}$ & $\begin{array}{l}\text { - The product } \\
\text { level } \\
\text { - The PSS level } \\
\text { - The spatio-social } \\
\text { level }\end{array}$ & $\begin{array}{l}\text { The second } \\
\text { half of the } \\
2000 \text { s }\end{array}$ \\
\hline $\begin{array}{l}\text { Design for social } \\
\text { innovation } \\
\text { (DfSI) } \\
\text { (Chapter 9) }\end{array}$ & $\begin{array}{l}\text { Assisting with the } \\
\text { conception, } \\
\text { development, } \\
\text { promotion and } \\
\text { scaling up of social } \\
\text { innovations }\end{array}$ & $\begin{array}{l}\text { - The PSS level } \\
\text { - The spatio-social } \\
\text { level }\end{array}$ & $\begin{array}{l}\text { The second } \\
\text { half of the } \\
2000 \text { s }\end{array}$ \\
\hline $\begin{array}{l}\text { Systemic design } \\
\text { (SD) } \\
(\text { Chapter 10) }\end{array}$ & $\begin{array}{l}\text { Designing locally } \\
\text { based productive } \\
\text { systems in which } \\
\text { waste from one } \\
\text { productive process } \\
\text { becomes an input to } \\
\text { other processes }\end{array}$ & $\begin{array}{l}\text { - The } \\
\text { spatio-social level } \\
\text { - The socio- } \\
\text { technical system } \\
\text { level }\end{array}$ & $\begin{array}{l}\text { The second } \\
\text { half of the } \\
2000 \text { s }\end{array}$ \\
\hline $\begin{array}{l}\text { Design for } \\
\text { sustainability } \\
\text { transitions } \\
\text { (DfST) } \\
\text { (Chapter 11) }\end{array}$ & $\begin{array}{l}\text { Transforming socio- } \\
\text { technical systems } \\
\text { through (strategic) } \\
\text { design }\end{array}$ & $\begin{array}{l}\text { The socio- } \\
\text { technical system } \\
\text { level }\end{array}$ & $\begin{array}{l}\text { The first half } \\
\text { of the } \\
2010 \text { s }\end{array}$ \\
\hline
\end{tabular}


well as an increased focus on the social aspects of sustainability. Due to this alignment between their findings and our own, we took inspiration from their analysis model and developed an adaptation of that framework (Ceschin \& Gaziulusoy, 2016) which then evolved into the framework we present here (see Figure 12.1).

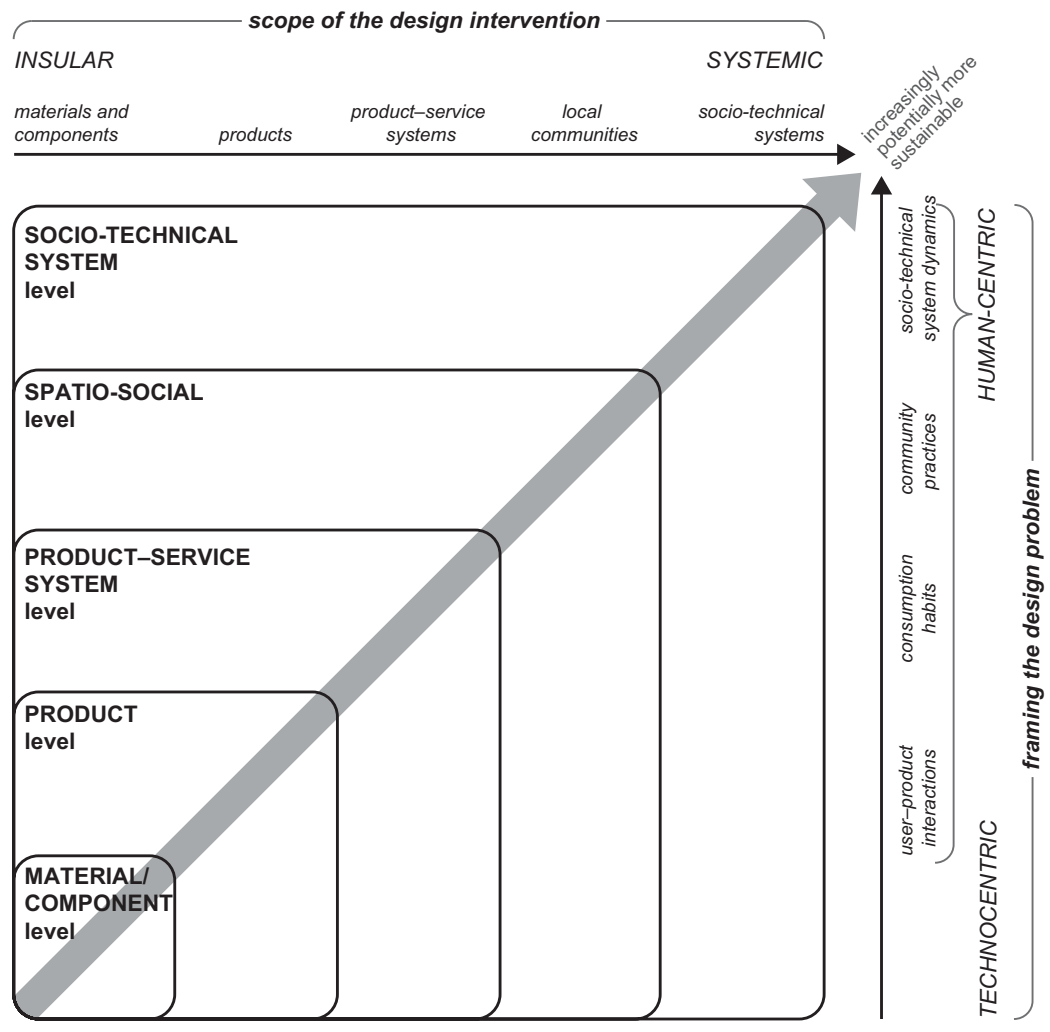

Figure 12.1 The DfS innovation framework

Our framework is characterised by three key elements.

\subsubsection{Five innovation levels}

The first characterising element of our framework is that it distinguishes five innovation levels, showing the different scales on which a design intervention can focus: 
- The materiallcomponent innovation level. This includes design interventions aimed at incrementally improving products by developing new materials, replacing materials and (more generally) improving the individual qualities of a product.

- The product innovation level. Here the focus is on improving existing products or developing new products by considering the whole product life cycle, from material extraction to disposal.

- $\quad$ The product-service system innovation level. Here the focus goes beyond individual products towards integrated combinations of products, services, stakeholder value chains and business models.

- The spatio-social innovation level. Here the context of innovation is human settlements and the spatio-social conditions of their communities; this can be addressed on different scales, ranging from neighbourhoods to cities.

- The socio-technical system innovation level. This encompasses design interventions which focus on promoting radical changes in how societal needs (such as nutrition and mobility) are fulfilled and thus focus on supporting transitions to new socio-technical systems.

The innovation levels are visualised through a series of concentric squares in order to make it explicit that narrower innovation levels are embedded within the wider ones.

\subsubsection{The 'scope of the design intervention' axis}

The second characterising element is the horizontal axis. This ranges from insular to systemic interventions and, similarly to the five innovation levels, visualises how the design scope can range from materials to socio-technical systems.

\subsubsection{The 'framing the design problem' axis}

The third characterising element is the vertical axis. This axis represents how a certain DfS problem is addressed. It ranges from technocentric to human-centric framing. While the former refers to design interventions which predominantly see sustainability problems as a technical challenge (e.g. improving energy efficiency and developing new materials), the latter tackles sustainability by predominantly focusing on human-related aspects. Here we can distinguish the different scales at which we can 
address sustainability through a human-centric intervention: (1) we can focus on the interaction between the user and a product, (2) we can look at the consumption habits that characterise individuals or groups, (3) we can look at the dynamics of individuals and groups of people within a certain community or different communities and (4) we can focus on complex dynamics in socio-technical systems, looking at the interrelated activities and behaviours of a range of socio-economic actors (ranging from citizens to businesses, governmental organisations and NGOs). This sequence of human-centric interventions is characterised by a progression from a narrow focus to a broad focus and from an individual focus to a collective focus.

It is important to note that the progression from one innovation level to another, as well as the progression through the different elements within each axis, should be seen as a continuum. For example, if we look at the vertical axis, there is no exact boundary between the technocentric framing and human-centric framing: the change from a technocentric to human-centric framing takes place gradually without clear dividing points.

The positioning of the DfS approaches in the framework takes into consideration the five innovation levels and the two axes. Each approach has been mapped following these steps (see Figure 12.2):

1. The approach is positioned along the horizontal axis. This process involves defining an interval on that axis. In fact, a DfS approach can be characterised by a varying design scope. For example, design for sustainable behaviour (DfSB) can be applied to support interventions on the product, product-service system (PSS) and spatio-social innovation levels. For this reason, using intervals is more accurate than using single points.

2. The same process is then repeated on the vertical axis. Even in this case, an interval is identified on the axis.

3. The results of the two positioning exercises are then combined in the framework by drawing an area corresponding to the intersection between the insular/systemic and technocentric/human-centric intervals for each approach. 


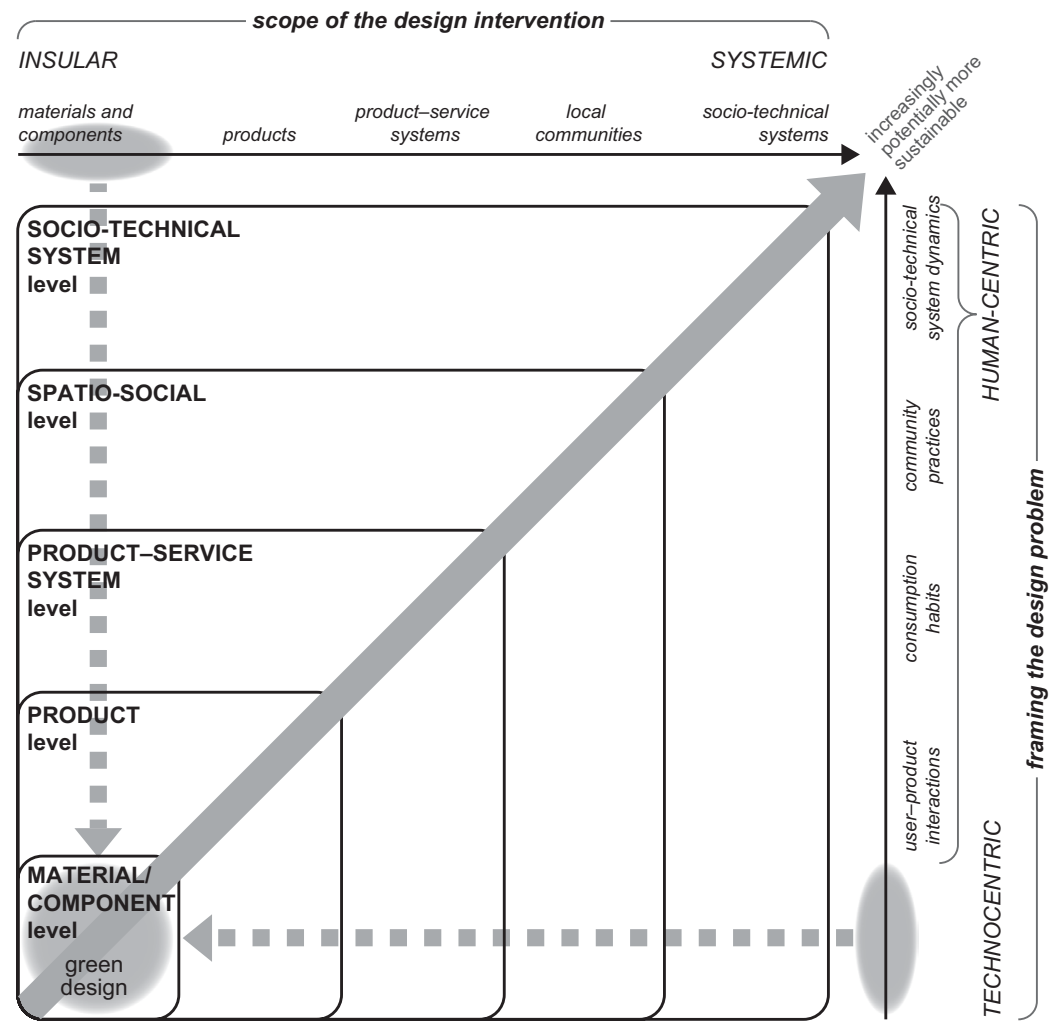

Figure 12.2 The process of positioning design approaches in the framework (with the green design approach used as an example)

The resulting framework is illustrated in Figure 12.3. It is important to highlight that this is a qualitative mapping, which might be dependent on interpretations and a certain degree of subjectivity. However, the crucial aspect of this framework is that it allows us to roughly map DfS approaches and visualise their relative position. In other words, we are not much interested in the exact position of the approaches, rather on where approaches are mapped in relation to one another.

As previously explained, each DfS approach is mapped as an area. This allows us to show the overlaps of different innovation levels. In fact, a single approach can potentially span over different innovation levels, which is the case for design for sustainable behaviour, for example. In addition, using different areas allows us to visualise the relationships 
between different DfS approaches in terms of overlaps, complementarities and inclusions. In fact, an approach can share common elements with another (e.g. biomimicry and cradle-to-cradle design) or even include other approaches (as is the case with ecodesign and green design).

The resulting framework is intended to provide an understanding of the overall evolution of DfS. To our knowledge this is the first time that a framework embracing all the DfS approaches has been developed, providing a synthesis of the DfS field, as well as a picture of how the various DfS approaches contribute to particular aspects of sustainability. The framework also visualises linkages, overlaps and complementarities between the different DfS approaches. All these aspects are explored further in the following sections.

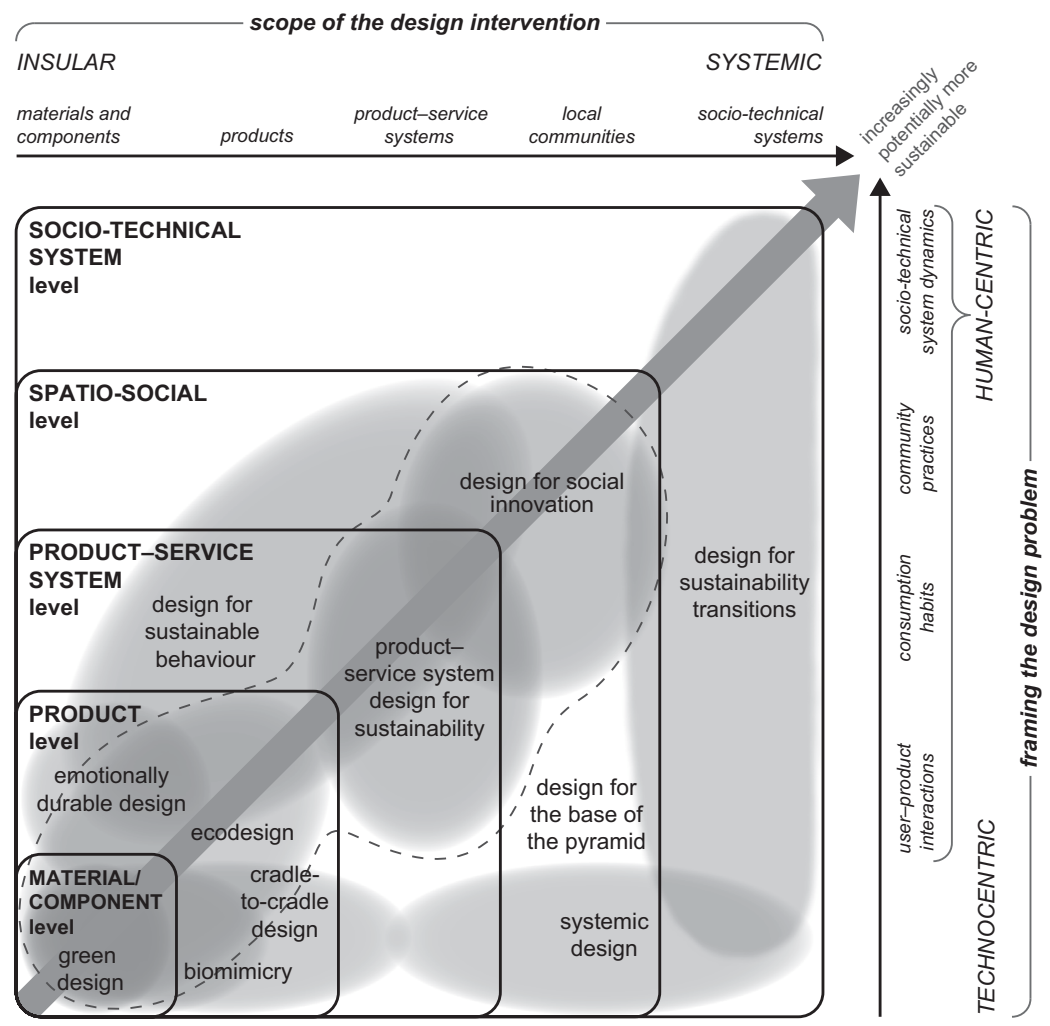

Figure 12.3 The DfS innovation framework with the DfS approaches mapped onto it 


\subsection{How did DfS evolve?}

In order to better understand the evolution of DfS approaches, it is useful to apply a colour code to the approaches mapped in the framework. In particular, we can apply different colour intensities: the more intense the colour, the more recently developed the approach is. The result is shown in Figure 12.4. The figure clearly shows that, in the last few decades, the DfS field has broadened its theoretical and practical scope, gradually expanding its focus from the individual elements of products to product life cycles, PSSs and, finally, on socio-technical system innovations. Let us go into more detail about this evolution.

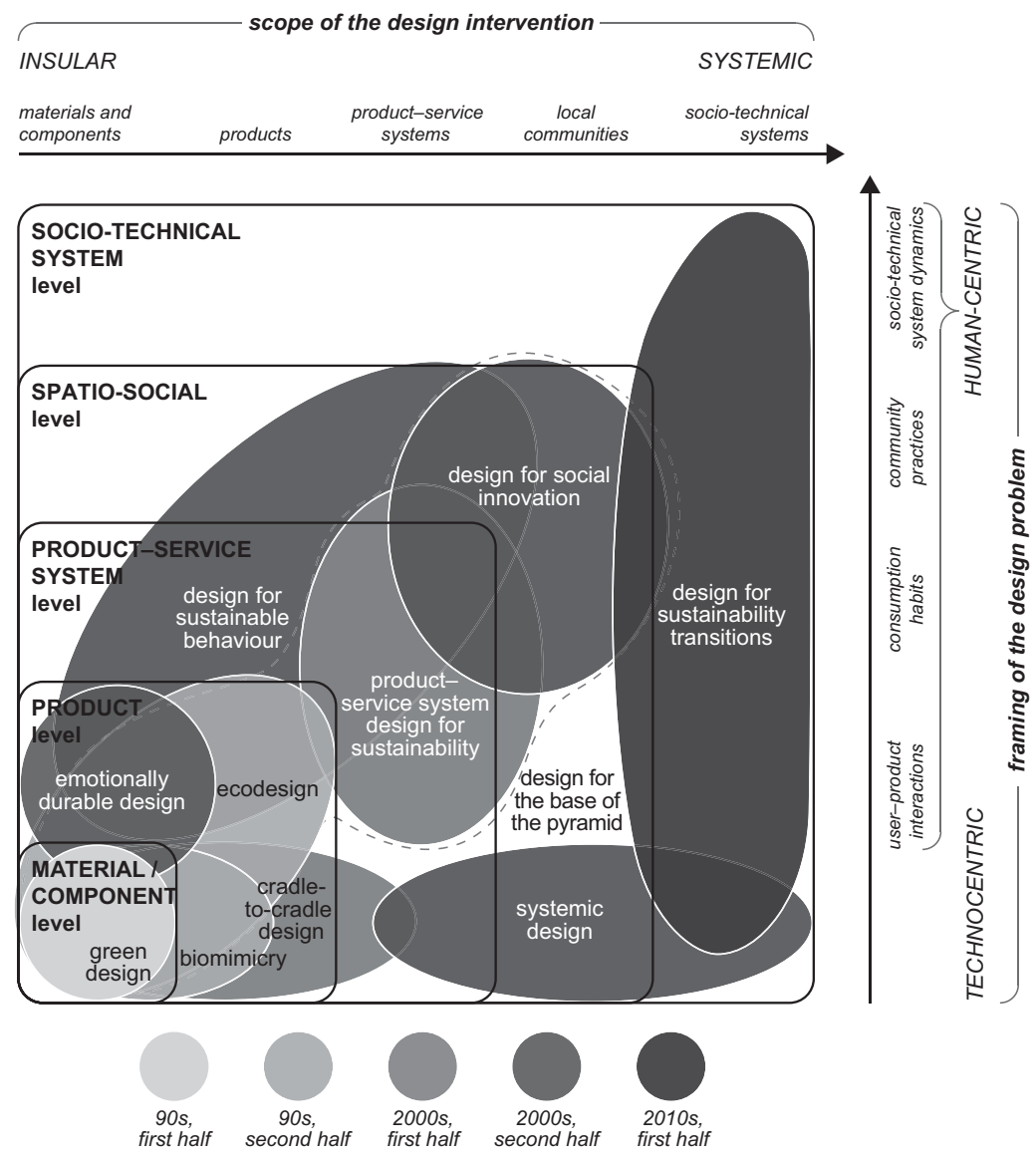

Figure 12.4 The evolution of the DfS field 
Early attempts to integrate environmental requirements into design go under the label of green design. In the first half of the 1990s, the emphasis was on improving the individual qualities of individual products. In other words, the design scope was essentially limited to the materials and components of a product. In the second half of the 1990s, recognising the limitations of green design, the focus broadened to address the entire life cycle of products, ranging from the extraction of resources to end-of-life. This is usually referred to as product ecodesign, and it represents an evolution of green design. Its main advantage over green design is that it systematically tackles all the technical aspects of a product life cycle. Product ecodesign is now considered to be a very consolidated approach in terms of both theoretical knowledge and practical know-how.

The late 1990s also saw design researchers begin to look at nature as a source of inspiration in order to address the environmental sustainability challenges of products. This generated two design approaches. The first one is known as cradle-to-cradle (CTC) design, and it places emphasis on designing products and systems whose resource flows are characterised by open loops of 'biological nutrients' and closed loops of 'technical nutrients'. The second one is biomimicry (BM), which is characterised by using nature as a model and inspiration for solving design challenges.

Even if product ecodesign is a solid approach for supporting the design of the whole product life cycle, this is mainly done from a technical perspective with limited attention to the human-related aspects. It is due to this limitation that design researchers in the second half of the 2000s began to explore design approaches that were capable of complementing product ecodesign, in particular emotionally durable design (EDD), which aims to strengthen and extend over time the emotional bond between the product and the user, and design for sustainable behaviour (DfSB), which focuses on influencing users to adopt desired sustainable behaviours and abandon undesired unsustainable behaviours. The work around DfSB was initially carried out with a focus on products and then expanded towards PSSs and social innovations.

With the realisation that the sustainability challenge cannot be met by improving products alone, the first half of the 2000s saw design researchers broadening the design focus to extend it from products to PSSs, looking at integrated solutions that combined products, services, business models and value chains. In the second half of the 2000s, this was coupled with an approach labelled systemic design (SD), which adopts a territorial perspective and seeks to develop locally based industrial systems wherein material and energy flows are designed so 
that the outputs from a socio-economic actor become the inputs for another actor.

In the second half of the 2000s, some design researchers began adopting a bottom-up approach and explored how communities conceive and implement solutions to address their daily needs. Researchers in this area, labelled design for social innovation (DfSI), have mainly focused on exploring the role that (professional) design can play in supporting, promoting and scaling up these community-based innovations.

The second half of the 2000s also saw some design researchers beginning to address the social aspects of sustainability. In particular, design for the base of the pyramid (DfBoP) has focused on understanding how design can address the social and environmental challenges faced by people in low- and middle-income contexts. Initially focusing on product design, its focus has gradually expanded to PSSs and social innovations.

More recently, understanding that the sustainability challenge requires the reconfiguration of our socio-technical systems, a handful of design researchers have begun (mainly from the beginning of the 2010s) to explore the role of design in supporting transitions towards sustainable socio-technical systems. This area, known as design for sustainability transitions (DfST), has drastically broadened the design scope and the complexity of design interventions. It is the least consolidated area and, as such, is gaining increased research attention.

Overall, we can identify three main characterising aspects of DfS's evolution:

- a widening of the design scope, from insular to systemic design;

- a shift from technocentric design to human-centric design;

- an expansion of the sustainability focus.

\subsubsection{From insular design to systemic design}

The first clear direction of the evolution of DfS relates to the scope of design interventions and, in particular, to its enlargement. In fact, we observe a progression from insular innovations to systemic innovations or, in other words, from incremental innovations to radical innovations. This widening of the design scope is directly linked to the understanding that sustainability cannot be achieved by intervening only at a product innovation level. This understanding pushed design researchers, around the late 1990s, to explore other ways through which design could contribute to sustainability, leading to discussions around the role of design in relation to PSSs and social innovations. More recently, the acceptance 
that sustainability requires changes at a socio-technical system level has triggered academic debate around investigating the potential of design to contribute to system innovations and socio-technical transitions.

This expansion in the scope of design interventions clearly goes hand in hand, with the object of design becoming increasingly more complex. If, in the beginning, design had to deal with the individual elements of a product (green design) and with individual products (see the approaches at the product innovation level), the scope has then gradually expanded to encompass designing combinations of products, services and business models. On the socio-technical system innovation level, complexity is even higher considering that in this case we are dealing with innovations which combine interlinked sets of products, technologies, PSSs and social innovations.

This increasing complexity requires the innovation team to be equipped with a greater amount of knowledge and competencies in a wide range of areas (see Section 12.5). In this sense, it is clear that the more we move towards systemic innovations, the more interdisciplinary innovation teams need to be. This means that designers can only operate individually at the lower innovation levels (and even then, not in all cases), while from the PSS innovation level upwards they must operate in synergy with experts from various disciplines.

Another observation that can be made about the increasing complexity is that this is also aligned with the number and type of societal stakeholders who need to be involved in the process. We can in fact note that the initial DfS approaches focused on sustainability problems in isolation (e.g. improving recyclability, improving product energy efficiency in use), the solutions to which can be developed and implemented by an individual actor (e.g. a firm). On the other hand, the complexity of PSS innovations requires, in terms of design and implementation, a stakeholder network made up of a variety of societal actors that may include manufacturers, service providers and public organisations. The same can be said for social innovations, for example, which might require forming collaborative partnerships with a variety of community and political stakeholders. Changes at the socio-technical system level require, as mentioned before, an interlinked set of innovations and therefore an interwoven variety of societal actors which include users, policymakers, local administrations, NGOs and other advocacy groups, consumer groups, industrial associations and research centres. In other words, the management of those innovations placed at the upper end of the framework is not in the hands of individual designers or companies. Rather, it requires multiple disciplines and a collaborative effort from a variety of societal actors. 


\subsubsection{From technocentric design to human-centric design}

The second characterising feature of the evolution of DfS is that there has been a shift from a technocentric design approach to a humancentric design approach. If we look at some of the first-developed DfS approaches (in particular green design, ecodesign, BM and CTC design), it is fair to say that they mainly tackle sustainability by focusing on the technical aspects of problems. In fact, they aim to improve material and energy efficiency by intervening in aspects related to materials (e.g. by increasing recyclability), manufacturing (e.g. by reducing energy consumption and material waste), distribution (e.g. by optimising transportation volumes), use (e.g. by reducing energy consumption, extending product longevity) and disposal (e.g. by facilitating disassembly and developing biodegradable materials). SD is another approach which mainly sees sustainability as a technical challenge and looks to create locally based productive systems wherein the waste from one socioeconomic actor becomes a resource for another actor.

On the other hand, the following approaches have begun to recognise the importance of human-related aspects. EDD addresses sustainability by focusing on the relationship and interactions between the product and the user in an attempt to increase the emotional connection. DfSB seeks to influence human behaviour and habits by intervening in physical and digital artefacts or policies. PSS design, with its focus on moving towards consumption based on access and sharing, is mainly concerned with changing individual consumption habits and collective consumption patterns. DfSI is also concerned with these aspects, but the focus is different. In fact, it looks mainly at consumption habits within communities and specific contexts (e.g. neighbourhoods) and the resilience of these communities, as well as looking at the internal dynamics linked to designing, developing and implementing solutions. DfST, with its focus on the complex dynamics in socio-technical systems, considers a wide range of individual and community behaviours, practices and consumption habits, as well as looking at the interrelated practices of a range of socio-economic actors (from businesses to governmental organisations and NGOs). In addition, it also places emphasis on the dynamics (between all these stakeholders) involved in the process of planning and managing these transitions.

It must be noted that the human-centric focus has gradually expanded, resulting in increased complexity in terms of both the scope and the stakeholders involved: it has expanded from looking at individual users and their interactions with products to looking at the 
interwoven practices, behaviours and dynamics of a range of socioeconomic actors.

\subsubsection{From a narrow sustainability focus to a broader sustainability focus}

Finally, the third characteristic of the DfS evolution is the broadening of the sustainability focus. In fact, if the earlier approaches (the material/ component and product levels) only deal with the environmental aspects of sustainability, the progression towards the other innovation levels has been accompanied by the inclusion of a range of socio-ethical sustainability aspects. With DfBoP, aspects such as meeting basic needs, poverty alleviation and labour conditions represent crucial elements to be considered in design interventions. PSS design has also integrated a wide range of aspects including improving labour conditions, integrating weak and marginalised people and promoting social cohesion. In addition, DfSI has also dealt with aspects relating to the democratic empowerment of citizens, as well as the valorisation of local resources and, more generally, community resilience. Despite its predominantly technical focus, SD also plays an important role in relation to community resilience through the valorisation and optimisation of local natural and human resources. Finally, DfST includes all the previously mentioned aspects, since it encompasses the approaches at the lower innovation levels.

\subsection{What are the relationships between the DfS approaches?}

The framework also offers us the opportunity to reflect on the relationships between the various DfS approaches and in particular on their overlaps and complementarities. To begin with, we can observe that some approaches are not limited to a single innovation level. Rather, they cross over various innovation levels. For example, DfSB can be applied at product, PSS and spatio-social levels and potentially even at the socio-technical system level. Similarly, PSS design is relevant to both the third and the fourth innovation levels and DfST spans the spatio-social and socio-technical system levels.

Looking at the relationships between the approaches, we must first of all acknowledge that the approaches are not mutually exclusive. In fact, they tend to overlap with one another and are usually interrelated. Let us go into more detail on this, starting from the material/component and product innovation levels. The first consideration is that there is a clear link between green design and ecodesign. In particular, the 
framework shows that the former has been completely encompassed by the latter. In fact, nowadays the term green design is no longer used in design practice as this has evolved into ecodesign.

At the product level we can also observe that some approaches share common elements. For example, both CTC design and ecodesign provide guidance in terms of material selection and end-of-life options. However, the former does this with a stronger technical focus on resource loops. In addition, BM is instrumental for both CTC design and ecodesign because it offers insights on how to address various aspects including energy and material efficiency and material recyclability.

If we consider all the approaches at the product level, we can note that, overall, they complement one another. In addition to what has been said above about CTC and BM design, ecodesign, EDD and DfSB provide a set of complementary strategies to improve products' environmental performance; in fact, while the first of these approaches looks at the product life-cycle stages and processes, the second focuses on the emotional attachment between the user and the product, and the third investigates how user behaviour can be influenced through product design.

Looking at the interlinks between the second and third innovation levels, we can see that there is a connection between ecodesign and PSS design. This is because the designing of circular business models must be coupled with an appropriate design of the products included in the offering, adopting ecodesign principles.

Moving to the third and fourth innovation levels, we can also observe that DfSI and PSS design have shared elements. Firstly, similar design methods and tools, related to the service and human-centred design fields, are adopted in both approaches. This is because most of the social innovation solutions combine physical, digital and service elements and thus can essentially be considered PSSs. In addition, we must acknowledge that PSS design can take inspiration from communitybased innovations to develop new product-service offerings (e.g. commercial vegetable box subscription services that mimic similar solutions developed at a local level by communities and farmers). More generally, aspects of the sharing economy and access-based economy can be found in both approaches.

Looking at the lower part of the framework, we can observe that CTC design overlaps with SD. In fact, they share some elements and principles since both focus on flows of resources, the closed loops of technical nutrients and the open loops of biological nutrients. However, if the former mainly applies these principles in relation to the product dimension (e.g. material selection, design for disassembly) and the 
business model dimension (e.g. product take-back services), the latter adopts a territorial approach and mainly looks at how flows of resources can be optimised considering the needs of local socio-economic actors. In addition, both of these approaches take inspiration from BM.

The DfBoP approach clearly overlaps with ecodesign, PSS design and DfSI, as it is essentially an application and adaptation of these approaches in low- and middle-income contexts.

Considering the last innovation level, DfST overlaps with PSS design, DfSI and SD. This is because DfST encompasses the other approaches at the lower levels. In fact, the development of visions for new socio-technical systems requires a combination of innovations, including new product-service offerings, new business models and new social practices. We elaborate more on this aspect in the next section.

At this point, it is also interesting to discuss the relationship between the DfS approaches and the concept of the circular economy (CE). The $\mathrm{CE}$ has been defined as 'an industrial economy that is restorative or regenerative by intention and design' (Ellen MacArthur Foundation, 2013). At the core of the concept are the so-called $3 \mathrm{R}$ principles (reduction of resources, reuse and recycling) and the realisation of a closedloop system of material flows (Geng and Doberstein, 2008) with the aim of reducing the material and energy resources that enter a production system and minimising waste (Lieder \& Rashid, 2016). In this sense, although the CE has been popularised and branded by Dame Ellen MacArthur, it can be seen as an umbrella concept that encompasses different principles which have been around for a long time (e.g. industrial ecology, BM and CTC). In relation to design, it is clear that various DfS approaches are crucial to the process of implementing CE solutions (Ceschin \& Gaziulusoy, 2016): CTC design and BM can provide support in selecting materials and designing products that foster closed-loop material flows. Ecodesign can offer a broader approach to the whole product life cycle and can enable the integration of the $3 \mathrm{R}$ principles in product design, with an emphasis on both material and energy flows. SD can be used to design products and industrial systems based on industrial ecology principles. PSS design can be instrumental in designing business models that enable and foster the CE. Finally, DfST can propose alternative forms of the CE for new socio-technical system scenarios. Overall, DfS can contribute to the CE in multiple ways, not only with regard to the technical aspects linked to material and energy flows but also with regard to aspects such as user practices and behaviour, as well as socio-technical transitions, which have so far received limited emphasis within the CE concept. 


\subsection{What synergies can be made between the DfS approaches in order to better address sustainability?}

According to our current understanding, sustainability is a challenge that must be addressed at a socio-technical system level. However, from a design perspective, this does not mean that our research and practice should be focused exclusively on DfST. This is because the DfS approaches that are placed at the lower innovation levels (i.e. those which are less systemic) are no less important than those placed at the higher levels. We can agree that the approaches at the lower level (and in particular those focusing on product innovation) are not sufficient to achieve sustainability when used in isolation. As highlighted by Ehrenfeld (2008), they only address the symptoms of the sustainability problems and are thus not able to tackle their causes. However, it would be a mistake to consider these approaches less useful. This is because the different DfS approaches are interlinked, and those at the higher innovation levels tend to depend on those at the lower levels. Let us explore this aspect in more detail.

Looking at PSS design, it is clear that solutions developed at this level require, among other things, material artefacts. As explained in Chapter 7, the potential environmental benefits of a PSS cannot be achieved if the products included in the solution are not properly designed. Depending on the type of PSS, this usually means that products should be designed for longevity (including maintainability, repairability and upgradeability), for reducing/optimising resource consumption and for facilitating remanufacturing and recycling. In order to achieve these characteristics, it is clear that the DfS approaches at the product level are crucial.

Similar to PSS design, even social innovations require material artefacts, and thus the same points raised above apply to a discussion on social innovation. In addition, social innovations might involve designing services, business models or stakeholder value chains, and thus they might require the application of PSS design principles, methods and tools.

It is also interesting to note the synergetic contribution that DfSB can offer in relation to various DfS approaches at different innovation levels. In fact, since sustainability requires a cultural and behavioural change, this approach can play a fundamental role by shaping or instilling new behaviours and habits. For example, it can be used to increase the adoption and acceptance of both PSS and social innovations.

At the spatio-social innovation level, the territorial approach of SD can be used to enhance the local dimension of both PSS and social innovations. In this sense it can support the optimisation of the use of local resources by creating symbiotic linkages among local 
socio-economic actors and their industrial, agricultural and natural processes.

The synergistic effect and interdependence between the various DfS approaches can be seen at the socio-technical innovation level. If we look at the DfST approach, its focus is on transforming systems by actively encouraging the development of long-term visions for new systems and the development of transition paths to reach these visions. These socio-technical systems will require a combination of innovations ranging from new technologies, materials and products to new services and business models, new behaviour and social practices, and new policies and regulations. For this reason, achieving these envisioned future systems will require design and innovation teams to use a combination of DfS approaches covering all innovation levels.

In conclusion, addressing sustainability challenges requires an integrated set of DfS approaches that span various innovation levels. Each DfS approach should be acknowledged for its associated strengths and shortcomings and utilised in conjunction with complementary approaches for any given project following a systemic analysis.

\subsection{What knowledge and know-how are required to apply the various DfS approaches?}

The types of knowledge and know-how that are required to apply the various DfS approaches included in this book cover a broad spectrum, ranging from technical and scientific approaches to socio-cultural and politico-economical approaches. As we move from the lower levels to the higher levels of innovation, the scope of the knowledge and knowhow required to apply the associated DfS approaches also becomes larger, making interdisciplinary collaboration between design and other areas of expertise a necessity.

To implement green design, the fundamental knowledge required is knowledge of materials, manufacturing processes and their related environmental impacts, since choice of material is one of the main interventions a designer can undertake in green design. Understanding the environmental characteristics of materials (e.g. extraction and production impacts, toxicity, recyclability, biodegradability) and manufacturing (e.g. the reduction of manufacturing waste and energy use) is thus key. In line with the rules of thumb introduced by green design, designers are required to know how to select low-environmental-impact materials and manufacturing processes for specific product-component applications.

In product ecodesign however, the environmental impacts of products throughout their life cycles need to be assessed. This requires 
LCA know-how; the associated tasks include the selection of an appropriate functional unit for analysis, the collection of data from material and component manufacturers (as well as from the suppliers of energy to industrial operations), the modelling of the product life cycle using dedicated software and the interpretation of assessment results in a way that can assist design decision-making. Compared to green design, the required knowledge is broader since it encompasses the different aspects and processes of a product life cycle: the extraction of materials, manufacturing, distribution, use and end-of-life. From a practical point of view, it means designers should know how to apply and integrate a range of ecodesign tools in the product design process (see Section 2.2).

The other two approaches that require highly technical know-how and knowledge are CTC and BM design. Both of these approaches require not just knowledge about the impacts of existing materials but also materials science knowledge in order to innovate in the creation of new materials. BM design specifically requires an understanding of biological and ecological systems, as well as requiring broad knowledge about the different characteristics of species.

EDD and DfSB both require insights from psychology and behavioural sciences, and implementing DfBoP also requires input from development studies and anthropology. SPSS design, in addition to know-how on product, service and business model development, requires a basic level of understanding of systems, as the successful functioning of any PSS depends on being able to properly conceptualise the interrelationships between the products, services, providers and users across time and space. In $\mathrm{SD}$, the systems understanding required is more sophisticated, as the interacting components are numerous and include not only technological but also natural elements, many of which are systems themselves. These numerous components are also spatially spread out. In design for social innovation, systemic understanding is also necessary; however, the emphasis is on social, organisational, political and economic relationships. In design for social innovation, two skills that are particularly necessary are group facilitation and the infrastructuring of communities in order to empower them to solve their own problems and make their (political) voices heard. More generally, as compared to most technical approaches (green design, ecodesign, CTC design and $\mathrm{BM}$ ), these approaches require designers to be equipped with a substantially different set of skills. In fact, the understanding of aspects such as consumption dynamics (what people want and why) and behaviour dynamics (what drives individual and group behaviour) becomes crucial. This means that human-centred design skills play a fundamental role, and the techniques used to gather insights from users 
(such as cultural probes and ethnographic observations) and to codesign with them become essential tools in the designer's toolkit.

In DfST the required knowledge covers theories of socio-technical change, sustainability science, futures inquiry methods (used in projects with normative and long-term orientation) and a fundamental understanding of complex adaptive systems theories. In addition, know-how of transdisciplinary research theories and methods form a key knowledge base for those designer researchers and practitioners who are looking to take part in the strategic management of system innovations and transitions. In addition to the human-centred design skills mentioned above, a key skill required in DfST is the ability to manage and engage with a large stakeholder base, along with an understanding of the processes involved in policymaking across different organisational units of society.

\subsection{What can the DfS framework be used for?}

The key value of the proposed DfS framework is that, to our knowledge, it is the first framework that attempts to encapsulate all the different DfS approaches in a coherent way. It was initially developed to support the understanding of the evolution of DfS, but we believe it can be used for a number of applications related to design research, education and practice.

\subsubsection{Design research}

Essentially, the DfS framework is a tool to assist in making sense of the complexity that characterises the DfS field. In this respect, it contributes to the DfS discourse, with the intention of engaging and triggering debate on the past, present and future of the field and to support academics and researchers in their discussions.

From a historical perspective, the framework can help us to understand how the field evolved. It can provide a snapshot of the state of the art of DfS at any time and can thus show how the related knowledge and know-how have changed over time. In this sense, it can also reveal if changes have been more incremental (e.g. the evolution of green design into ecodesign) or more radical (e.g. the introduction of design for social innovation).

The framework can also be used to discuss the current state of the art of DfS. In fact, it can be applied to support discussion around the interrelations and linkages between the different DfS approaches (similarly to what was done in Section 12.2). In addition, it can be employed as a tool for literature analysis that can be used to understand, for example, in which areas of the framework research is more active. 
The framework can also be used as a research tool to support the analysis of DfS in a particular sector or geographical context. For example, it can be adopted to investigate which of the DfS approaches are more often applied in the furniture sector. Or it can be used to compare the state of the art of DfS in different geographical contexts and see, for example, what the main differences are in terms of research focus and/ or practical application.

In addition, the framework can act as basis for opening up discussions around how DfS could change and evolve in the future, as was done in Section 12.7.

More generally, the framework can be used to facilitate dialogue between academics and researchers (not necessarily from design) who are focusing their research on particular areas of the framework. In this sense it can support the creation of bridges between design academics working on specific areas of the framework or between and among academics (from other disciplines) who share an interest in aspects of DfS.

\subsubsection{Design education}

In relation to design education, the DfS framework can be used, first of all, as a support tool to enhance the teaching of DfS-related subjects. The DfS field is characterised by a certain degree of complexity: there are several different DfS approaches, each with its own particular way of seeing and addressing sustainability problems. In addition, these approaches overlap and complement one another. The framework can be used to reduce this complexity and provides a simplified overview of the DfS field. In this sense it can support teachers in better communicating the richness and complexity of the DfS field to students and explaining how individual DfS approaches contribute to the different aspects of sustainability.

In addition, the framework might support teachers in designing courses and programmes on DfS. For example, it can be used to map out the DfS approaches to be taught in the different years of a programme or to better understand which courses within a programme contribute to certain aspects of DfS.

\subsubsection{Design practice}

From a design practice perspective, the first potential application of the framework is to support practitioners and organisations in better understanding and navigating the complexity of the DfS landscape. In fact, similarly to what was said above, the great benefit of the framework 


\section{2}

The past, present and future of DfS

is its ability to and synthesise DfS reduce its complexity in one single schematic. More specifically, the framework can potentially be used to support design practice in a number of ways:

- Businesses and design agencies could use the framework in the initial stages of a design project to identify the appropriate DfS approach(es) to be applied in order to address a specific sustainability challenge.

- The framework can be applied for auditing purposes. It could be used as a tool to identify and map the current DfS knowledge and knowhow in a specific organisation. In connection with this, the framework might also support organisational change processes in organisations which aim to integrate DfS in their strategy and operations.

- Finally, it might be used for communication purposes. For example, it can support design agencies in communicating their expertise and portfolio in relation to DfS.

\subsection{Where do we go from here?}

We wrote this book shortly after the release of the IPCC special report on the impacts of a global average temperature rise of $1.5^{\circ} \mathrm{C}$ above pre-industrial levels on natural and human systems (IPCC, 2018), as discussed in Chapter 1. Also, climate strikes by schoolchildren's which originated in Sweden are currently gaining traction in the USA, in the rest of the EU and in some other countries. We feel that we are living in exceptional times - times of pressing urgency for international political action and times in which sustainability issues must be taken on board in all (but particularly applied) disciplines as a central concern. Design - with its focus on context sensitivity, problem-finding, problem(re)framing and problem-solving, and as a potent agent of culture making in the contemporary world - has a significant responsibility as well as the potential to take a leadership role in the collective imagining and enacting of futures that are sustainable, desirable and just.

Loorbach (2007) argued that transitions theory is an inclusive and flexible meta-theory that could be integrated with existing models and theories. This could also be considered true for DfST theory and practice. Therefore, each DfS approach should be acknowledged for its associated strengths and shortcomings, and utilised in conjunction with complementary approaches for any given project following a systemic analysis, as addressing sustainability challenges requires an integrated set of DfS approaches that span various innovation levels. In Section 12.4, we discussed the synergies that exist between different types of DfS approaches. Together with the framework presented in this chapter, 
this discussion could help design research and practice to build conceptual and operational bridges between the short-term and small-scale focuses of design research and practice projects and the large, systemic and long-term agendas of DfST projects.

We have identified the cutting edge of DfS to be DfST. Although this emerging field is starting to find resonance in design research and practice, we should not assume there is any closure in the evolution of the DfS field. Indeed, in a way we are just starting to think of the ways in which DfS can really make a difference by assisting in the creation of collective imaginaries about long-term futures that are sustainable and desirable to live in, and by helping the large stakeholder base to articulate pathways to achieving these alternative futures. In Chapter 11, where we discussed future research directions for DfST, we mentioned some nascent DfS approaches, such as design for conviviality, design for resilience and design for co-habitation. We also referred to some early work in design research informed by feminist theory, animal studies, degrowth studies, post-humanist ethnography, political ecology and the literature on the decolonising methodology. We pointed out that these emerging works can inform visions of new systems and assist with the decentring of the human and giving voice to the voiceless in design theory and practice, thus paving the way for creating sustainable, resilient and just futures.

DfST is implicitly a project of hope, a hope that is based on the assumption that society can achieve a major transformation towards sustainability in a timely manner and along a smooth path. Nevertheless, in the broader context of academic and public sustainability discourse, hope and despair go hand in hand. This is particularly amplified with regard to climate change. For example, on the one hand, record renewable energy deployment was observed globally in 2016 (IEA, 2017), but on the other hand, the window of opportunity to reduce the risk of severe climate change by keeping the average global temperature rise between $1.5^{\circ} \mathrm{C}$ and $2^{\circ} \mathrm{C}$ is closing (Raftery, Zimmer, Frierson, Startz, \& Liu, 2017; UNEP, 2017). The observable impacts of an already changed climate include the migration of animal species to higher altitudes, shrinking glaciers, the loss of sea ice, more intense heat waves, and more frequent and severe extreme weather events. This calls for daring to ask the question, 'What if transitions do not happen in a timely fashion or do not happen smoothly?' Some transitions may happen more quickly than others, depending on contextual dynamics. In some cases, they may be induced only by crises and in some other cases there may be systemic collapses. So there is no one single type of transition. DfST should expand its theoretical base, as well as the tools used in practice, by learning from several of the proposed transitions typologies (Berkhout, Smith, \& Stirling, 2004; de Haan \& Rotmans, 2007; Smith, Stirling, \& Berkhout, 2005; Geels \& Schot, 
2007). Another question that comes to mind is 'What comes after those transitions that can be societally accomplished in the next $15-30$ years, when new dynamic equilibriums have been reached but further transformations are still needed?' Therefore, in the DfS field there is a pressing need to begin focusing on the what and the how of the contributions that design can make in post-transition contexts.

In the light of these discussions, we close out this book by adding one more innovation level to the framework we developed, one which represents how we envision the DfS field to further evolve (Figure 12.5). This innovation level focuses on socio-technical-ecological systems in their entirety, with a focus on ongoing transitions as well as on post-transition contexts. With the addition of this level, we envision the DfS field to become Earthcentric and to operate with consideration of the future of not only existing humans but also of non-humans and future generations.

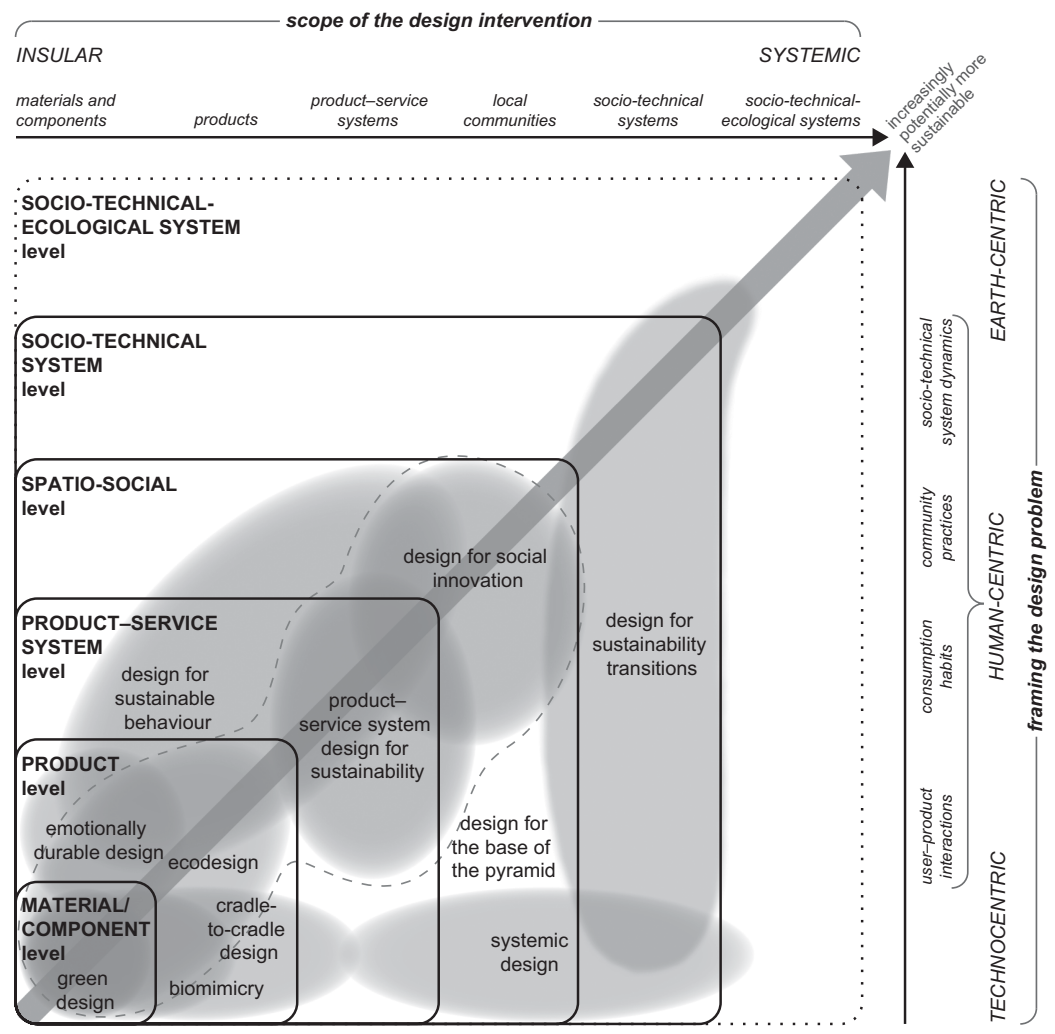

Figure 12.5 The DfS innovation framework with the additional sociotechnical-ecological system level 


\section{References}

Adams, R., Jeanrenaud, S., Bessant, J., Denyer, D., \& Overy, P. (2016) Sustainability-oriented innovation: A systematic review. International Journal of Management Reviews, 18(2), 180-205. doi:10.1111/ijmr.12068

Berkhout, F., Smith, A., \& Stirling, A. (2004). Socio-technical regimes and transition contexts. In B. Elzen, F. W. Geels, \& K. Green (Eds.), System innovation and the transition to sustainability: Theory, evidence and policy (pp. 48-75). Cheltenham, UK: Edward Elgar.

Ceschin, F., \& Gaziulusoy, İ. (2016). Evolution of design for sustainability: From product design to design for system innovations and transitions. Design Studies, 47, 118-163.

de Haan, H., \& Rotmans, J. (2007). Pillars of change: A theoretical framework for transition models. Paper presented at the 7th International Conference of the European Society for Ecological Economics (ESEE), Leipzig, Germany, 5-8 June.

Ehrenfeld, J. H. (2008) Sustainability by design: A subversive strategy for transforming our consumer culture. New Haven, CT: Yale University Press.

Ellen MacArthur Foundation (2013). Towards the circular economy: Economic and business rationale for an accelerated transition, Vol. 1. Ellen MacArthur Foundation. Retrieved from www.ellenmacarthurfoundation.org/assets/ downloads/publications/Ellen-MacArthur- Foundation-Towards-the-CircularEconomy-vol.1.pdf.

Geels, F. W., \& Schot, J. (2007). Typology of sociotechnical transition pathways. Research Policy, 36(3), 399-417.

Geng, Y. and Doberstein, B. (2008). Developing the circular economy in China: Challenges and opportunities for achieving "leapfrog development". International Journal of Sustainable Development \& World Ecology, 15(3), 231-239.

IEA. (2017). Renewables 2017: Analysis and forecasts to 2022. International Energy Agency.

IPCC. (2018). Summary for Policymakers. In V. Masson-Delmotte et al. (Eds.), Global warming of $1.5^{\circ} \mathrm{C}$ : An IPCC Special Report on the impacts of global warming of $1.5^{\circ} \mathrm{C}$ above pre-industrial levels and related global greenhouse gas emission pathways, in the context of strengthening the global response to the threat of climate change, sustainable development, and efforts to eradicate poverty. Geneva, Switzerland: World Meteorological Organization.

Lieder, M. and Rashid, A. (2016). Towards circular economy implementation: A comprehensive review in context of manufacturing industry. Journal of Cleaner Production, 115, 36-51.

Loorbach, D. (2007). Transition management: New mode of governance for sustainable development. PhD Thesis, Erasmus University Rotterdam, Utrecht, the Netherlands. 
166 The past, present and future of DfS

Raftery, A. E., Zimmer, A., Frierson, D. M. W., Startz, R., \& Liu, P. (2017). Less than $2^{\circ} \mathrm{C}$ warming by 2100 unlikely. Nature Climate Change, 7(9), 637-641. doi:10.1038/nclimate3352

Smith, A., Stirling, A., \& Berkhout, F. (2005). The governance of sustainable socio-technical transitions. Research Policy, 34(10), 1491-1510.

UNEP. (2017). Emissions gap report 2017: A UN environment synthesis report. United Nations Environment Programme. 


\section{Index}

Note: Page references to figures are in italics and those in bold refer to tables.

absolute obsolescence 26

adaptable products, in EDD design practice 33

'age with dignity', in EDD design practice 33

Ahmedabad Declaration of Industrial Design and

Development 88

anthropocentrism 70,135

Base of the Pyramid Protocol 95, 96

base-of-the-pyramid (BoP) design 87-98, 91-94, 96, 96, 143, 149, 151,164

$\mathrm{BCD}$ (behaviour-centred design) framework 45,47

behavioural change models 40-41

behavioural level, of user-product connection 27

behaviour-centred design (BCD) framework 45, 47

Berol's Karisma coloured pencils 13,13

bi-directional biomimicry design 64, 67

Biobased Xorel textile collection 55 biodegradability 53, 153, 158

bio-inspired design 63-71, 64-66, 68, $\mathbf{1 4 2}, 148,149,150,164$

biomimetics/biomimicry/bionics design 63-71, 64-66, 68, 142, 148, $149,150,164$

BoP (base-of-the-pyramid) design 87-98, 91-94, 96, 96, 143, 149, 151,164 broader sustainability focus, and narrow sustainability focus 154 business models $9,48,58,90,95$, 127,142 ; circular $76,80,155$; and PSS design for sustainability 74 , $76,78,80$; and reflections on DfS $152,156,157,158,159$

CADM (comprehensive action determination model) 40,41 circular business model 76, 80, 155 circular economy 17, 22, 60, 76, 156 climate change 5-6, 70, 163 co-creation 88, 95, 97 co-design 32, 33, 78-79, 92, 160 coffee waste reuse 116-117 collaborative design 105, 106, 109, 133-134

collaborative realisation 107 community-oriented toolkits 110 comprehensive action determination model (CADM) 40, 41 constructive technology assessment 125

consumption behaviour 27, 32 , 46,121 consumption levels 73,121 context-driven methods and tools, in DfSB methods and tools 47 Cradle-to-Cradle Certified Product Standard 57 cradle-to-cradle (CTC) design 53-60, $55, \mathbf{1 4 2}, 148,149,164$ cultural change 47-48, 125 customisation, product $28,32,33$ 
decision support framework (DfSB), for promoting sustainable behaviour 44,45

decision support systems 21 , $44-45,45$

decolonising design 97, 109

decolonising methodology 135, 163

design education 108, 109, 127, 132,161

design for behavioural change 39-44, $41,42-43$

design for eco-efficiency, productservice system (PSS) 75, 76, 78, 79-80, 142

design for product attachment 27 design for social innovation (DfSI) 102-110

Design for Sustainability: A Practical Approach for Developing Economies 94, 96

design for sustainability innovation framework 144, 147, 148, 149, 164 design for sustainability transitions (DfST) 10, 124-136, 126, 129, 130 design for sustainable behaviour (DfSB) 39-50, 41, 42, 43, 45; and DfS innovation framework 143, $148,149,164$

design for the BoP (DfBoP) 87-98, 91-94, 96, 143, 148, 149, 164

Design for the Real World: Human Ecology and Social Change 8 design priorities $18-19,76,79,80$ design research 22, 90, 98, 103, 109, $125,133-134$; and reflections on DfS 150-151, 160-161, 163 designing sustainable futures 130-131 desirability, and BoP design 89-90 development aid 87

Development Impact \& You (DIY) toolkit 106

DfBoP (design for the BoP) 87-98, 91-94, 96, 143, 148, 149, 164

DfS innovation framework 144,147 , $148,149,164$

DfS transitions 10, 124-135, 126, 129,130

DfSB (design for sustainable behaviour) 39-50, 41, 42, 43, 45; and DfS innovation framework $\mathbf{1 4 3}, 148,149,164$
DfSI (design for social innovation) 102-110

DfST (design for sustainability transitions) 10, 124-135, 126, 129,130

diffuse design 109, 131

digital manufacturing technologies 32, 36

DIY (Development Impact \& You) toolkit 106

DIY repair activities, in EDD design practice 33

Do Scratch lamp 30, 30

domains of everyday life 127

double-flow scenario method 133

Dutch National Inter-Ministerial Programme for Sustainable Technology Development 124

ecodesign, product see product ecodesign

Ecodesign Framework Directive, European Commission 17

EcoDesign project 12

eco-effectiveness $53,54,56,59$

eco-efficacy 121

eco-efficiency $53,58,59,121$; design

for $75,76,78,79-80,142$

eco-friendliness 70

ecological effects 59

EcoReDesign project 12

EDD (emotionally durable design) 26-36, 30, 31, 32, 82, 142, 148, 149, 150,164

efficiency $8,12,15$, 20; eco- 53, 58, 59,121 ; energy $17-18,58-59,145$, 152, 153, 155; material 155

efficiency improvements 12, 14, 20 emotional attachment/emotional bonds 20, 26-29, 30, 33-34, 36, $\mathbf{1 4 2}, 150,155$

emotionally durable design (EDD) 26-36, 30, 31, 32, 82, 142, 148, 149, 150,164

energy consumption $16,39,42$, 49-50, 58-59, 74, 80, 153

environmental ceiling 6 environmental impact/ environmentalism 2, 8, 9, 39, 48, $121, \mathbf{1 4 2}, 158-159$; and cradle-tocradle design 53,58 ; and green 
design and product ecodesign 12 , 14, 16, 16-17, 18-19, 21; and PSS design for sustainability 73,81 epistemology 108, 135

ethical considerations/ethics 7, 48, 70, $81,121, \mathbf{1 4 2}, 154$

Eurocentrism 97

European Commission, Ecodesign Framework Directive of 17

European Economic Community

Waste Framework Directive 17, 19-20

European Social Innovation Toolkit 2018106

European Union Circular Economy Action Plan 17

evaluation protocols 49

expert design 109, 131

feasibility, and BoP design 90

Field Guide to Human-Centered Design, The 94-95, 96

financial returns 48

'framing the design problem' axis, of DfS innovation framework 144, $145-148,147,148,164$

FRIA refrigerator 15,15

Fuller, Buckminster 7

Global North/Global South 9

green consumerism 12, 20

green design 12-14, 13, 14,

17, 19-21; and reflections on

DfS 142, 147, 148, 149, 150, $154-155,158,164$

group affiliation, and product attachment 28

handbook for the scaling up of PSSs 133

highly unique products, in EDD design practice 32

Host a Student 104

household water purification system 117,118

human behaviour, changing 39-44, $41,42-43$

human-centric design, and technocentric design $151,153-154$

human-driven environmental change 6 idea generation 19, 20, 80, 95

identity, personal $28,34-35,82$

implementation 19, 21, 49, 55, 57, 58, $78,82,95,119,152$

individual-cognitive methods and tools, in DfSB methods and tools 46

innovation: place-based 102-104; radical 57, 124, 151; social 102-110; sustainability-oriented $69,141-144$, 142-143

innovation processes 50, 70, 94-95, 98, 103, 108, 133

insular design, to systemic design 151-152

Intergovernmental Panel on Climate Change (IPCC) 5

knowledge and know-how 89 , 114-115, 158-160, 162

LCA (life-cycle assessment) 16-18, $20,59,159$

life-cycle, of a product $8,12-17,13$, $14,20,39,54,58,142$; and PSS design for sustainability 73,74 , $78,80-81$; and reflections on DfS $145,150,156,158-159$

life-cycle assessment (LCA) 16-18, 20, 59, 159

lifespan, product $8,15,15,18,26,27$, $34,35,54,73,78$

lifestyles $6,7,91,124-128,126,132$

low-income people 81, 87-91, 91-93, 91, 92, 93, 94

making experiences 28,33

Market Creation Toolbox 95, 96

material/component level, of DfS innovation framework 142, 144, $145,147,148,149,164$

MDM (multi-level design model) 133

memories, and product attachment 28, 32

method for system design for sustainability (MSDS) 76-78, 79 methodology $67,79,95,115,135,163$ metrics $48,49,71$

middle-ground methods, in DfSB methods and tools 44, 46-47 
mid-range transition pathway creation toolset (MTPT) 133-134

Mitti Cool natural refrigerator 93, 93, 94

MLP (multi-level perspective), on system innovations $125,126,127$

MOMA (Museum of Modern Art) 43, 44

MSDS (method for system design for sustainability) 76-78, 79

MTPT (mid-range transition pathway creation toolset) 133-134 multi-level design model (MDM) 133 multi-level perspective (MLP), on system innovations $125,126,127$

Museum of Modern Art (MOMA) 43, 44

Nappi Naapuri online platform 104-105

narrow sustainability focus, and broader sustainability focus 154 nature-inspired design 53

Nifty Neighbour online platform 104-105

Nike Considered boots 55, 55

obsolescence 26

Open Book of Social Innovation, The 106

Open Food Network online platform 105

Papanek, Victor 8, 88-89 participatory design 105-106, 109, 120,128

Patagonia clothing products 77

Pay-per-lux lighting service 77-78, 78 personal identity $28,34-35,82$ personalisation, of the product 28 , $29,30,31,32-33,36$

place-based innovations 102-104 'Planetary Boundaries' framework 6 pleasure, and product attachment 27, 32 policy design 132 pollution, caused by products $12,17,19$ poverty $9,87,88,102,154$ Power-Aware Cord 42, 42, 44
PPP (purchasing power parity) 87 Prendi in Casa Uno Studente 104 product attachment 27, 28-33, 29, 30, $31,34,35-36$

product characteristics 27

product design thinking 9, 75

product ecodesign $8,12-17,15,16$, 18-22, 26-27, 39, 94; and DfS innovation framework 142, 148 , 149, 164

product innovation $73,95,145,151$, $152,154,157$

product innovation level, of DfS innovation framework 144,145 , $152,154,147,148,149,164$

product lifespan $8,26,27,34,73,78$

product replacement 9, 27, 35

production process $7,73,115$, 119,121

production-consumption systems 6 , $9,10,53,54,56,58,63,113,114$, 125,127

product-oriented product-service systems $74,77,81$

product-service system (PSS); design for eco-efficiency 75 , 76, 78, 79-80, 142; design for sustainability $73-83, \mathbf{1 4 2}$; and DfS innovation framework 144, 145, $147,148,149,152,164$

psychological obsolescence 8 , 26,27

purchasing power parity (PPP) 87

radical innovation $57,124,151$

rebound effects $9,34,81$

recyclability/recycling 59, 60, 77, 81; and green design and product ecodesign 12, 14, 14, 16, 16-17, 19; and reflections on DfS 155,156 , 157,158

reflective level, of user-product connection 27

relationships, between DfS approaches 154-156, 159

relative obsolescence 26 renewable energy $12,54,56,58,163$ resource distribution 6-7 'respect diversity' design principle $53,54-55$ 
result-oriented product-service systems 74-75, 77-78

Riversimple hydrogen-powered cars 77,77

SafariSeat wheelchair 91, 91, 92

Save/Space/Vase 31, 31, 32

Sayl office chair 16, 16

scenario approaches 131

'scope of the design intervention' axis, of DfS innovation framework $144,145,147,148,149,164$

SD see systemic design (SD)

self-expression, and product attachment 28

service design 105, 109, 127, 132

Shinkansen bullet train 64,65

situational influences 27

Smart Energy Transitions project 130,130

social entrepreneurship 90-91

social foundations 6

social franchising 110

social innovation, design for (DfSI)

$102-110$

social media 34,36

societal stakeholders 152

societal values 70

socio-ethical aspects 81, 142, 154

socio-technical system level, of DfS

innovation framework 144, 145,

$147,148,149,164$

socio-technical systems

124-128, 126

socio-technical-ecological system

level, of DfS innovation framework 164,164

'Spaceship Earth' 7

spatio-social level, of DfS innovation framework $144,145,147,148$, 149,164

SPSSs (sustainable PSSs) 73-83, 142

Stain teacup 30, 30

stakeholder tools 79-80

stakeholders, societal 152

strategic niche management

124-125

Strategies Towards the Sustainable Household (SusHouse) Project 124,125 subject-object relationship 26

Sun Shines for All home solar energy, The 92, 92

SuperAmma (SuperMum) 43, 43

Supertree Grove 65, 65, 66

SusHouse (Strategies Towards the Sustainable Household) Project 124,125

sustainability 5-7, 69, 80, 87, 90; and reflections on DfS 141, 144, 150, $151,158,162$

sustainable behaviour, design for (DfSB) 39-50, 41, 42, 43, 45, 143, $148,149,164$

sustainable PSSs (SPSSs) 73-83, 142 system design thinking 9,75

systemic design (SD) 10, 69, 113-122, $116,117,118$; and reflections on

DfS 143, 148, 149, 151-152, 164; principles 114-115

systemic transformation 22

technocentric design, and humancentric design 151, 153-154

technology/people dimension, of sustainability-oriented innovations 141

territorial approach 113, 120, 156, 157-158

Tetra Pak repurposing 14, 14

TM (transition management) 125 , 130, 130, 132

transformation 2, 22, 124, 127, 132,164 ; and sustainability by design $5,7,8,10$

transformational change 12, 107 transition design 10, 124-136, 126, 129,130

transition management (TM) 125 , $130,130,132$

use-oriented product-service

systems 74,77

user behaviour 9, 40, 46, 48, 82, 155

user-product relationship 27

viability, and $\mathrm{BoP}$ design 90

visceral level, of user-product connection 27

Visions and Pathways 2040 128, 129 


\section{Index}

visualisation tools 19 , 78-79, 120

vocabulary, DfSB 50

waste becomes a resource 114 , 120,143

waste equals food design principle 53 , $54-55,55,114$
Waste Framework Directive, European Economic Community 17, 19-20

waste hierarchy $15-16,17,19-20$

water purification system, household 117,118

World Wide Fund for Nature

(WWF) 6 